US Army Corps

of Engineers $S_{\circledast}$

Engineer Research and

Development Center

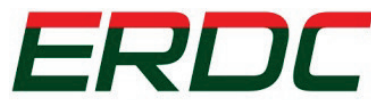

INNOVATIVE SOLUTIONS for a safer, better world

\title{
Sediment Dynamics in a Vegetated Tidally Influenced Interdistributary Island: Wax Lake, Louisiana
}

Richard Styles, Duncan Bryant, Joe Gailani, Jarrell Smith, July 2017

Brandon M. Boyd, and Greg Snedden
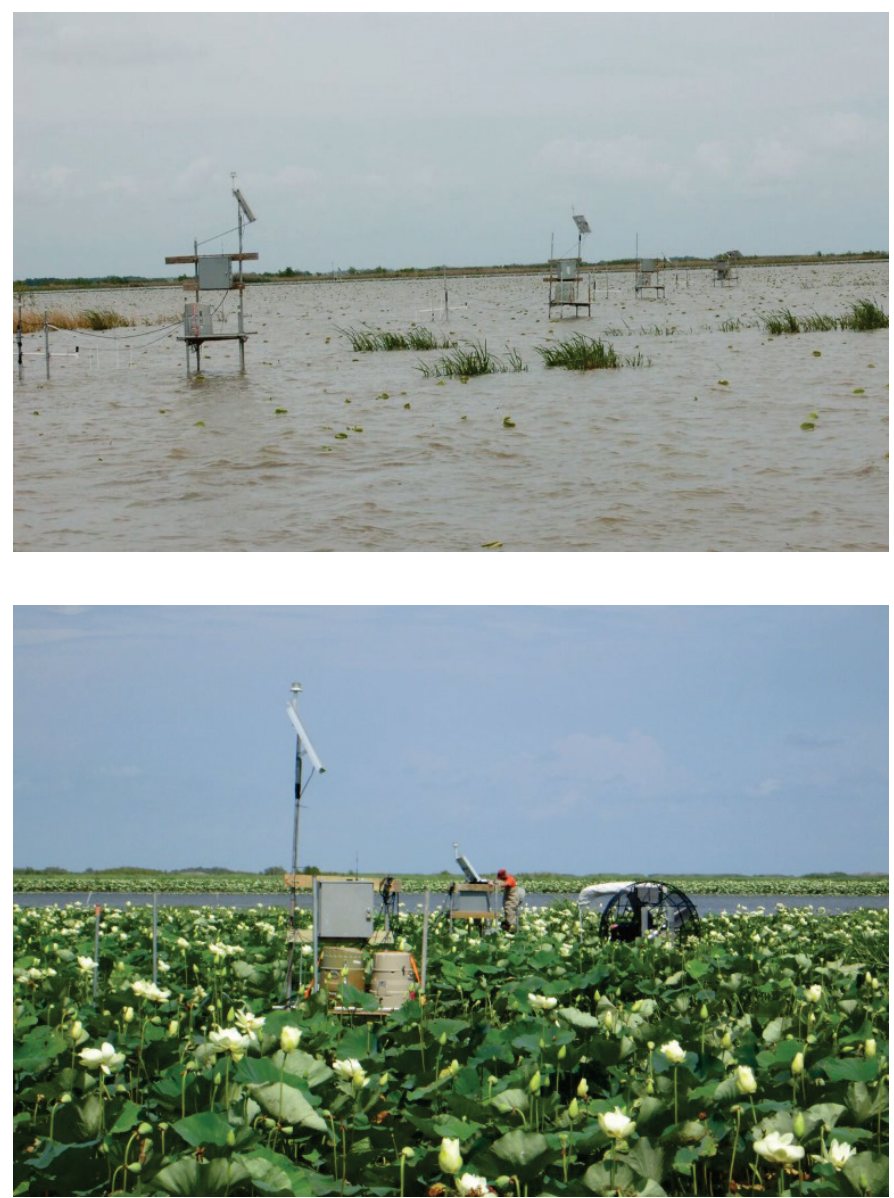
The U.S. Army Engineer Research and Development Center (ERDC) solves the nation's toughest engineering and environmental challenges. ERDC develops innovative solutions in civil and military engineering, geospatial sciences, water resources, and environmental sciences for the Army, the Department of Defense, civilian agencies, and our nation's public good. Find out more at www.erdc.usace.army.mil.

To search for other technical reports published by ERDC, visit the ERDC online library at http://acwc.sdp.sirsi.net/client/default. 


\section{Sediment Dynamics in a Vegetated Tidally Influenced Interdistributary Island: Wax Lake, Louisiana}

Richard Styles, Duncan Bryant, Joe Gailani, Jarrell Smith, and Brandon M. Boyd Coastal and Hydraulics Laboratory

U.S. Army Engineer Research and Development Center

3909 Halls Ferry Road

Vicksburg, MS 39180-6199

Gregg Snedden

Wetland and Aquatic Research Center

624 N. Fourth St.

U.S. Geological Survey

Baton Rouge, LA 70803

Final report

Approved for public release; distribution is unlimited.

Prepared for U.S. Army Engineer Research and Development Center 3909 Halls Ferry Road

Vicksburg, MS 39180-6199

Under Work Unit ERDC-219CDR-14-TT-Sediment Management, "Section 219 Center Directed Research Program" 


\section{Abstract}

River deltas are maintained by a continuous supply of terrestrial sediments that provide critical land-building material to help sustain and protect coastal communities. In order to examine the mechanisms of sediment delivery, a field study was conducted at Wax Lake Delta located in St. Mary Parish, LA. Instrumented platforms equipped with wave, current, tide and sediment sensors were installed on Mike Island, an interdistributary island located near the centerline axis of the delta complex. This report focuses on the hydrodynamic measurements, which imply multiple regimes of sediment delivery based on seasonal differences in climate and biological activity. In winter, vegetation is absent, and the primary flow is driven by tides. In the spring, increased river discharge inundates the island producing lateral flows and increase in suspended sediment concentrations that supply large quantities of terrestrial sediments to interior regions. In late spring, persistent southeasterly winds create setup along the coast and higher water levels over the island allowing waves to more easily penetrate the island interior. The emergence of American lotus (Nelumbo lutea) in summer forms a dense canopy over the island reducing wave and current energy, increasing the potential for sediment deposition.

DISCLAIMER: The contents of this report are not to be used for advertising, publication, or promotional purposes. Citation of trade names does not constitute an official endorsement or approval of the use of such commercial products. All product names and trademarks cited are the property of their respective owners. The findings of this report are not to be construed as an official Department of the Army position unless so designated by other authorized documents. 


\section{Contents}

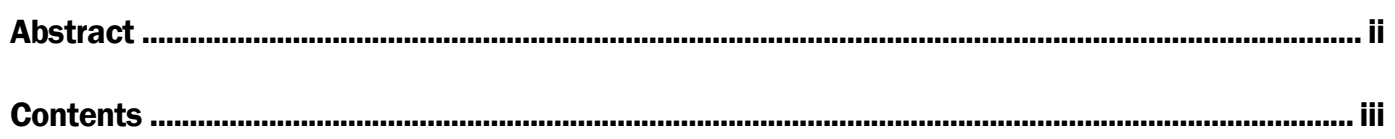

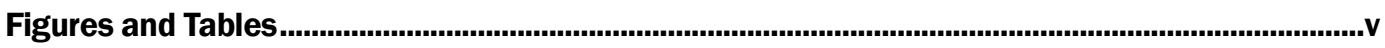

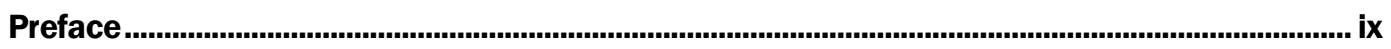

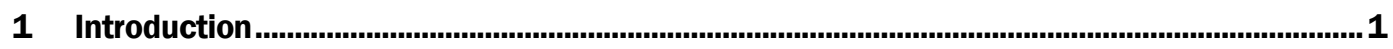

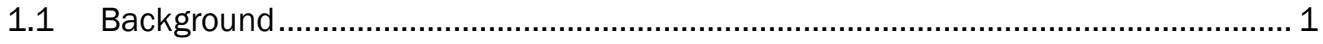

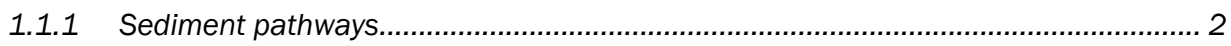

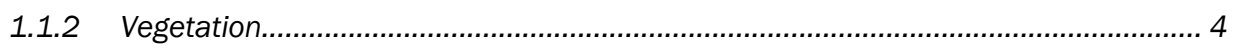

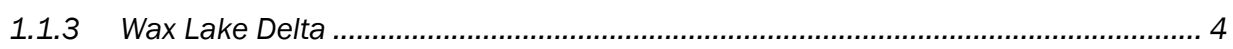

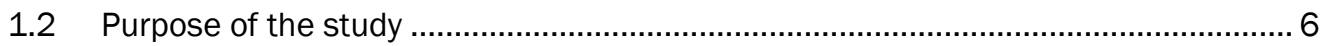

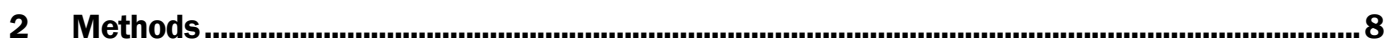

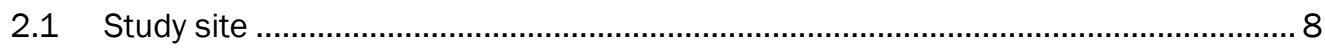

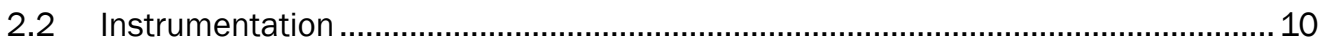

2.3 Hydrodynamic analysis methods ...................................................................... 12

2.3.1 Water level and wave analysis ......................................................................... 12

2.3.2 Acoustic Doppler velocimeter (ADV) analysis ................................................... 13

2.3.3 Shear velocity estimates................................................................................ 14

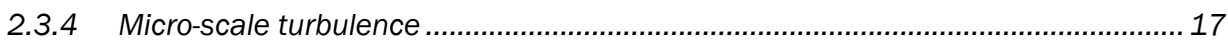

2.4 Sediment analysis ................................................................................... 18

2.4.1 Critical shear stress and the initiation of sediment motion..................................... 19

2.4.2 Suspended sediment concentration data processing .............................................20

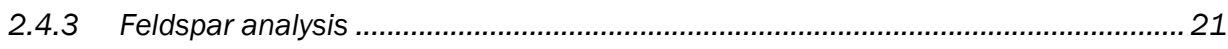

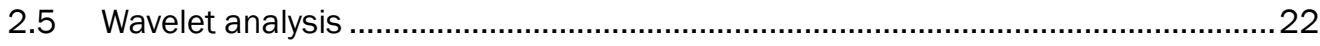

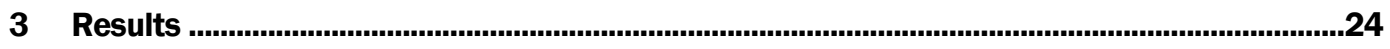

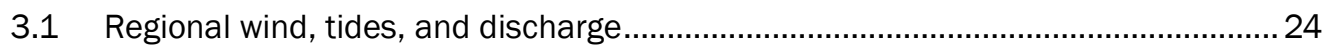

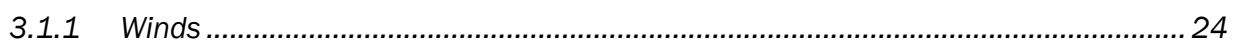

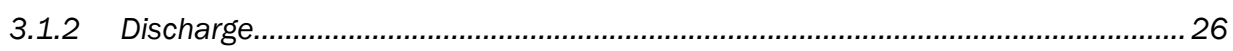

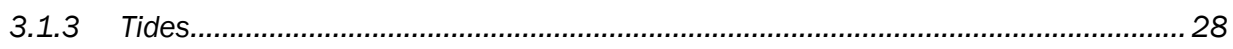

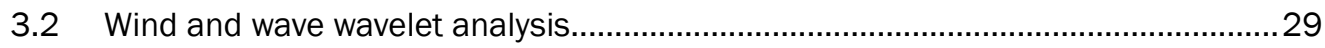

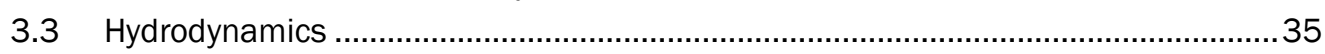

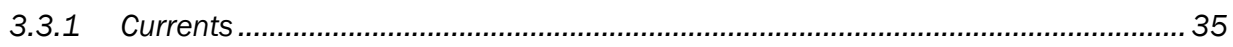

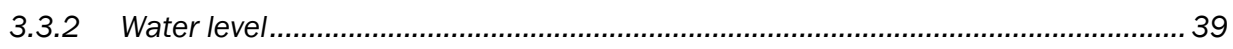

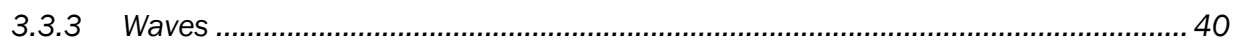

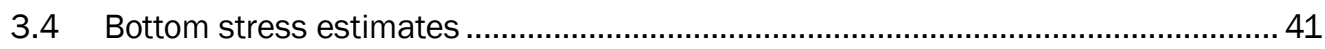

3.5 Sediment characterization ................................................................................ 44

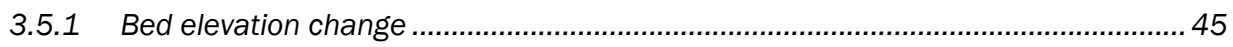

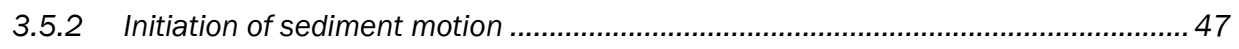

3.5.3 Micro-scale turbulence and floc size .................................................................. 50 
4 Conceptual Site Model .....................................................................................................53

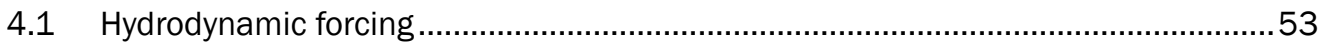

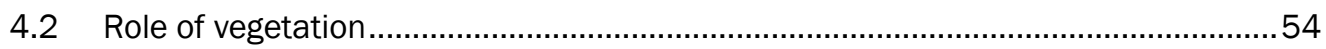

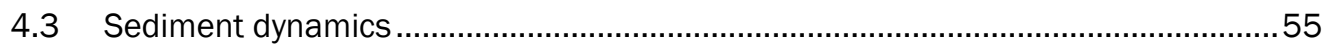

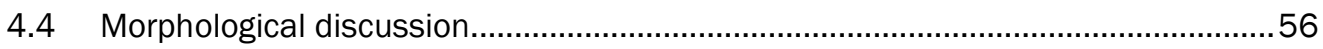

5 Conclusions...........................................................................................................................58

References ...............................................................................................................................................60

Appendix A: Time Series of Wax Lake Hydrological Measurements...............................................65

Appendix B: Feldspar Samples to Measure Bed Accretion for Each Station .................................90

Report Documentation Page 


\section{Figures and Tables}

\section{Figures}

Figure 1. Study site including regional coastline. Lower inset depicts the location of the four platforms installed on the western levee of Mike Island. 9

Figure 2. Instrumented platform surrounded by dense growth of Nelumbo lutea.

Figure 3. Mike Island stations looking eastward. Station 1 is the closest platform on the left. The photograph was taken in May 2014 before the emergence of Nelumbo lutea. The ADVs and wave gauges are mounted on the two poles at the left of each station.

Figure 4. Platform locations and bed elevation measured with RTK-GPS. Bed elevation is interpolated between measurement points and is referenced to NAVD88.

Figure 5. Wave spectrum for 17:30, 12 April 2014, with vertical lines (red) bookending $90 \%$ of the wave energy.

Figure 6 . Turbulent energy spectrum for the east velocity component for 17:30, 12 April 2014 , including wave oscillations in blue. The red curve denotes the cropped spectrum based on the wave.

Figure 7. Calibration curves for the suspended sediment concentration. ..........................................21

Figure 8. Offshore wind speed. Dashed lines denote the start and end of the study period.............24

Figure 9. Wind speed spectral density for 2014.

Figure 10. Low-pass filtered wind vectors. Dashed lines denote the start and end of the study period.

Figure 11. Discharge measured at WLO. Dashed lines denote the start and end of the study period.

Figure 12. Spectral density of discharge for 2015. Peaks at one and two cycles per day denote dominant diurnal and semi-diurnal components.

Figure 13. Sea surface elevation derived from offshore tide station AMRL1 at Amerada Pass, LA. Dashed lines denote start and end of the deployment.

Figure 14. Spectral density for sea surface elevation.

Figure 15. Coherence squared between wind stress magnitude directional component and $H_{s}$ along the directions of $-180^{\circ} \mathrm{T}$ to $180^{\circ} \mathrm{T}$ in $5^{\circ}$ increments obtained from crossspectral analysis (Bendat and Piersol 1986). The white line indicates the direction of maximum wind forcing, estimated according to Garrett and Toulany (1982).

Figure 16. Wavelet power spectrum for east-west (left) and north-south wind stress (right). In each plot, the global wavelet spectrum is shown to the right of the wavelet plot, and and the original time series is shown below.

Figure 17. Wavelet power spectrum for $H_{s}$. The global wavelet spectrum is shown to the right of the wavelet plot, and and the original time series is shown below.

Figure 18. Wavelet coherence spectra between $H_{s}$ and northward (upper left), eastward (upper right), southward (lower left), and westward (lower right) directional components of the wind stress magnitude. In each plot, the color indicates the coherence, and the direction of the arrow indicates the nature of the phase relation. An arrow to the right indicates the two variables are in phase; a downward arrow indicates $H_{s}$ lags wind stress by $90^{\circ}$; a leftward arrow indicates the variables are $180^{\circ}$ out of phase; and an upward arrow indicates $H_{s}$ leads wind stress by $90^{\circ}$. 
Figure 19. Amplitude and phase of transfer function between $H_{s}$ and northward (upper left), eastward (upper right), southward (lower left), and westward (lower right) directional components of the wind stress magnitude. In each plot, the color indicates the amplitude, and the direction of the arrow indicates the nature of the phase. An arrow to the right indicates the two variables are in phase; a downward arrow indicates $H_{s}$ lags wind stress by $90^{\circ}$; a leftward arrow indicates the variables are $180^{\circ}$ out of phase; and an upward arrow indicates $H_{s}$ leads wind stress by $90^{\circ}$

Figure 20. Time series of currents from the four island stations. St1 is near the western bank, and numbers progress eastward towards the island center.

Figure 21. Low-pass filtered current vectors. The arrows denote the magnitude and direction of the tidally averaged current in earth coordinates (up = north; right = east; down = south; left = west).

Figure 22. Monthly averaged current ellipses. The vertical axis denotes north (+) and south (-) directed currents, and the horizontal axis denotes east and west currents. The arrows denote the monthly averaged mean flow vector.

Figure 23. Water depth measured at the four island stations..........................................................39

Figure 24. Significant wave height measured at the four island stations. ........................................40

Figure 25. Time-averaged shear velocity derived from the six different methodologies.

Figure 26. Monthly averaged shear velocity. Error bars denote $95 \%$ confidence limits. Legend represents curves at all stations but is displayed in only the last panel for clarity.

Figure 27. Time series depicting the time-averaged shear velocity and the maximum combined shear velocity for the wave and current predicted from the BBLM.

Figure 28. Bed elevation change inferred from the capacitance rods. The rods can only be used to measure bed elevation when the bed is exposed.

Figure 29. Time series of sediment concentration including a 15-day low pass filtered to remove the tidal component.

Figure 30. Shields parameter and critical Shields parameter for the initiation of sediment motion

Figure 31. Ratio of maximum wave shear velocity and time-averaged shear velocity for the current. Dashed line is for clarity and signifies when the ratio is equal to one, and thus the wave and current contribute equally to the shear stress.

Figure 32. Concentration versus square of combined wave and current shear velocity. The correlation coefficient $(r)$ is determined from linear regression.

Figure 33. Monthly averaged shear parameter. Error bars denote $95 \%$ confidence limits

Figure 34. Monthly averaged Kolmogorov micro-scale. Error bars denote $95 \%$ confidence limits.

Figure 35. Data for 5 February to 1 March 2014 for Wax Lake Remote Station 1 where a) Wax Lake Discharge $\left(\mathrm{m}^{3} / \mathrm{s}\right)$, b) Wind Speed $\left.(\mathrm{m} / \mathrm{s}), \mathrm{c}\right)$ Wind Direction (degrees), d) Water Level (blue -local, red-Buoy AMRL1, cm), e) Wave Height (cm), f) Wave Period (s), and g) Velocity (red-north, green-east, blue-vertical, $\mathrm{cm} / \mathrm{s}$ ).

Figure 36. Data for 1 March to 1 April 2014 for Wax Lake Remote Station 1 where a) Wax Lake Discharge $\left(\mathrm{m}^{3} / \mathrm{s}\right)$, b) Wind Speed (m/s), c) Wind Direction (degrees), d) Water Level (blue -local, red-Buoy AMRL1, cm), e) Wave Height (cm), f) Wave Period (s), and g) Velocity (red-north, green-east, blue-vertical, $\mathrm{cm} / \mathrm{s}$ ).

Figure 37. Data for 1 April to 1 May 2014 for Wax Lake Remote Station 1 where a) Wax Lake Discharge $\left(\mathrm{m}^{3} / \mathrm{s}\right)$, b) Wind Speed $(\mathrm{m} / \mathrm{s})$, c) Wind Direction (degrees), d) Water Level (blue -local, red-Buoy AMRL1, cm), e) Wave Height (cm), f) Wave Period (s), and g) Velocity (red-north, green-east, blue-vertical, cm/s). 
Figure 38. Data for 1 May to 1 June 2014 for Wax Lake Remote Station 1 where a) Wax Lake Discharge $\left(\mathrm{m}^{3} / \mathrm{s}\right)$, b) Wind Speed $(\mathrm{m} / \mathrm{s})$, c) Wind Direction (degrees), d) Water Level (blue -local, red-Buoy AMRL1, cm), e) Wave Height (cm), f) Wave Period (s), and g) Velocity (red-north, green-east, blue-vertical, $\mathrm{cm} / \mathrm{s}$ ).

Figure 39. Data for 1 June to 1 July 2014 for Wax Lake Remote Station 1 where a) Wax Lake Discharge $\left(\mathrm{m}^{3} / \mathrm{s}\right)$, b) Wind Speed $(\mathrm{m} / \mathrm{s})$, c) Wind Direction (degrees), d) Water Level (blue -local, red-Buoy AMRL1, cm), e) Wave Height (cm), f) Wave Period (s), and g) Velocity (red-north, green-east, blue-vertical, $\mathrm{cm} / \mathrm{s}$ ).

Figure 40. Data for 1 July to 1 August 2014 for Wax Lake Remote Station 1 where a) Wax Lake Discharge $\left(\mathrm{m}^{3} / \mathrm{s}\right)$, b) Wind Speed $(\mathrm{m} / \mathrm{s})$, c) Wind Direction (degrees), d) Water Level (blue -local, red-Buoy AMRL1, cm), e) Wave Height (cm), f) Wave Period (s), and g) Velocity (red-north, green-east, blue-vertical, $\mathrm{cm} / \mathrm{s}$ ).

Figure 41. Data for 5 February to 1 March 2014 for Wax Lake Remote Station 2 where a) Wax Lake Discharge $\left(\mathrm{m}^{3} / \mathrm{s}\right)$, b) Wind Speed $\left.(\mathrm{m} / \mathrm{s}), \mathrm{c}\right)$ Wind Direction (degrees), d) Water Level (blue -local, red-Buoy AMRL1, cm), e) Wave Height (cm), f) Wave Period (s), and g) Velocity (red-north, green-east, blue-vertical, $\mathrm{cm} / \mathrm{s}$ ).

Figure 42. Data for 1 March to 1 April 2014 for Wax Lake Remote Station 2 where a) Wax Lake Discharge $\left(\mathrm{m}^{3} / \mathrm{s}\right)$, b) Wind speed $(\mathrm{m} / \mathrm{s})$, c) Wind Direction (degrees), d) Water Level (blue -local, red-Buoy AMRL1, cm), e) Wave Height (cm), f) Wave Period (s), and g) Velocity (red-north, green-east, blue-vertical, $\mathrm{cm} / \mathrm{s}$ ).

Figure 43. Data for 1 April to 1 May 2014 for Wax Lake Remote Station 2 where a) Wax Lake Discharge $\left(\mathrm{m}^{3} / \mathrm{s}\right)$, b) Wind Speed $(\mathrm{m} / \mathrm{s})$, c) Wind Direction (degrees), d) Water Level (blue -local, red-Buoy AMRL1, cm), e) Wave Height (cm), f) Wave Period (s), and g) Velocity (red-north, green-east, blue-vertical, $\mathrm{cm} / \mathrm{s}$ ).

Figure 44. Data for 1 May to 1 June 2014 for Wax Lake Remote Station 2 where a) Wax Lake Discharge $\left(\mathrm{m}^{3} / \mathrm{s}\right)$, b) Wind Speed $(\mathrm{m} / \mathrm{s})$, c) Wind Direction (degrees), d) Water Level (blue -local, red-Buoy AMRL1, cm), e) Wave Height (cm), f) Wave Period (s), and g) Velocity (red-north, green-east, blue-vertical, $\mathrm{cm} / \mathrm{s}$ ).

Figure 45. Data for 1 June to 1 July 2014 for Wax Lake Remote Station 2 where a) Wax Lake Discharge $\left(\mathrm{m}^{3} / \mathrm{s}\right)$, b) Wind Speed $(\mathrm{m} / \mathrm{s})$, c) Wind Direction (degrees), d) Water Level (blue -local, red-Buoy AMRL1, cm), e) Wave Height (cm), f) Wave Period (s), and g) Velocity (red-north, green-east, blue-vertical, $\mathrm{cm} / \mathrm{s}$ ).

Figure 46. Data for 1 July to 1 August 2014 for Wax Lake Remote Station 2 where a) Wax Lake Discharge $\left(\mathrm{m}^{3} / \mathrm{s}\right)$, b) Wind Speed $(\mathrm{m} / \mathrm{s})$, c) Wind Direction (degrees), d) Water Level (blue -local, red-Buoy AMRL1, cm), e) Wave Height (cm), f) Wave Period (s), and g) Velocity (red-north, green-east, blue-vertical, $\mathrm{cm} / \mathrm{s}$ ).

Figure 47. Data for 5 February to 1 March 2014 for Wax Lake Remote Station 3 where a) Wax Lake Discharge $\left(\mathrm{m}^{3} / \mathrm{s}\right)$, b) Wind speed $(\mathrm{m} / \mathrm{s})$, c) Wind Direction (degrees), d) Water Level (blue -local, red-Buoy AMRL1, cm), e) Wave Height (cm), f) Wave Period (s), and g) Velocity (red-north, green-east, blue-vertical, $\mathrm{cm} / \mathrm{s}$ ).

Figure 48. Data for 1 March to 1 April 2014 for Wax Lake Remote Station 3 where a) Wax Lake Discharge $\left(\mathrm{m}^{3} / \mathrm{s}\right)$, b) Wind Speed $(\mathrm{m} / \mathrm{s})$, c) Wind Direction (degrees), d) Water Level (blue -local, red-Buoy AMRL1, cm), e) Wave Height (cm), f) Wave Period (s), and g) Velocity (red-north, green-east, blue-vertical, $\mathrm{cm} / \mathrm{s}$ ).

Figure 49. Data for 1 April to 1 May 2014 for Wax Lake Remote Station 3 where a) Wax Lake Discharge $\left(\mathrm{m}^{3} / \mathrm{s}\right)$, b) Wind Speed $(\mathrm{m} / \mathrm{s})$, c) Wind Direction (degrees), d) Water Level (blue -local, red-Buoy AMRL1, cm), e) Wave Height (cm), f) Wave Period (s), and g) Velocity (red-north, green-east, blue-vertical, $\mathrm{cm} / \mathrm{s}$ ). 80

Figure 50. Data for 1 May to 1 June 2014 for Wax Lake Remote Station 3 where a) Wax Lake Discharge $\left(\mathrm{m}^{3} / \mathrm{s}\right)$, b) Wind Speed $(\mathrm{m} / \mathrm{s})$, c) Wind Direction (degrees), d) Water Level 
(blue -local, red-Buoy AMRL1, cm), e) Wave Height (cm), f) Wave Period (s), and g) Velocity (red-north, green-east, blue-vertical, cm/s).

Figure 51. Data for 1 June to 1 July 2014 for Wax Lake Remote Station 3 where a) Wax Lake Discharge ( $\left.\mathrm{m}^{3} / \mathrm{s}\right)$, b) Wind Speed (m/s), c) Wind Direction (degrees), d) Water Level (blue -local, red-Buoy AMRL1, cm), e) Wave Height (cm), f) Wave Period (s), and g) Velocity (red-north, green-east, blue-vertical, cm/s).....

Figure 52. Data for 1 July to 1 August 2014 for Wax Lake Remote Station 3 where a) Wax Lake Discharge ( $\left.\mathrm{m}^{3} / \mathrm{s}\right)$, b) Wind Speed (m/s), c) Wind Direction (degrees), d) Water Level (blue -local, red-Buoy AMRL1, cm), e) Wave Height (cm), f) Wave Period (s), and g) Velocity (red-north, green-east, blue-vertical, cm/s).

Figure 53. Data for 5 February to 1 March 2014 for Wax Lake Remote Station 4 where a) Wax Lake Discharge ( $\left.\mathrm{m}^{3} / \mathrm{s}\right)$, b) Wind Speed (m/s), c) Wind Direction (degrees), d) Water Level (blue -local, red-Buoy AMRL1, cm), e) Wave Height (cm), f) Wave Period (s), and g) Velocity (red-north, green-east, blue-vertical, cm/s).

Figure 54. Data for 1 March to 1 April 2014 for Wax Lake Remote Station 4 where a) Wax Lake Discharge ( $\left.\mathrm{m}^{3} / \mathrm{s}\right)$, b) Wind Speed (m/s), c) Wind Direction (degrees), d) Water Level (blue -local, red-Buoy AMRL1, cm), e) Wave Height (cm), f) Wave Period (s), and g) Velocity (red-north, green-east, blue-vertical, cm/s).

Figure 55. Data for 1 April to 1 May 2014 for Wax Lake Remote Station 4 where a) Wax Lake Discharge ( $\left.\mathrm{m}^{3} / \mathrm{s}\right)$, b) Wind Speed $\left.(\mathrm{m} / \mathrm{s}), \mathrm{c}\right)$ Wind Direction (Degrees), d) Water Level (blue -local, red-Buoy AMRL1, cm), e) Wave Height (cm), f) Wave Period (s), and g) Velocity (red-north, green-east, blue-vertical, cm/s).

Figure 56. Data for 1 May to 1 June 2014 for Wax Lake Remote Station 4 where a) Wax Lake Discharge $\left(\mathrm{m}^{3} / \mathrm{s}\right)$, b) Wind Speed $\left.(\mathrm{m} / \mathrm{s}), \mathrm{c}\right)$ Wind Direction (Degrees), d) Water Level (blue -local, red-Buoy AMRL1, cm), e) Wave Height (cm), f) Wave Period (s), and g) Velocity (red-north, green-east, blue-vertical, cm/s).

Figure 57. Data for 1 June to 1 July 2014 for Wax Lake Remote Station 4 where a) Wax Lake Discharge (m3/s), b) Wind Speed (m/s), c) Wind Direction (degrees), d) Water Level (blue -local, red-Buoy AMRL1, cm), e) Wave Height (cm), f) Wave Period (s), and g) Velocity (red-north, green-east, blue-vertical, cm/s).

Figure 58. Data for 1 July to 1 August 2014 for Wax Lake Remote Station 4 where a) Wax Lake Discharge ( $\left.\mathrm{m}^{3} / \mathrm{s}\right)$, b) Wind Speed (m/s), c) Wind Direction (degrees), d) Water Level (blue -local, red-Buoy AMRL1, cm), e) Wave Height (cm), f) Wave Period (s), and g) Velocity (red-north, green-east, blue-vertical, cm/s).

\section{Tables}

Table 1. Shear velocity statistics. Units are centimeters per second except for COR $\mathrm{H}_{m 0}$, which is dimensionless. (BBLM - bottom boundary layer model; TKE - turbulence kinetic energy; COV - covariance; IDM - inertial dissipation method; COR - correlation coefficient denoting the correlation between $u *$ and $H_{m 0}$.)

Table 2. Grain size distribution and texture measured at each station.............................................45

Table 3. Feldspar plot sedimentation results for the six month deployment.......................................45

Table 4. Raw feldspar data. 


\section{Preface}

This study was conducted for U.S. Army Engineer Research and Development Center (ERDC), under the ERDC "Section 219 Center Directed Research Program."

The work was performed by the ERDC Coastal and Hydraulics Laboratory (CHL), Coastal Engineering Branch (HNC), the Field Data Collection Branch (HNF) of the Navigation Division (NH), and the Coastal Processes Branch (HFC) of the Flood and Storm Protection Division (HF). The Technical Director for Navigation was Mr. W. Jeff Lillycrop, and the Technical Director for Flood and Coastal was Dr. Julie Rosati.

At the time of publication, Ms. Tanya Beck was Chief, CEERD-HNC; Mr. Thad Pratt was Chief CEERD-HNF; Dr. Jackie Pettway was Chief, CEERD-HN; Ms. Ashley Frey was Chief CEERD-HFC; and Dr. Cary A. Talbot was Chief, CEERD-HF. The Deputy Director of ERDC-CHL was Mr. Jeffrey R. Eckstein, and the Director was Mr. José E. Sánchez.

COL Bryan S. Green was the Commander of ERDC, and Dr. David W. Pittman was the Director. 


\section{Introduction}

Sea level rise and its effect on coastal areas is of global importance and represents one of the most prolific environmental concerns of this century (Nicholls and Cazenave 2010). An encroaching sea increases the likelihood of flooding and storm inundation, imposing greater risk to coastal communities. Predicting long-term sea level change and the subsequent coastal response are active areas of research given the potential economic, political, and social impacts sea level rise embodies.

A primary concern is the degree and rate of land loss in coastal areas. The rate of land loss is controlled not only by rising sea level but the processes that govern erosion and deposition. Sediment supply from terrestrial sources provides land building material so long as accumulation exceeds the rate of submergence and erosion. Complex morphodynamic processes redistribute material reshaping the coastal landscape in ways that can increase or decrease land cover. Ultimately, erosion and sea level rise will submerge low-lying areas, but the ability for the coastal plain to maintain a buffer through delta and wetland building even as the coastline retreats is a major question for understanding long-term morphologic behavior. This is likewise important for planners and engineers, as information gleaned from natural sediment processes may hold the key to developing engineering strategies to mitigate the effects of inevitable land loss. If areas of accretion can be identified and accumulation rates predicted on the basis of the local hydrodynamics, then it may be possible to develop more resilient coastal protection measures.

\subsection{Background}

River deltas form in response to fluvial processes that deposit sediments at the mouths of rivers. Deposition is a function of the hydrodynamic forces and the regional geological makeup of the basin and river complex. Riverdominated configurations occur in micro-tidal environments. If the offshore slope is mild, then wave energy is dissipated farther from shore reducing sediment transport effects due to waves. Under these conditions, Wright (1977) identifies three types of sediment deposition patterns based on the relative strength of the primary forcing mechanisms: (1) inertia, (2) friction, or (3) buoyancy. If the river and adjacent basin are relatively shallow, then friction dominates, and the effluent forms a wide-angled jet that reduces in 
strength offshore and laterally. Lateral dispersion leads to lower velocities offshore increasing deposition and initially forming a radial bar. As the bar grows upward, the effluent produces incised cuts that split the bar into longitudinal segments. Eventually, instabilities in this highly turbulent flow lead to channel formation as the bars meld and bifurcate to produce a distributary network (Edmonds and Slingerland 2007). Over time, the bars continue to build upward and seaward forming interdistributary islands that support a variety of flora, which in turn act to stabilize island sediments and encourage further growth. Channel networks continue to grow into the subaqueous zone further enhancing offshore migration of the delta complex (Shaw and Mohrig 2014). Eventually, a mature delta emerges complete with well-defined distributary channel networks interspersed between interdistributary islands.

Because of the abundant sediment supply and the mild offshore slope, deltas can continue to grow as they prograde farther into the receiving bay (Shaw and Mohrig 2014). Eventually, channel length reaches a critical point and becomes less efficient at carrying sediment. The river then takes a more direct path towards the bay, usually through one of its minor distributaries (Fisk 1952; Roberts 1998). The new, shorter path has a steeper hydraulic grade line, and the delta begins to build new land and prograde into the bay. This cycle can be repeated many times through a succession of increasing channel length and accompanying diminished hydraulic grade line replaced by shorter channels with a higher hydraulic grade line and more direct path to the bay. The Mississippi River has undergone delta switching many times throughout its history, as evident by the discovery of relic or abandoned channels and engineering efforts to limit discharge into the Atchafalaya River (Roberts 1998).

Under a regime of global sea level rise, submergence disrupts this balance in a manner that is difficult to predict. If relative sea level rise can submerge channels at a rate faster than their growth, sediment delivery could continue through existing networks for longer periods delaying the transition to new channel cuts.

\subsubsection{Sediment pathways}

Delta island sediment delivery is composed of two main mechanisms:

(1) creek networks hydraulically connected to adjacent channels and (2) sheet flow during periods of high water when the island is totally or partially submerged. If the tidal range is very small, then sediment is 
delivered primarily through creek networks except during periods of high discharge when the island may become inundated. The degree and delivery rate are controlled by the size (length) and density of the creek network distribution. A highly distributed network can be an effective sediment delivery method similar to coastal salt marshes (Novakowski et al. 2004). Under higher tidal range, larger portions of the island become submerged during the tidal cycle, and both mechanisms contribute to sediment delivery. Sediment distribution is spread over a much wider area, and presumably sediments carried in suspension have the potential to reach a much larger fraction of the island interior.

Island topography plays a role in controlling hydraulic pathways and associated sediment distribution. In general, island elevation transitions from subaerial at the upland limit to subaqueous towards the bay. The transition is often gradual with a centralized intertidal zone separating the uplands near the island apex and subtidal zone at the bay's edge. Natural levees form around the island exterior elevating the perimeter with respect to the interior. Islands located closer to the bay may form an interior lagoon (O'Connor and Moffett 2015). Once water levels exceed the levee height, flow begins to spill over and accelerate as it fills the interior. Tidal flow can also enter through the subtidal regions and progress landward across the island interior. Creek networks likewise deliver sediment directly to the island interior. If the sediment delivery is high, mature creeks can infill with fine-grained sediment, reducing the exchange capacity. In response, new creeks form and continue the alluvial cycle.

Bidirectional tidal flow can transport fine-grained sediment through the mechanisms discussed above. Sheet flow over low-lying coastal wetlands exhibits spatially complex current patterns (Leonard and Luther 1995; Torres and Styles 2007) that vary in flow speed and direction between stations located only a few meters apart. Sediment is carried in suspension during maximum flood and then begins to settle near slack high tide when current speeds drop below the minimum required to maintain sediments in suspension. In contrast, periods of high discharge deliver an abundant supply of fine- and coarse-grained sediment to the delta complex in a relatively short period. Higher water elevation during floods leads to sheet flow that covers the island interiors and may be the primary mechanism for island growth. 


\subsubsection{Vegetation}

The role of vegetation in controlling flow and sediment transport in lowlying coastal areas has been investigated with field measurements and numerical models (Leonard and Luther 1995; Nepf 2012; Temmerman et al. 2005; Torres and Styles 2007). Comprehensive studies have been conducted in coastal plain salt marshes, and a large body of literature focusing on various aspects of the interaction between hydrodynamics, sediment dynamics, and vegetation exists (Nepf 2012; Neumeier and Amos 2006). Vegetation has two primary effects on the hydrodynamics: (1) flow blockage and (2) turbulence generation. Flow blockage results from the presence of submerged vegetation, which impedes the flow, reducing velocities in proportion to increases in vegetation density (Temmerman et al. 2005). Flow separation in the lee of individual plants sheds eddies generating wake turbulence. In fully submerged vegetation, a low flow turbulence zone forms within the canopy, and velocities are reduced with respect to creeks and unvegetated areas (Neuweier and Amos 2006).

Lateral gradients in flow speed at the boundaries between vegetated and unvegetated areas lead to increased probability of particle settling at the fringes and within the vegetated canopy. This is more pronounced for partially submerged vegetation, as model results have shown abrupt changes in flow velocity at the interface leading to rapid deposition (Temmerman et al. 2005). For fully submerged vegetation, the flow is more or less uniform under sheet flow conditions, and sediment deposition is more homogeneous.

Vegetation has also been shown to dissipate wave energy and help reduce storm surge in coastal marshes (Anderson and Smith 2014). Wave attenuation in low-lying coastal plains such as salt marshes can be twice as high in vegetated versus non-vegetated areas (Cooper 2005). Experiments to investigate wave attenuation sensitivity to stem density and the level of vegetation emergence have generally indicated increased attenuation with increasing stem density and highest dissipation under emergent conditions (Augustin et al. 2009).

\subsubsection{Wax Lake Delta}

Wax Lake Delta (WLD) is located in St. Mary Parish on the southwestern Louisiana coast. In 1942, the U. S. Army Corps of Engineers (USACE) constructed a canal from Wax Lake, an abandoned meander of the 
Atchafalaya River, to the Gulf of Mexico as a flood control measure to divert flow from the lower Atchafalaya River and help protect Morgan City, LA (Fisk 1952). The diversion canal known as Wax Lake Outlet (WLO) created a new pathway for terrestrial sediments through low-lying wetlands to an open coastline. The WLD formed in response to this flood control measure and represents one of the few coastal areas that is actively accreting sediment. This new delta has been monitored since its inception, providing a wealth of historical knowledge on the geomorphological evolution of this evolving system (Edmonds and Slingerland 2007; Roberts et al. 2003; Shaw et al. 2013).

The WLD first became subaerial in the wake of the 1973 Mississippi River flood, following decades of sand scoured from the lower Atchafalaya River and redeposited in the bay via the WLO (Roberts et al. 1997). WLD has continued to develop as a network of bifurcated channels separated by alternating interdistributary islands. Annual sediment input is estimated at 38.4 million tons with $18 \%$ being sand (Kim et al. 2009). The average vertical accretion rate is $27 \mathrm{~mm} / \mathrm{yr}$ (Edmonds et al. 2011), and as of 2005, the delta complex has prograded approximately $8 \mathrm{~km}$ into Atchafalaya Bay. WLD is sand rich ( $70 \%)$, and considering it receives a significant fraction of Mississippi River fines, wave and wind action bypass a large fraction of these fines to the continental shelf (Roberts et al. 2003). WLD continues to build new land and along with the Atchafalaya Delta, currently fills most of Atchafalaya Bay. WLD continues to prograde into deeper water (Roberts et al. 2003) and will eventually form a new shelf delta west of the mature Mississippi River delta.

Because WLD represents one of the few deltas that is building new land, a number of studies focusing on the role of river discharge, hydrodynamics, and sediment delivery in contributing to delta growth have been carried out. Carle et al. (2015) investigated the effect of extreme discharge on delta land changes after the historic 2011 Mississippi River flood. Based on shifts in vegetation coverage and species distribution derived from satellites, they found net areal growth of $6.5 \mathrm{~km}^{2}$ and a $31.8 \%$ increase in species that occupy higher elevations inferring vertical accretion.

Shaw et al (2013) conducted bathymetric surveys and sediment sampling to investigate channel networks at WLD. They noted that $85 \%$ to $98 \%$ of the channel consisted of muddy bedrock, which is highly resistant to erosion, and the rest was covered by alluvial sands. Based on their 
analysis, the channels have eroded up to 40\% (between 1973 and 1999) and widened by 11\% (between 1991 and 2009). Channel erosion was responsible for downstream island migration, and measurements during the 2009 spring flood showed significant sand concentrations carried as suspended load in the channels.

Hiatt and Passalacqua (2015) investigated the hydraulic connectivity between an adjacent channel and a WLD interdistributary island. Their process-based study examined (1) the mechanisms responsible for water exchange, (2) the primary forcing agents responsible for that exchange, and (3) the travel times across the island and the adjacent channel. They found that between $23 \%$ and $54 \%$ of the incoming discharge was diverted to the islands and that travel times through the island were three times longer than the adjacent channel. Dye tracer results revealed island residence times greater than 3.8 days. Primary water pathways included seaward flow in the channels with a reversing tidal current over the island. The complex flow patterns they measured over broad low-lying topography with mild relief revealed the subtle control morphology holds on the hydrodynamics.

\subsection{Purpose of the study}

The USACE is responsible for flood and storm protection in coastal areas. It has been suggested that low-lying coastal wetlands dissipate wave energy and may help reduce the effect of storm surge thereby serving as natural buffers to protect coastal areas (Costanza et al. 2008; Gedan et al. 2011; Wamsley et al. 2010). However, these studies acknowledge the scarcity of data to unequivocally establish the degree to which wetlands dampen storm energy. The economic benefit of wetlands in protecting coastal assets has been estimated at USD 23.2 billion/year (Costanza et al. 2008). River diversions introduce new sediment to coastal wetlands and have been proposed as viable engineering alternatives to promote land building and further storm protection measures (Kim et al., 2009; Snedden et al., 2007). As environmental stewards, the USACE is also charged with protecting coastal wetlands, which are critical habitats for a wide variety of organisms. Likewise, understanding coastal wetland subsidence is a major issue affected by global sea level rise (Cahoon et al., 2006). The degree and rate of land loss in terms of sediment supply versus submergence remain active areas of research, and understanding wetland geomorphological processes provides the context for developing 
restoration alternatives and best practice strategies that can be applied across a variety of USACE projects.

The purpose of this technical report (TR) is to describe the hydrodynamic and sediment transport processes active within an interdistributary delta island to better understand the mechanisms controlling sediment delivery and associated land building. The report focuses on measurements and analyses from a field data collection effort conducted at WLD between February and August 2014. The results present a summary of the meteorological, current, wave, turbulence, and sediment transport characteristics at the study site. The site conceptual model section reveals insight into the seasonal variations in sediment pathways and accretion that help inform coastal wetland management strategies in the context of global sea level rise. 


\section{Methods}

\subsection{Study site}

The study was conducted at WLD located in St. Mary Parish, LA (Figure 1). Instrumented platforms were installed on Mike Island, an interdistributary island located near the centerline axis of the delta complex. Mike Island is oriented north-south and bracketed by two main channels that carry a combined discharge equal to nearly $30 \%$ of the WLD total.

Water and sediment delivery is controlled through the WLO. Based on U.S. Geological Survey (USGS) records, annual and peak discharge are estimated at 2,500 m3/s and 5,000 m3/s, respectively (Hiatt and Passalacqua 2015). The WLO project design flood flow capacity is $12,000 \mathrm{~m} 3 / \mathrm{s}$, which represents approximately one-third of the Atchafalaya River capacity.

Land elevation on the islands is highest near the apex (subaerial) and decreases towards the bay (subaqueous). Island flora distribution follows a similar trend with large terrestrial vegetation such as black widow (Salix nigra) occupying the subaerial regions transitioning to aquatic vegetation in the subaqueous regions. A common species of aquatic vegetation is the American lotus (Nelumbo lutea). Nelumbo lutea is an emergent, aquatic plant common to the southeastern United States and grows in lakes, swamps, and areas prone to flooding (Hall and Penfound 1944). The roots anchor in the mud, and the leaves emerge above the water surface. The stalk can grow to be $2.0 \mathrm{~m}$ in length, and the leaves grow up to $1.0 \mathrm{~m}$ in diameter. The plant flowers in spring, and the leaves reach full size within a month or so but then die back in the fall. Nelumbo lutea grows in dense patches and produces a thick canopy that covers large sections of the shallow WLD island interior (Figure 2). The thick coverage can block the wind reducing surface stresses and associated wind driven currents. The large leaves likewise dampen surface displacements, which in turn impedes local wave propagation. Thus, currents under the canopy are driven primarily by tidal forces, low-frequency shelf motions, or discharge. Because of the absence of plants in the fall and winter and the rapid growth in the spring, Nelumbo lutea has a distinctive seasonal influence on the hydrodynamics and sediment transport processes. 
Figure 1. Study site including regional coastline. Lower inset depicts the location of the four platforms installed on the western levee of Mike Island.

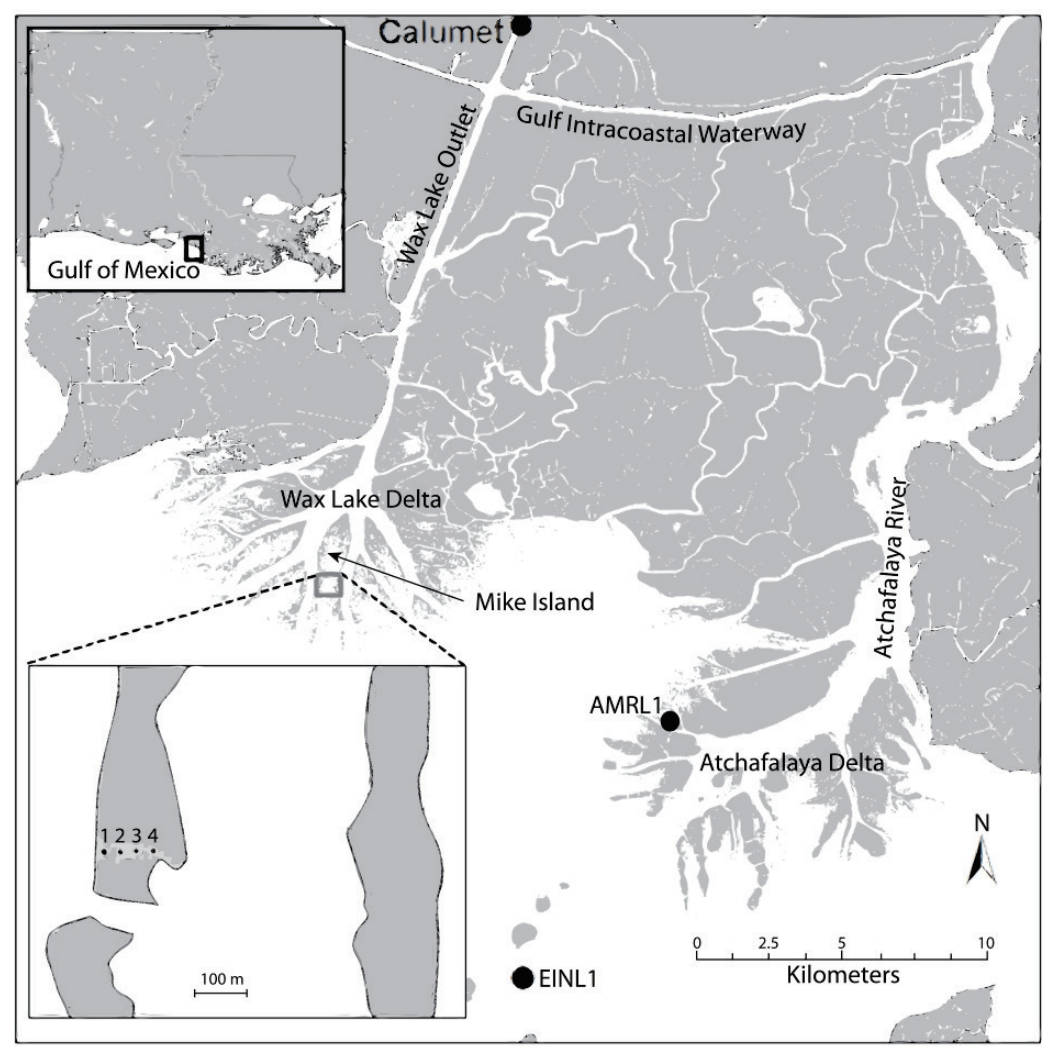

Figure 2. Instrumented platform surrounded by dense growth of Nelumbo lutea.

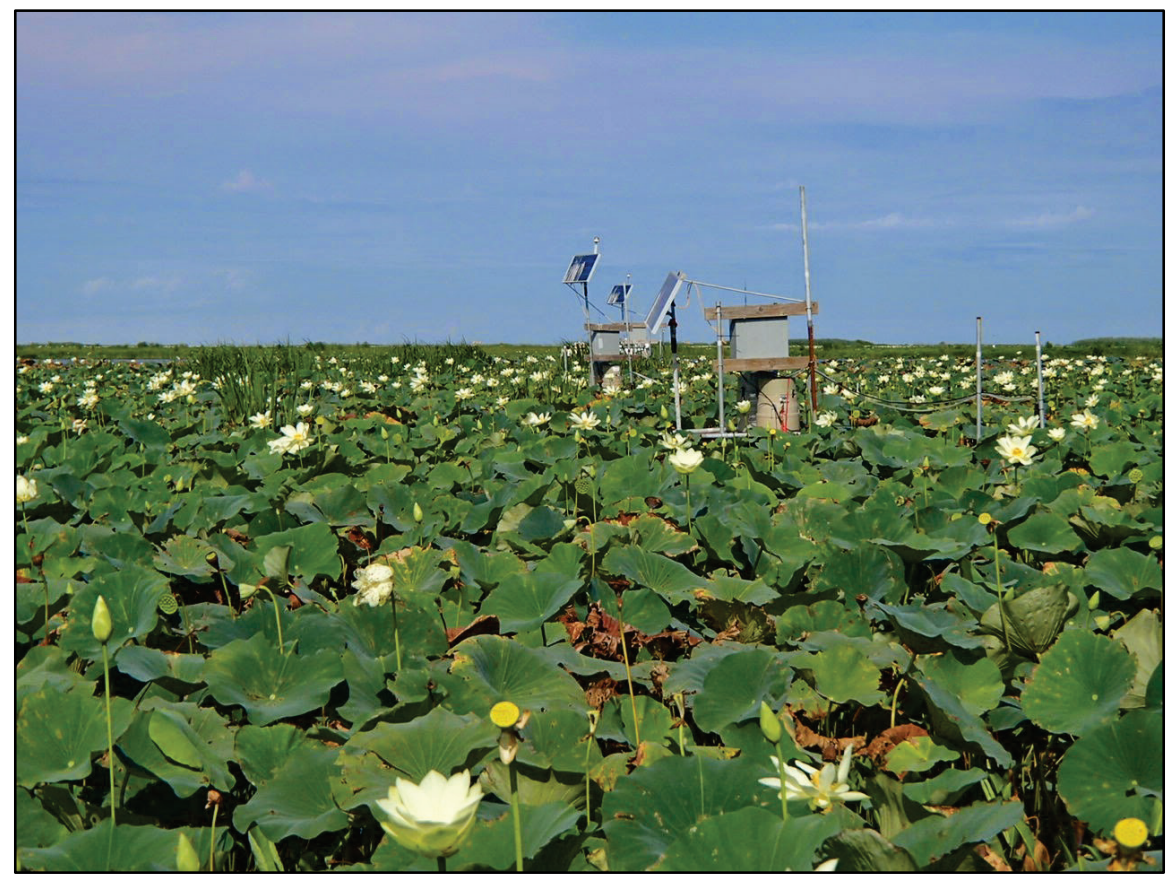




\subsection{Instrumentation}

Platforms. Four platforms are installed on Mike Island to support instrumentation for the Wax Lake study (Figure 3). The equally spaced platforms $(33 \mathrm{~m})$ form a linear array from the islands' western edges to approximately $100 \mathrm{~m}$ into the interior. The westernmost platform is installed on the natural channel bank levee and is at a slightly higher elevation (Figure 4). Bed elevation decreases towards the island center with a maximum elevation difference of approximately $0.5 \mathrm{~m}$. The array is $2.6 \mathrm{~km}$ from the island apex, and the island width at the array is $0.7 \mathrm{~km}$.

Each platform is equipped with an acoustic Doppler velocimeter (ADV) to measure currents and turbulence, a surface-piercing capacitance water level gauge, and a suspended sediment sampler. The westernmost platform also contains a video camera oriented towards the island interior. Solar panels are installed on each platform to provide long-term power to the instrumentation.

The ADVs are programmed to sample at $25 \mathrm{~Hz}$ for a 2-minute burst every 15 minutes. The ADVs measure east $(u)$, north $(v)$, and vertical $(w)$ velocities, which are decomposed into mean $(U, V, W)$ and fluctuating $\left(u^{\prime}\right.$, $\left.v^{\prime}, w^{\prime}\right)$ components to calculate average and turbulence quantities, respectively. Tidal currents are extracted from the time series using the T_TIDE software (Pawlowicz et al. 2002). A detailed explanation of the velocity data processing is given in the following section.

Wave and water level are measured at each platform with an Ocean Sensor Systems OSSI-010-002E wave staff, outfitted with a $1 \mathrm{~m}$ long staff. The wave staff converts analog capacitance to digital counts and serially streams the 12-bit digital data to the data logger. With 12-bit digital resolution distributed over the $1,000 \mathrm{~mm}$ rod length, the wave staff resolution is nominally $0.25 \mathrm{~mm}$. The manufacturer's stated accuracy of the staff measurements is $0.025 \%$ of full scale (in this case, $0.25 \mathrm{~mm}$ ). Data ensembles are collected with a 15-minute sampling interval. Each ensemble consists of 3,600 water surface positions collected at $30 \mathrm{~Hz}$ for $120 \mathrm{~s}$. Water level and wave measurements are not available when the island becomes subaerial and the wave staff is completely exposed. Wave and water level data are generated through data processing and analysis, which is described in Section 2.3.1. 
Figure 3. Mike Island stations looking eastward. Station 1 is the closest platform on the left. The photograph was taken in May 2014 before the emergence of Nelumbo lutea. The ADVs and wave gauges are mounted on the two poles at the left of each station.

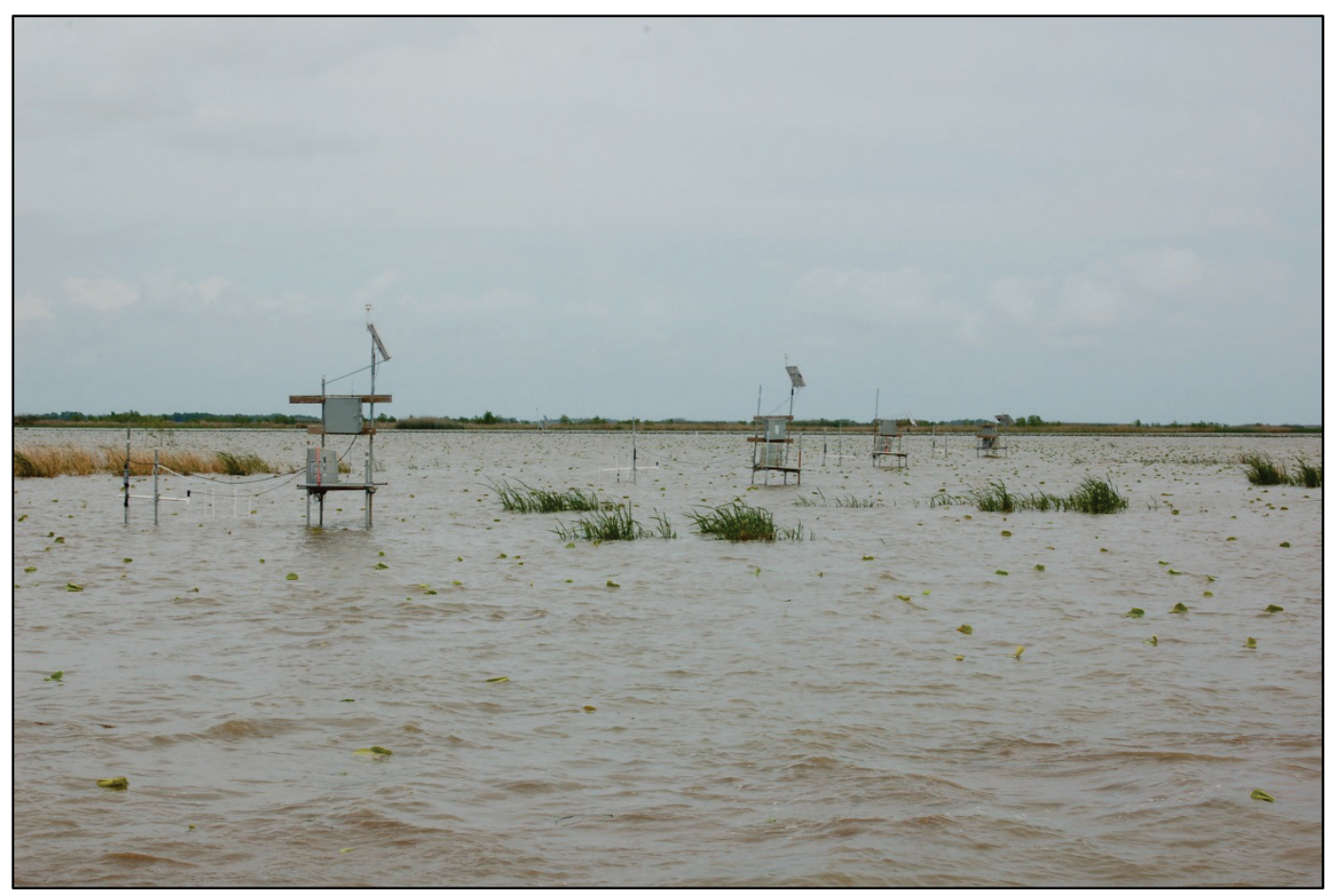

Figure 4. Platform locations and bed elevation measured with RTK-GPS. Bed elevation is interpolated between measurement points and is referenced to NAVD88.

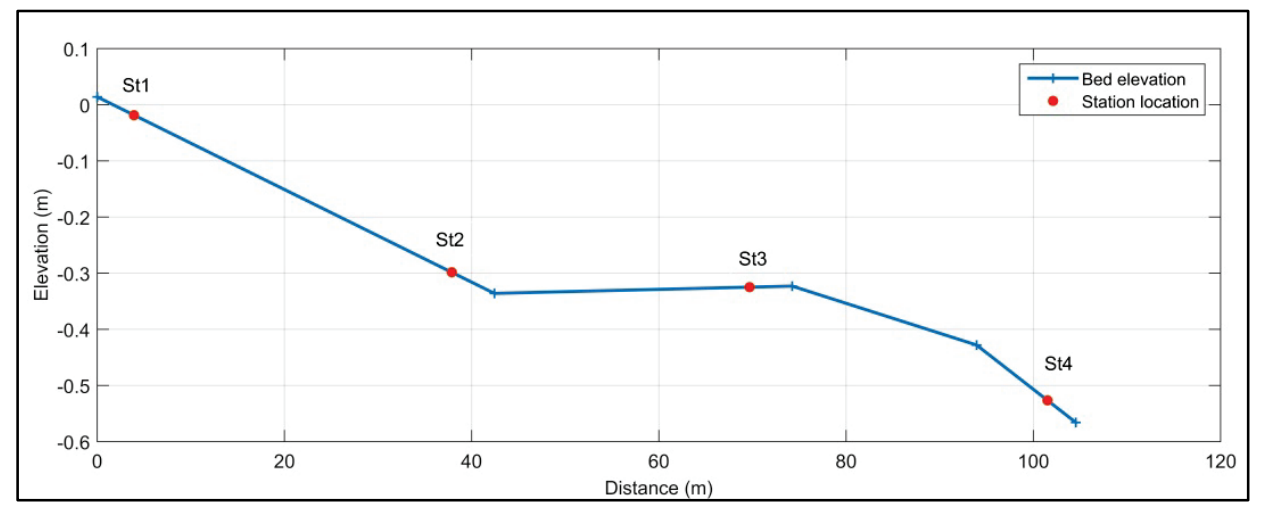

The wave and current sensors were deployed on 4 February 2014 and recovered on 11 August 2014. All instruments were operational for the duration of the study except the wave staff mounted on the easternmost platform (St4) due to sensor malfunction. The wave staff was operational between May 11 and the end of the deployment. The platforms were recovered in August over concerns that increased recreational activity in the WLD with the upcoming hunting season would place the instrumentation at a greater risk of damage. 
Discharge, winds, and tide data were obtained from federally managed monitoring stations within the WLD complex to place the platform measurements in the context of the regional climatology.

Discharge. Discharge is measured from the USGS Wax Lake Outlet Station (073811590) located at Calumet, LA. The station provides 6-minute measurements within the diversion canal approximately $5 \mathrm{~km}$ south of Wax Lake and $23 \mathrm{~km}$ north of the study area. The outlet is the primary hydraulic connection between Wax Lake and the WLD and is the source of terrestrial sediments from the Atchafalaya and ultimately the Mississippi River.

Winds. Wind data are obtained from National Oceanographic and Atmospheric Administration (NOAA) Buoy EINL1 (8764314) located northwest of Eugene Island, LA. The station is located approximately 14 $\mathrm{km}$ south-southeast of the study site in open water and provides 6-minute wind speed and direction at $10 \mathrm{~m}$ above the surface.

Tides. Water surface elevation is obtained from NOAA Station AMRL1 (8764227) located at Amerada Pass, LA. The station provides 6-minute water surface elevation measurements and is located approximately $12 \mathrm{~km}$ east of the study site near the mouth of the Atchafalaya River.

\subsection{Hydrodynamic analysis methods}

\subsubsection{Water level and wave analysis}

Water levels were determined at each platform from the ensemble-mean water level from the water-level staffs. This ensemble averaging removes the effects of surface wind waves. The mean water level for each 2-minute data ensemble was recorded as the local water depth at that time. The water level staffs were not surveyed to a vertical datum for this study, so the tides are relative to local bed but can be approximately referenced to local tidal levels with additional analysis.

Initial processing of the water level data for wave analysis included detrending the signal (to remove low-frequency signals such as tides and vessel wakes) with a high-pass elliptic filter with stopband and passband frequencies of 0.10 and $0.20 \mathrm{~Hz}$, respectively. Surface variations with frequencies higher than $0.20 \mathrm{~Hz}$ were analyzed by time- and frequencydomain methods for estimating wave parameters. 
In the time domain, a standard zero-upcrossing method (CERC, 1984) was applied to the highpass filtered water surface signal to generate a dataset of wave heights $\left(H_{x}\right)$ and wave periods $\left(T_{x}\right)$. The significant wave height $\left(H_{s}\right)$ is defined as the mean of the largest third of $H_{x}$. The root-meansquare wave height is given by $H_{r m s}=\sqrt{\frac{1}{N} \sum_{i=1}^{N} H_{x, i}^{2}}$. For the zero-crossing methods, the characteristic wave period is the mean wave period, which is $T_{m}=\frac{1}{N} \sum_{i=1}^{N} T_{x, i}$.

In the frequency domain, the Welch (1967) method for power spectral density estimate was applied to the high-pass filtered water surface record to determine spectral estimates of wave characteristics (CERC 1984). The spectral wave height is given as $H_{m 0}=4 \sqrt{\int_{f 1}^{f 2} S_{\eta}(f) d f}$, where $f$ indicates frequency (Hz), $S_{\eta}$ is the spectral density estimate, and the limits of the integral are the frequency bounds over which surface gravity waves are expected at the site (in this case, $f_{1}=0.3 \mathrm{~Hz}$ and $f_{2}=3.0 \mathrm{~Hz}$ ). The peak frequency, $f_{p}$, is the frequency associated with the peak of the energy spectrum within the expected frequency interval $f_{1}$ to $f_{2}$. The peak wave period is the reciprocal of the peak frequency, $T_{p}=\frac{1}{f_{p}}$.

\subsubsection{Acoustic Doppler velocimeter (ADV) analysis}

The velocity data are put through several quality control (QC) measures prior to analysis. The $10 \mathrm{MHz}$ Sontek Acoustic Doppler Velocimeters are accurate to within $1 \%$ of the measured data. However, data dropouts occur when the probes are not submerged, the acoustic signal is blocked, or an inadequate number of scatters exist in the flow. Waves at moderate water depths were also found to cause partial data dropouts, as a portion of the $\mathrm{ADV}$ probe might not be submerged during wave troughs. ADVs can likewise experience velocity spiking when the probe is not submerged, when large objects pass through or near the measurement volume (leaf litter, vegetation, etc.), or by aliasing of the Doppler signal. Therefore, each 2-minute burst was evaluated in a two-step QC procedure prior to analysis-data quality check and de-spiking. First, data quality was assessed by examination of the SNR (signal to noise ratio) and the correlation between successive pings for each sample in a 2-minute burst $(3,600$ samples per burst). Samples with return amplitudes $<50$ and 
correlation $<70 \%$ were flagged. These criteria identified both the conditions of unsubmerged probes and inadequate scatters. While data dropouts occurred during most low tides when water levels fell below the sensor height, close inspection of the ADV data in conjunction with water level showed that data dropouts due to low numbers of scatters were not a problem. In fact, SNRs were rarely below 95 when measured water levels were clearly above the probe. Bursts with $<85 \%$ qualifying correlation and $<50$ SNR were removed from further evaluation while those whose samples exceeded the $85 \%$ threshold were passed to the second QC routine with the errant data flagged.

Second, the data were passed through a de-spiking routine developed by Goring and Nikora (2002) with recommended improvements by Wahl (2003). Once errant spikes were identified, they were flagged. If the combined flagged samples from the data quality and de-spiking analysis exceeded $15 \%$, that burst was removed from further analysis. Filtered data were then used to calculate the mean flow properties.

\subsubsection{Shear velocity estimates}

In the absence of waves, the flow energetics and mixing can be described by the absolute intensity of the velocity fluctuations, calculated as turbulent kinetic energy $(q)$, and the covariance of velocity fluctuations (Equation (2)).

$$
\begin{gathered}
q=\frac{1}{2}\left(\overline{u^{\prime} u^{\prime}}+\overline{v^{\prime} v^{\prime}}+\overline{w^{\prime} w^{\prime}}\right) \\
\operatorname{cov}=\left(\overline{u^{\prime} w^{\prime}}\right)+\left(\overline{v^{\prime} w^{\prime}}\right)
\end{gathered}
$$

The shear velocity, $u_{*}$, is also a measure of mixing and typically used in conjunction with sediment properties to estimate sediment transport. The shear velocity can be calculated from the turbulent kinetic energy (TKE) as

$$
u_{*}=\sqrt{C_{D} q}
$$

where $C_{D}$ is a constant taken as 0.19 (Kim et al. 2000; Pope et al. 2006; Stapleton and Huntley 1995). Shear velocity can also be calculated from the covariance: 


$$
u_{*}=\sqrt{-\operatorname{cov}}
$$

(Kim et al. 2000; Salehi and Strom 2012).

The correlation between horizontal and vertical wave orbital velocity components can create errors in bottom stress estimates computed using the covariance method (Shaw and Trowbridge 2001). As the covariance is a direct estimate of stress, several independent methods have been developed to reduce the potential errors that occur when waves are present.

Bursts sampled in the presence of waves require additional processing to accurately calculate the TKE and covariance. Each flow component contains the mean flow $(U, V, W)$, the turbulent component $\left(u^{\prime}, v^{\prime}, w^{\prime}\right)$, and the wave component $(\tilde{u}, \tilde{v}, \tilde{w})$. Removing the wave component from the fluctuating velocity requires the velocity to be analyzed in the frequency domain, which requires a continuous time series. Therefore, any flagged velocity points are replaced using a cubic spline interpolation. Analysis found that this interpolation changed the calculated metrics by less than $5 \%$.

Using the wave power spectrum, the velocity fluctuations due to waves can be eliminated (Stapleton and Huntley 1995). For example, the frequency range containing $90 \%$ of the wave energy is calculated for each sampling burst defined as the range between $0.53 \mathrm{~Hz}$ and $2.87 \mathrm{~Hz}$ (vertical red lines in Figure 5). The turbulent energy spectra are considered linear across this frequency range. Figure 6 shows the associated turbulent energy spectra for the east component of the velocity with (blue) and without (red) the wave energy removed. 
Figure 5. Wave spectrum for 17:30, 12 April 2014, with vertical lines (red) bookending $90 \%$ of the wave energy.

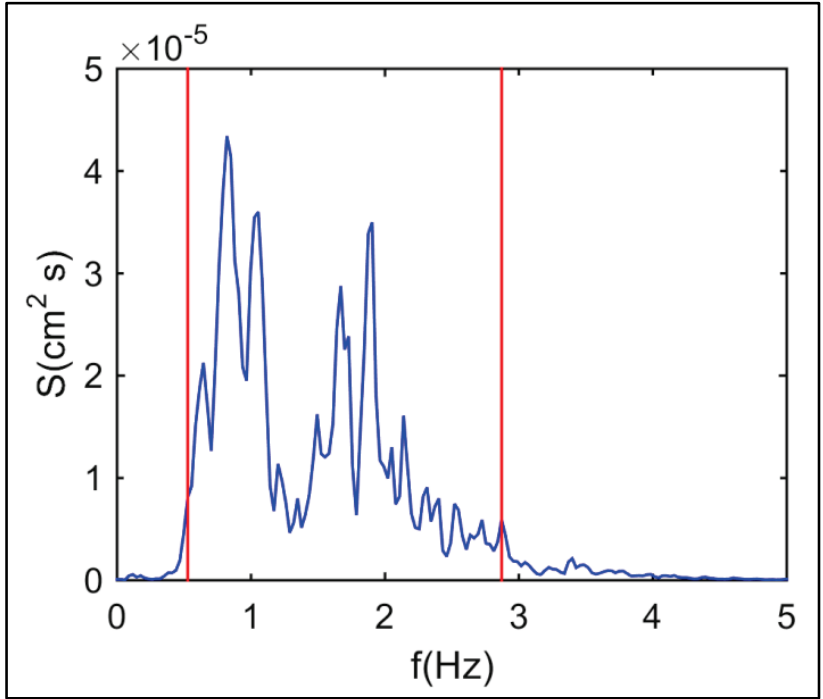

Figure 6 . Turbulent energy spectrum for the east velocity component for 17:30, 12 April 2014, including wave oscillations in blue. The red curve denotes the cropped spectrum based on the wave.

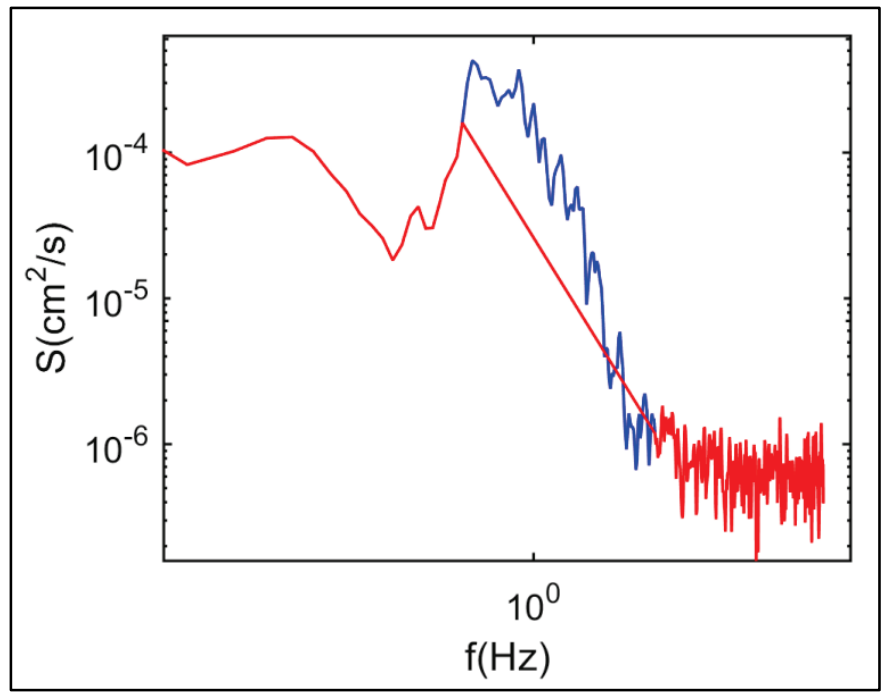

The turbulent normal stresses that are used to calculate the turbulent kinetic energy can be found by integrating the velocity power spectrum (Equation (5)). To eliminate the wave oscillations, Equation 3 can use a cropped spectrum like the one shown in Figure 6 for calculating the turbulent normal stresses.

$$
\overline{u^{\prime} u^{\prime}}=\int_{f_{0}}^{f_{\max }} \phi_{x x} d f
$$


An additional method for calculating the shear stress called the inertial dissipation method was proposed by Stapleton and Huntley (1995). This method assumes that turbulence generation and dissipation are in a local balance and that the measurements are made within the constant stress part of the logarithmic boundary layer (i.e., the local stress is assumed equal to the bottom stress). The basis of this method given in Equation 6 calculates the shear velocity based on the assumption that an inertial subrange exists in which the spectral transfer of TKE is controlled primarily by dissipation. By Taylor's frozen turbulence hypothesis, the TKE equation can be transformed from wavenumber space to frequency space, allowing for the calculation of the shear velocity,

$$
u_{*}=\left(\phi_{i i}(k) k^{5 / 3} / \alpha_{i}\right)^{1 / 2}(\kappa z)^{1 / 3}
$$

where $\kappa$ equals the von Karman's constant (0.4) and $\alpha_{i}$ equals the Kolmogorov constant with $\alpha_{1}=0.51, \alpha_{2}=\alpha_{3}=4 \alpha_{1} / 3$ (Kim et al. 2000).

Bottom shear velocity is estimated using the methods described above: TKE method through Equation (3), covariance method through Equation (4), TKE frequency domain method similar to Equation (5), covariance frequency domain method, and inertial dissipation method, Equation (6). Shear velocity is also computed using a bottom boundary layer model as described next.

\subsubsection{Micro-scale turbulence}

Suspended particles in fine-grained sediment environments tend to form cohesive flocs (Winterwerp and Van Kesteren 2004). Floc size is controlled by complex interactions between concentration and turbulence intensity. Neglecting particle collisions, floc size is limited by turbulence shear stresses that tend to break up flocs. Two measures used to investigate cohesive sediment dynamics are the dissipation parameter $(G)$,

$$
G=\sqrt{\frac{\varepsilon}{v}}
$$

and the Kolmogorov micro-scale $\left(\lambda_{0}\right)$, 


$$
\lambda_{0}=\left(\frac{v^{3}}{\varepsilon}\right)^{1 / 4}
$$

where $\varepsilon$ is the turbulence kinetic energy dissipation and $v$ is the kinematic viscosity of water (Kolmogorov 1941). In shear-generated boundary layer flows, dissipation approximately balances production allowing $\varepsilon$ to be written as

$$
\varepsilon=\frac{u_{*}^{3}}{\kappa z}
$$

The Kolmogorov micro-scale is a measure of the size of the smallest turbulent eddies and therefore the maximum sustainable floc size. Flocs of greater diameter are subject to turbulence stresses that can overcome the cohesive bonding properties of fine-grained sediment, thereby limiting floc growth. At scales less than $\lambda_{0}$, viscous effects dominate, and the sediment cohesive properties can more easily maintain floc stability. Typical values obtained in estuaries range from 100 to 1,000 microns (Winterwerp 1998). The dissipation parameter represents the velocity rate of strain and is proportional to the local shear. Higher rates of strain produce greater shearing force causing the breakup of larger flocs. Laboratory experiments conducted by Manning and Dyer (1999) show reductions in average floc size from 150 to 80 microns for $G$ ranging from 45 to $12 \mathrm{~s}^{-1}$.

\subsection{Sediment analysis}

The wave and current time-series measurements at each platform are used to drive a bottom boundary layer model to predict the combined wave and current shear stress components. The theoretical model is an extension of the combined flow model developed by Glenn and Grant (1987) as modified by Styles and Glenn (2000) but without the correction for suspended sediment induced stratification. The details of the model formulation can be found in the above references.

The model input includes near-bed wave excursion amplitude $(A b)$, wavebottom orbital velocity amplitude $\left(U_{b}\right)$, and near-bed mean current $\left(u_{r}\right)$ at a known height above the bed $(z r)$. The wave parameters are estimated from the wave height, wave period, and water depth measurements using linear wave theory, (e.g., (Dean and Dalrymple, 1991)). The mean current is determined from the burst-averaged $\mathrm{ADV}$ measurements, and $z_{r}$ is set equal 
to $10 \mathrm{~cm}$ corresponding to the height of the ADVs above the local bed elevation. The model computes the time-averaged shear stress associated with the current $\left(\tau_{c}\right)$, the maximum shear stress associated with the wave $\left(\tau_{w m}\right)$, and the combined maximum wave plus current shear stress $\left(\tau_{c w}\right)$. The corresponding shear velocities are $u^{*} c\left(=\sqrt{\tau_{c} / \rho}\right), u^{*} w m\left(=\sqrt{\tau_{w m} / \rho}\right)$, and $u^{*} c w\left(=\sqrt{\tau_{c w} / \rho}\right)$, respectively, where $\rho$ is fluid density. The timeaveraged shear velocity provides an independent measure to gauge the uniformity between the various data-derived methods to compute shear velocity described above.

\subsubsection{Critical shear stress and the initiation of sediment motion}

Initiation of sediment motion is determined using the Shields criteria,

$$
\psi=\frac{\left|\tau_{b}^{\prime}\right|}{\rho(s-1) g d_{r}}
$$

where $\left|\tau_{b}^{\prime}\right|$ is the magnitude of the maximum skin friction shear stress over a wave period, $d_{r}$ is the grain diameter, and $s$ is the specific gravity $\left(=\rho_{s} /\right.$ $\rho, \rho_{s}$ is sediment density). Sediment mobilization occurs when the Shields parameter $(\psi)$ exceeds the critical value for initiation of sediment motion $\left(\psi_{c r}\right)$. The Shields criteria help identify wave and current conditions that favor sediment resuspension and thus provide a quantitative measure of sediment transport activity at each of the four sites.

The critical shear stress for the initiation of sediment motion for finegrained sediments varies widely in natural environments (Winterwerp and Van Kesteren 2004). For loose, unconsolidated sediments, as typical of freshly deposited material, motion can occur at approximately 0.1 Pa. As new material is deposited on top of old, compaction leads to consolidation, increasing the internal bonding properties of the sediment. Critical stresses on the order of $5 \mathrm{~Pa}$ are not uncommon for compacted cohesive sediments (Winterwerp and Van Kesteren 2004). To the authors' knowledge, $\psi_{c r}$ has not been measured previously at the study site, but critical erosion stress has been measured at Horseshoe Bend located in the lower Atchafalaya River, LA ${ }^{1}$ (S. Jarrell Smith, personal comm.). That

\footnotetext{
${ }^{1}$ S. Jarrell Smith, 1 May 2016, personal communication, ERDC-CHL, Vicksburg, MS.
} 
study measured critical erosion stresses between $0.1 \mathrm{~Pa}$ and $0.75 \mathrm{~Pa}$ with stress increasing as a function of bulk sediment density. The critical stress used in the bottom boundary layer model (BBLM) for this study is set to o.1 $\mathrm{Pa}$, to simulate conditions that most favor maximum sediment mobilization.

\subsubsection{Suspended sediment concentration data processing}

Discrete suspended sediment concentration (SSC) samples were taken over the course of the field study and used to calibrate the turbidity sensors (YSI model 6136) and the ADVs. The SSC samples were collected by a portable sampler (Teledyne ISCO) mounted on a platform with the sample tube intake mounted at the same vertical position as the optical backscatter sensor (OBS) and ADV (nominally, $10 \mathrm{~cm}$ above the sediment bed) and within approximately $1 \mathrm{~m}$ of one another in horizontal position. The collected suspended sediment samples were vacuum filtered according to ASTM Method D 3977-97 (ASTM 1997). The turbidity sensors' calibration was checked on a nominal 4-week interval over the course of the deployment against recently prepared standards. There was little to no drift observed over each 4-week deployment interval.

The ISCO sampling tubes' close proximity to the sediment bed is believed to have contributed to spurious data in the calibration dataset. Initially, the ISCO sampling routine involved first a purging of the sampling line, followed by sample withdrawal. Under conditions with weak currents, the collected sample and/or the measured turbidity may have been impacted by sediment suspended by the purging operation. Therefore, conditions in which the currents were less than $2 \mathrm{~cm} / \mathrm{s}$ were excluded from the calibration dataset. Additionally, sedimentation over the study area resulted in a reduction in the sampling height above the bed with time. Spurious suspended sediment concentrations and turbidities were more frequent near the end of the deployment, and these periods of anomalously high values were excluded from the calibration. The remaining data (Figure 7) were calibrated to produce a continuous record of turbidity at each site. 
Figure 7. Calibration curves for the suspended sediment concentration.

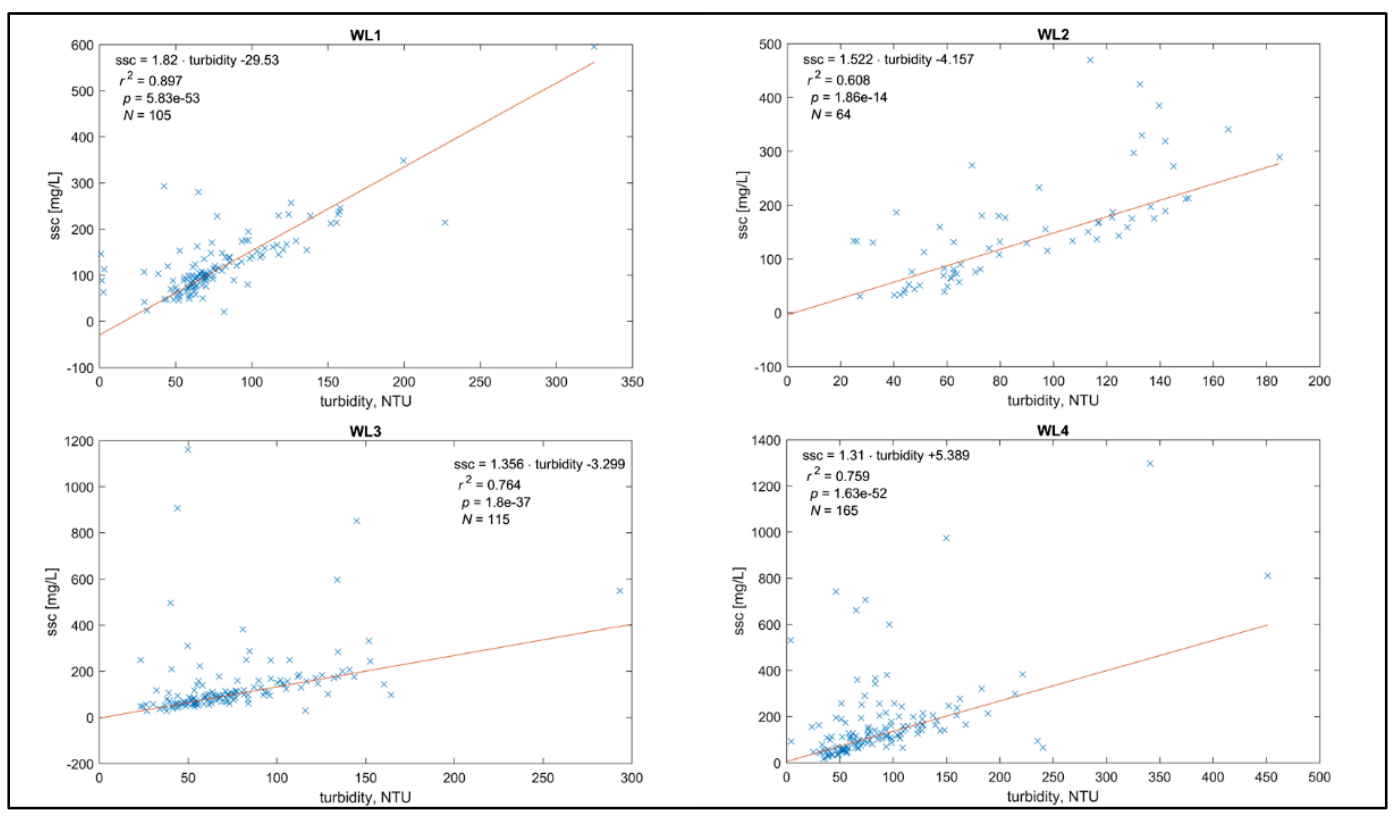

The calibration of ADV acoustic backscatter to SSC was unsuccessful. Analysis of water levels at which the sensors and sampling ports became dry suggests that the ADVs were deployed higher in the water column than the ports of the ISCO sampler. This positioning discrepancy may have contributed to the poor correlations between sampled SSC and acoustic backscatter.

\subsubsection{Feldspar analysis}

Rates of short-term sediment deposition at each of the platforms were determined with feldspar marker horizon techniques. A $1 \mathrm{~cm}$ thick layer of dry white feldspar clay (DeLaune et al., 1983) was placed in two replicate $0.5 \mathrm{~m} \times 0.5 \mathrm{~m}$ plots at each platform in January 2014. Each plot was marked with two PVC poles, and care was taken to ensure the plots remained undisturbed by humans for the duration of the study. Each feldspar plot was cored 6 months after deployment. Cores were collected in each feldspar plot by vertically inserting a thin, hollow copper rod into the plots, after which liquid nitrogen was pumped continuously into the rod for approximately 2 minutes. This procedure acts to freeze the marsh sediment immediately surrounding the copper rod onto the rod, allowing a thin core of the plot to be obtained with the rod once it is removed. The feldspar marker typically appeared as a discrete white layer in the core, and the height of sediment above the top of the feldspar layer was measured to quantify vertical accretion. Ideally, each core was measured four times with calipers, rotating the core $90^{\circ}$ between each measurement. This procedure 
was conducted once in each of the two plots at each platform, except for platform 4 where the liquid nitrogen supply was exhausted before the second plot could be sampled. The accretion rate at each platform was taken as the average of all measurements for each core in each plot.

\subsection{Wavelet analysis}

A wavelet transform can be used to analyze time-series data that contain nonstationary variability that occurs over multiple timescales (Daubechies 1990). This approach has been used in numerous studies of geophysics, including the El Nino Southern Oscillation (ENSO) (Jevrejeva et al. 2003; Torrence and Webster 1999), river discharges (Labat et al. 2004), sea level changes (Jevrejeva et al. 2005), and precipitation variability (Kayano and Andreoli 2006).

A wavelet analysis is akin to time-series spectral analysis such as the wellestablished Fourier transform method. Unlike spectral analysis, which applies the basis functions to the full time record, the time domain is divided into discrete and sometimes overlapping segments. The spectral analysis is applied independently to each segment. In this way, it is possible to analyze a time signal whose spectral characteristics evolve through time. A wavelet is a function with zero mean that is localized in both time and frequency. One particular wavelet, the Morlet, is defined as

$$
\psi_{o}(\eta)=\pi^{-0.25} e^{i \omega_{o} \eta} e^{-0.5 \eta^{2}}
$$

where $\omega_{o}$ is dimensionless frequency and $\eta$ is dimensionless time. This wavelet is a complex wave $\left(e^{i \omega_{o} \eta}\right)$ within a Gaussian envelop $\left(e^{-0.5 \eta^{2}}\right)$, which localizes the wavelet in time. The wavelet transform of a time series $\left(x_{n}, n=1,2, \ldots, N\right)$ with uniform time-steps $\delta t$ is defined as the convolution of $x_{n}$ with the scaled and translated wavelet,

$$
W_{n}^{x}(s)=\sqrt{\frac{\delta t}{s}} \sum_{n^{\prime}=1}^{N} x_{n} \psi\left[\left(n^{\prime}-n\right) \frac{\delta t}{s}\right]
$$

where $s$ is the timescale. Like the Fourier power spectrum, the wavelet power spectrum is defined as the absolute value squared of the wavelet transform $\left(\left|W_{n}^{x}\right|^{2}\right)$. In simple terms, the wavelet spectrum provides an estimate of variance for a time series as a function of time and timescale of variability. It does so by measuring localized sinusoidal variance over varying timescales throughout the duration of a time series. 
Because the length of time-series records is finite, errors occur at the left and right regions of the wavelet spectrum. To cope with the boundaries of time series, each end of the time series is padded with zeroes. This procedure introduces discontinuities and decreases variance at the ends of the time series. The region of the wavelet spectrum where these issues occur is termed the cone of influence, and caution should be made in these regions as it is uncertain whether decreases in variance are due to true decreases in the signal or are simply artifacts of zero padding.

Given two time series $x$ and $y$, with wavelet transforms $W_{x}(t, s)$ and $W_{y}(t$, $s)$, the cross-wavelet transform is defined as $W_{x y}(t, s)=W_{x}(t, s) \cdot W_{y}(t$, $s)^{*}$, where * indicates the complex conjugate of the preceding quantity. The cross-wavelet power spectrum is then $\left|W_{x y}(t, s)\right|^{2}$. Cross-wavelet power indicates regions in time-frequency space where two time series share high variance. The cross-wavelet transform can be used to compute the wavelet coherence, which indicates the localized correlation between two time series in time-frequency space, estimated as

$$
R^{2}(t, s)=\frac{\left|\left\langle s^{-1} W_{x y}(t, s)\right\rangle\right|^{2}}{\left\langle s^{-1}\left|W_{x}(t, s)\right|^{2}\right\rangle\left\langle s^{-1}\left|W_{y}(t, s)\right|^{2}\right\rangle}
$$

where \langle\rangle indicates smoothing in both time and scale. Bearing in mind that the definition of the wavelet coherence spectrum closely resembles that of a traditional correlation coefficient, it is useful to consider it as a localized correlation coefficient in time-frequency space. The wavelet phase spectrum is estimated as

$$
\varphi_{x y}(t, s)=\tan ^{-1}\left(\frac{\operatorname{Im}\left\{\left\langle s^{-1} W_{x y}\right\rangle\right\}}{\operatorname{Re}\left\{\left\langle s^{-1} W_{x y}\right\rangle\right\}}\right)
$$

where $I m$ and $R e$ indicate taking the imaginary and real components of the following complex quantity, respectively. The phase spectrum provides an indication of the relative timing of the two time series in question, that is, by how much time $y$ lags or leads $x$. Finally, the wavelet transfer function amplitude, defined as the magnitude of response to a unit of input forcing, is defined as

$$
H_{x y}(t, s)=\frac{W_{x y}(t, s)}{W_{x}(t, s)}
$$




\section{Results}

The results focus on the hydrodynamics and sediment transport processes. Regional wind, tide, and fluvial discharge measurements place the results of the study in a broader synoptic context and help provide insight into the WLD interdistributary island dynamics.

\subsection{Regional wind, tides, and discharge}

\subsubsection{Winds}

Winds from NOAA buoy EINL1 located northwest of Eugene Island, LA, are depicted in Figure 8. In addition to the 6-minute data, the time series has been averaged using a 15-day window to illustrate the low-frequency variability. The same averaging window is applied to all the time series data allowing a comparison between wind, water level, and currents. The 6-minute record shows high-frequency variations with periods of strong winds associated with frontal systems. Spectral analysis reveals a strong diurnal signal along with higher harmonics including semi-diurnal and third-diurnal (three times per day) modes (Figure 9). The diurnal signal indicates sea breeze, and the latter are the associated higher harmonics.

Figure 8. Offshore wind speed. Dashed lines denote the start and end of the study period.

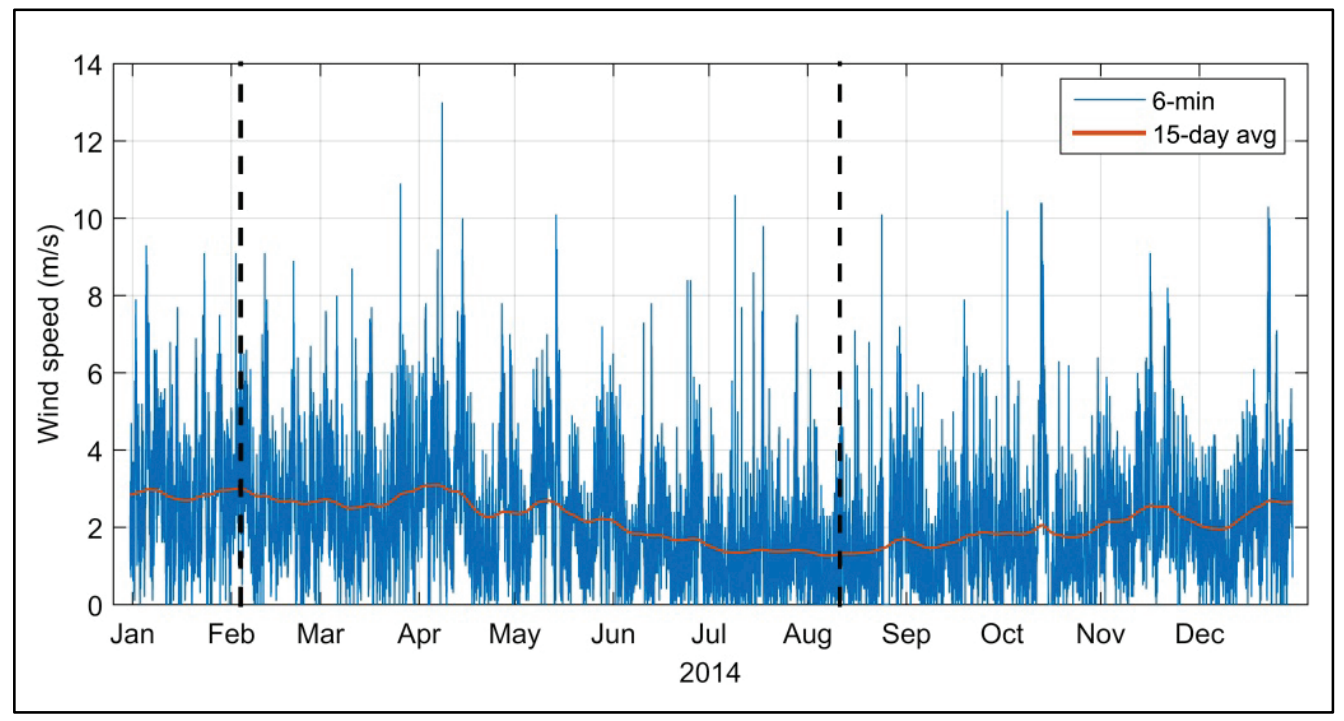


Figure 9. Wind speed spectral density for 2014.

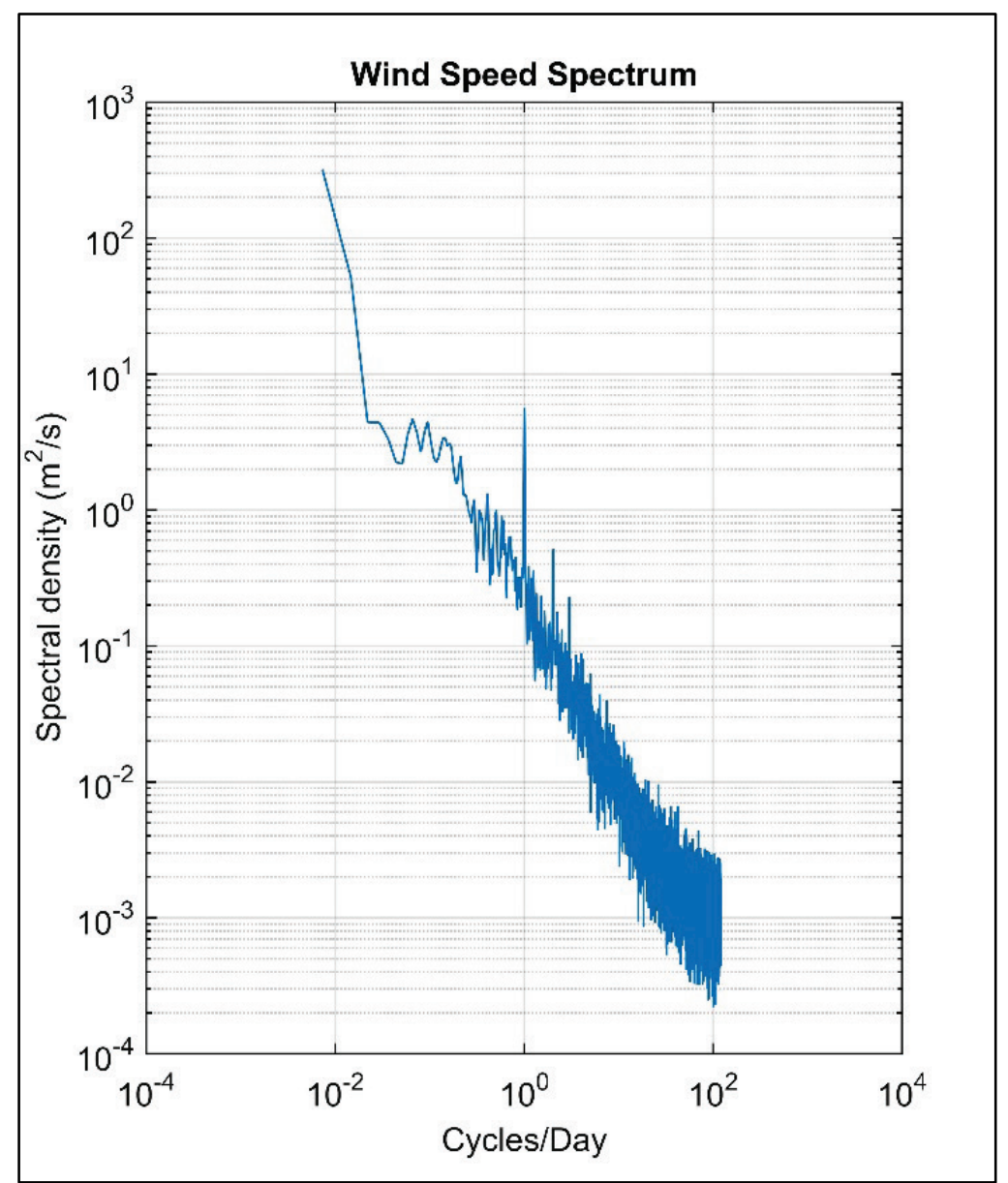

Vector plots of the low-frequency winds reveal a weak and variable pattern separated by persistent south-southeasterly winds from early April until the end of June (Figure 10). The persistent winds are associated with the Bermuda High, which shifts westward during the spring and summer driving clockwise rotating winds on its western flank. The southerly winds bring moist air from the Gulf of Mexico and generate a persistent setup along the Gulf coast. 
Figure 10. Low-pass filtered wind vectors. Dashed lines denote the start and end of the study period.

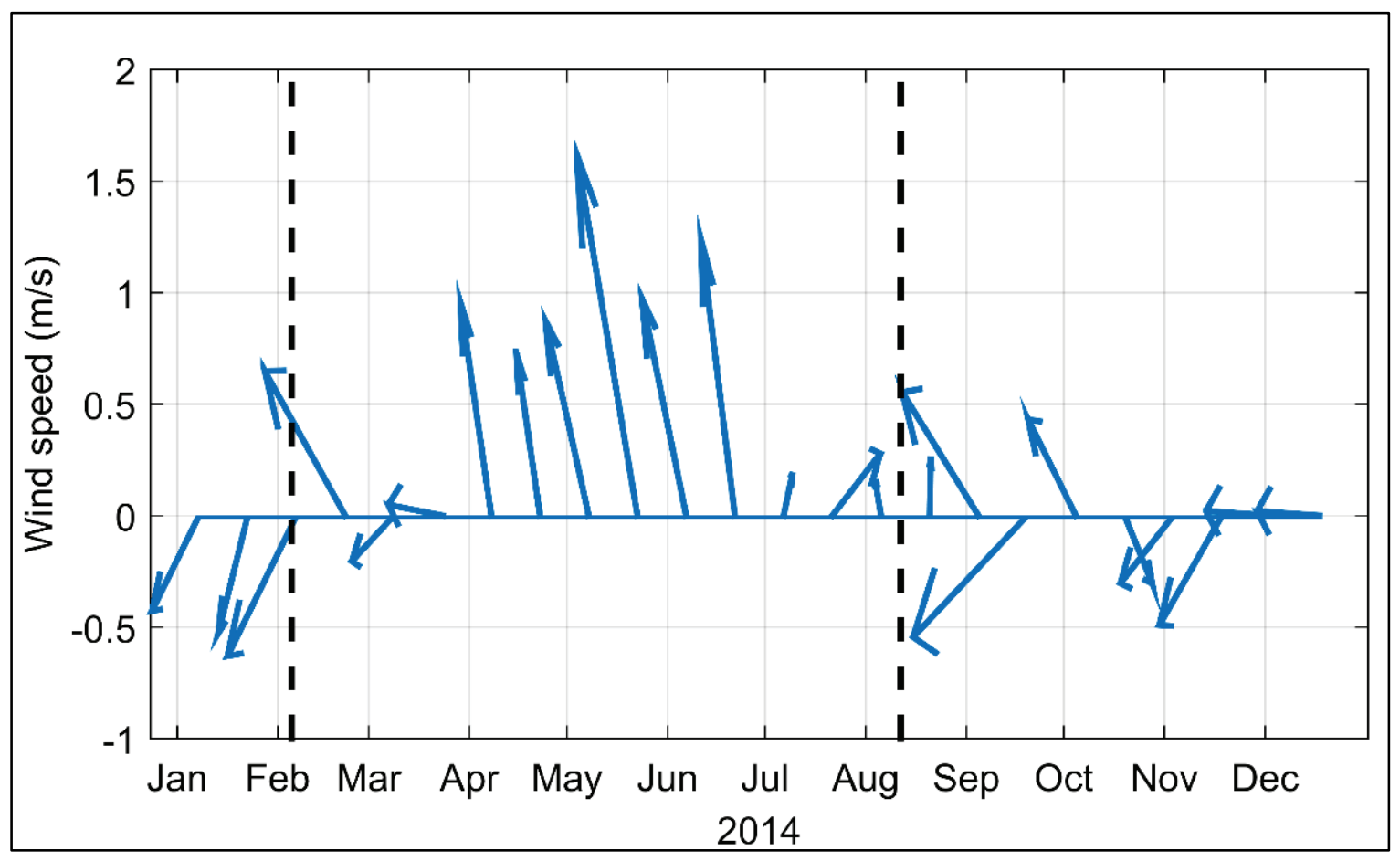

\subsubsection{Discharge}

Discharge from the USGS Calumet, LA, station is depicted in Figure 11. Annual mean and maximum discharge are $2,625 \mathrm{~m}^{3} / \mathrm{s}$ and $4,842 \mathrm{~m} 3 / \mathrm{s}$, respectively, which places 2014 within $\pm 5 \%$ of the long-term average conditions. The steady increase during the spring culminating with a peak discharge at the end of April coincides with the spring freshet. Discharge during the study period transitions from near-average conditions in early February to high discharge in the spring and then to below-average conditions in August. A distinctive quasi-monthly cycle persists through the study period. Inspection of gauges upstream of tidal influence reveals this fluctuation is associated with river discharge and not an artifact of tidal resonance. 
Figure 11. Discharge measured at WLO. Dashed lines denote the start and end of the study period.

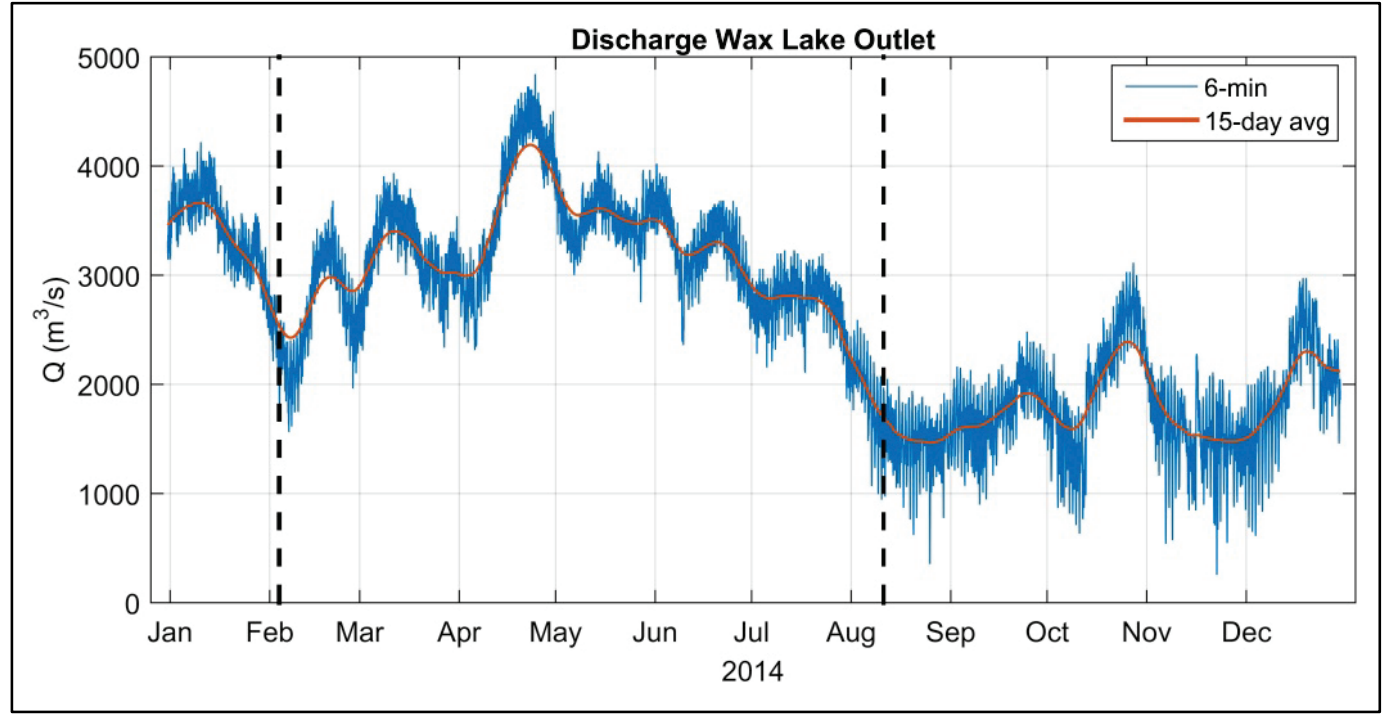

The discharge spectral density has a clear diurnal and semi-diurnal signal indicating that flow in WLO is influenced by the tides (Figure 12).

Figure 12. Spectral density of discharge for 2015. Peaks at one and two cycles per day denote dominant diurnal and semi-diurnal components.

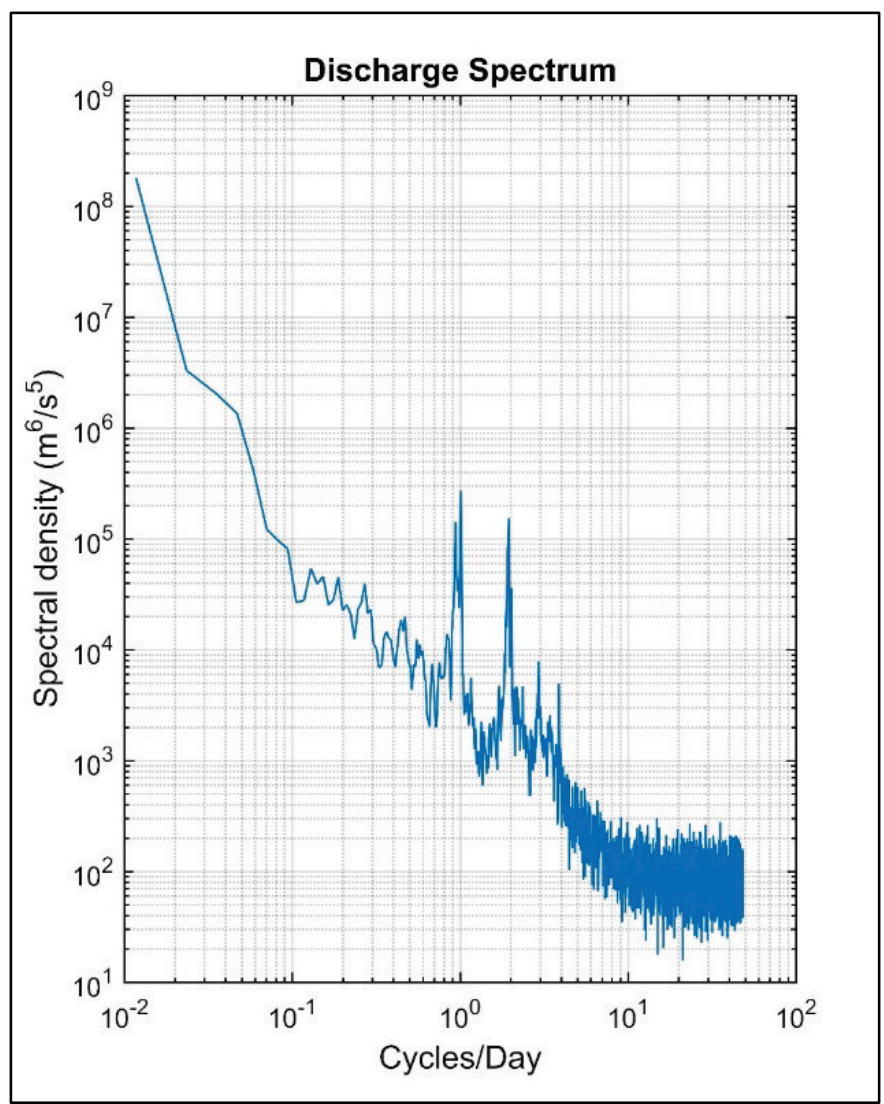




\subsubsection{Tides}

Water surface elevation from NOAA Station AMRL1 at Amerada Pass, LA, is depicted in Figure 13. Tidal amplitude varies with the spring-neap cycle and is locally amplified during periods of strong winds; the average amplitude is $32 \mathrm{~cm}$. The 15-day average surface elevation increases until June and then decreases towards the end of the deployment. The increase in the rate of elevation change in April coincides with the maximum discharge, but surface elevation continues to increase until June while river discharge is decreasing. Persistent southerly winds relax in late June coinciding with the decrease in water levels through the remainder of the study period. Lowest surface elevations occur during the beginning of the deployment.

Figure 13. Sea surface elevation derived from offshore tide station AMRL1 at Amerada Pass, LA. Dashed lines denote start and end of the deployment.

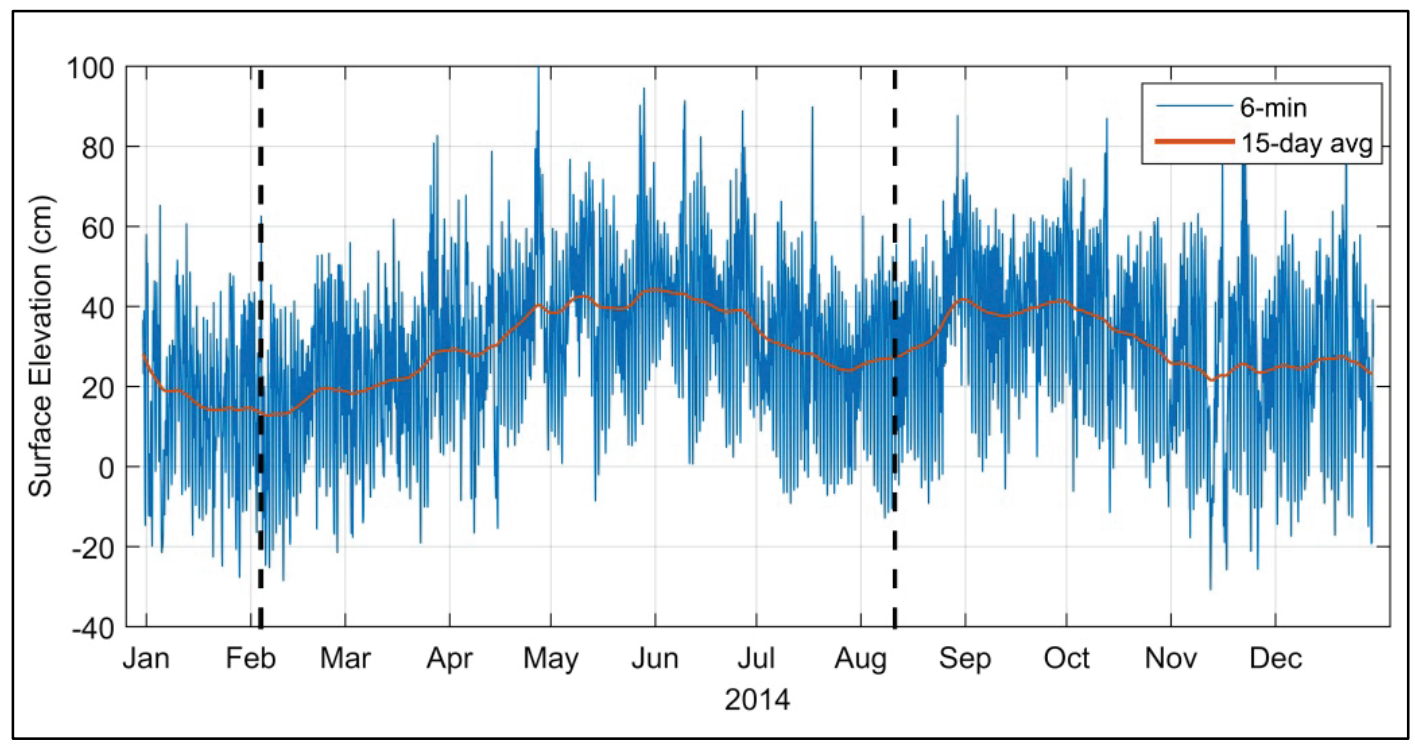

Like the discharge, the surface elevation spectrum shows well-defined diurnal and semi-diurnal peaks (Figure 14). 
Figure 14. Spectral density for sea surface elevation.

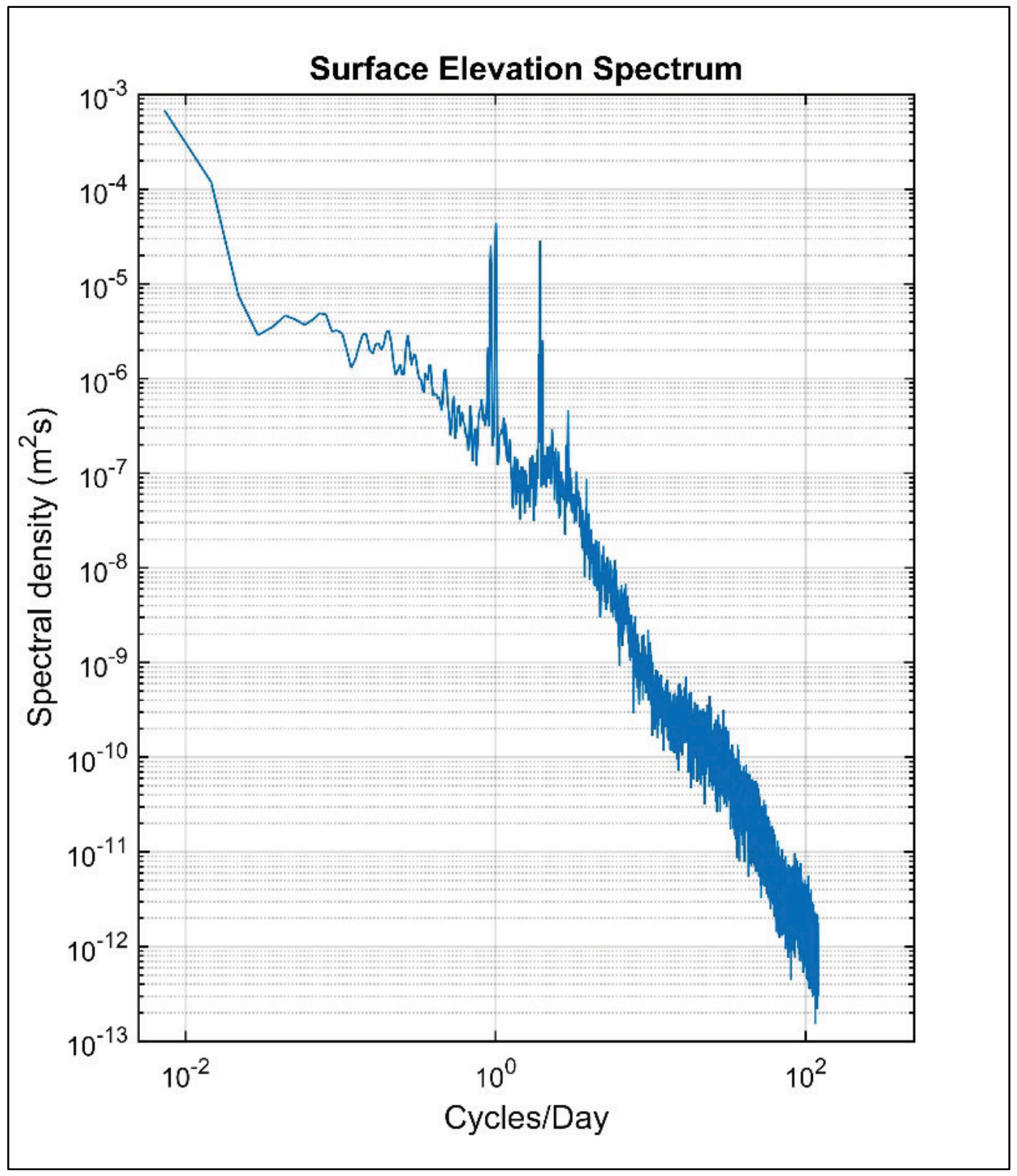

\subsection{Wind and wave wavelet analysis}

The coherence spectrum for each directional component of the wind stress magnitude (from $-180^{\circ} \mathrm{T}$ to $0^{\circ} \mathrm{T}$ to $180^{\circ} \mathrm{T}$ ) in $5^{\circ}$ bins indicates a band of maximum coherence between approximately 0.15 and 0.33 cycle per day (or about 3-7 day periods) exists, which corresponds well with the synoptic weather frequency band for winter storm passages (Figure 15). Here, $+/-180^{\circ}$ indicate wind blowing toward the south, and $\mathrm{o}^{\circ} \mathrm{T}$ indicates wind blowing toward the north. 
Figure 15. Coherence squared between wind stress magnitude directional component and $H_{s}$ along the directions of $-180^{\circ} \mathrm{T}$ to $180^{\circ} \mathrm{T}$ in $5^{\circ}$ increments obtained from cross-spectral analysis (Bendat and Piersol 1986). The white line indicates the direction of maximum wind forcing, estimated according to Garrett and Toulany (1982).

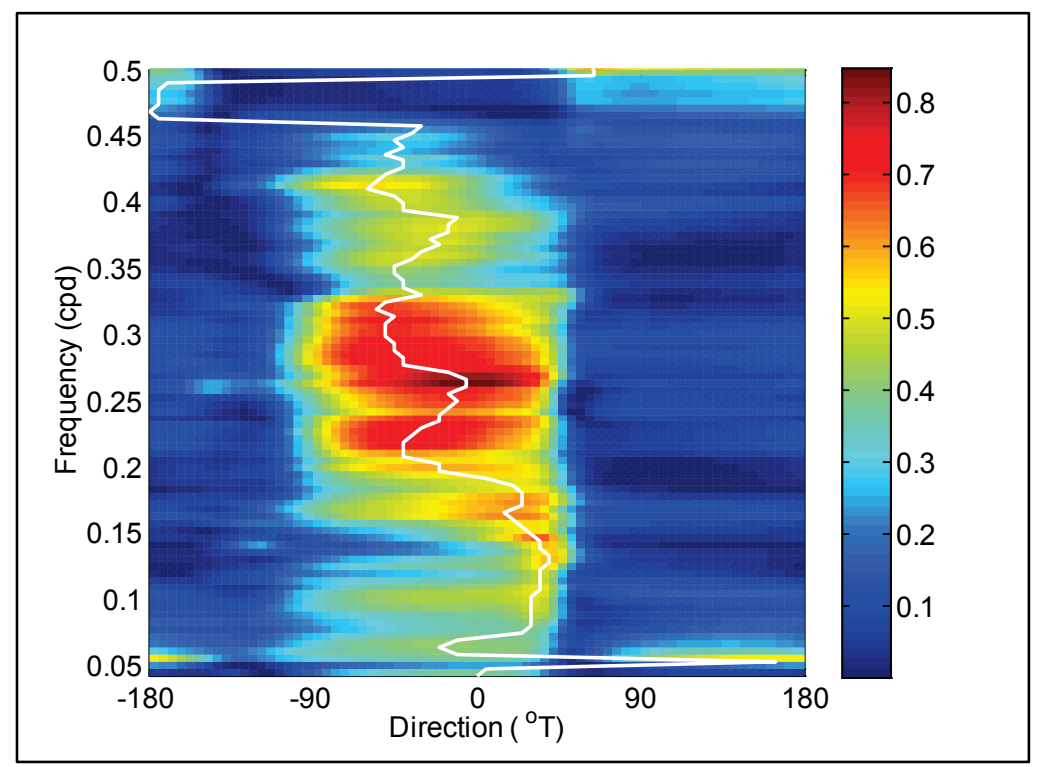

The direction of maximum coherence for each frequency is defined as

$$
\theta=\frac{\pi}{2}+\frac{1}{2} \tan ^{-1} \frac{2\left|h_{1} \| h_{2}\right| \cos \varphi}{\left|h_{1}\right|^{2}-\left|h_{2}\right|^{2}}
$$

(Garrett and Toulany 1982), where $h_{1}$ and $h_{2}$ are partial transfer functions relating the orthogonal wind stress components, in this case from the east and north, to significant wave height $H_{s}$, and $\varphi$ is the phase difference between $h_{1}$ and $h_{2}$. In the $0.15-0.33 \mathrm{cpd}$ frequency band, the coherence is highest in a directional band approximately between $\mathrm{o}^{\circ}$ and $-45^{\circ} \mathrm{T}$ (winds blowing toward the northwest). The coherence threshold for significance ( $\alpha=0.05$; averaging window size $=15$ samples, $\mathrm{df}=30$ ) is 0.34 . Due to seasonality in the wind stress and wave height datasets, a high degree of nonstationarity exists, meaning that the statistical properties of the signals vary throughout the course of the deployment.

Both wind stress components show the same general pattern, with high variance during the winter months, which ends rather abruptly in May (Figure 16). This temporal pattern aligns well with seasonal patterns of wind forcing on the Louisiana coast, with strong wind forcing during winter and spring that strongly diminishes into the summer. 
Figure 16. Wavelet power spectrum for east-west (left) and north-south wind stress (right). In each plot, the global wavelet spectrum is shown to the right of the wavelet plot, and and the original time series is shown below.

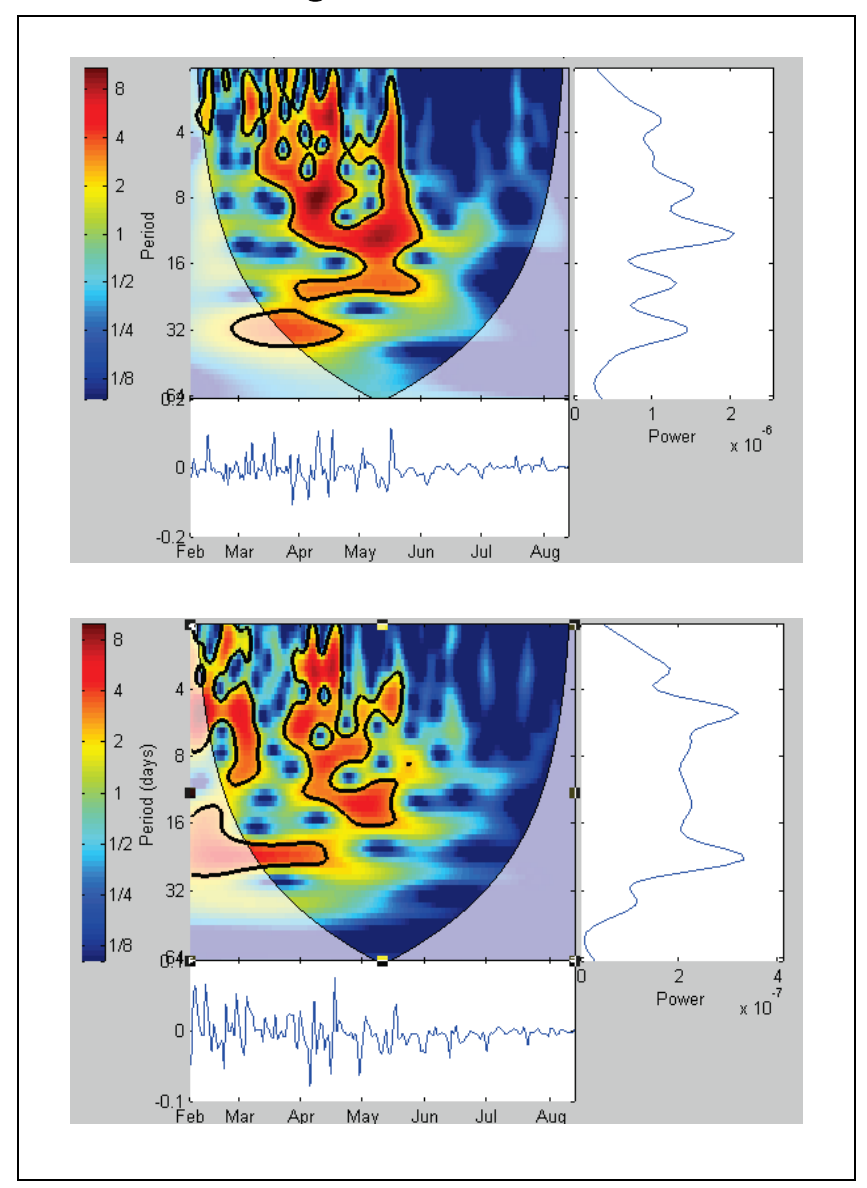

The wavelet spectrum for the response variable $H_{s}$ is shown in Figure 17. There is a very large event at the end of April that makes this spectrum look peculiar, but the general pattern is high variability between approximately April and June. The lack of variability prior to April can likely be explained by the presence of large amounts of floating vegetation (water hyacinth) present in the early part of the deployment while the lack of variability after June may be explained by the presence of wavedampening vegetation on the island greatly reducing the variance (power) in the wave data. 
Figure 17. Wavelet power spectrum for $H_{s}$. The global wavelet spectrum is shown to the right of the wavelet plot, and and the original time series is shown below.

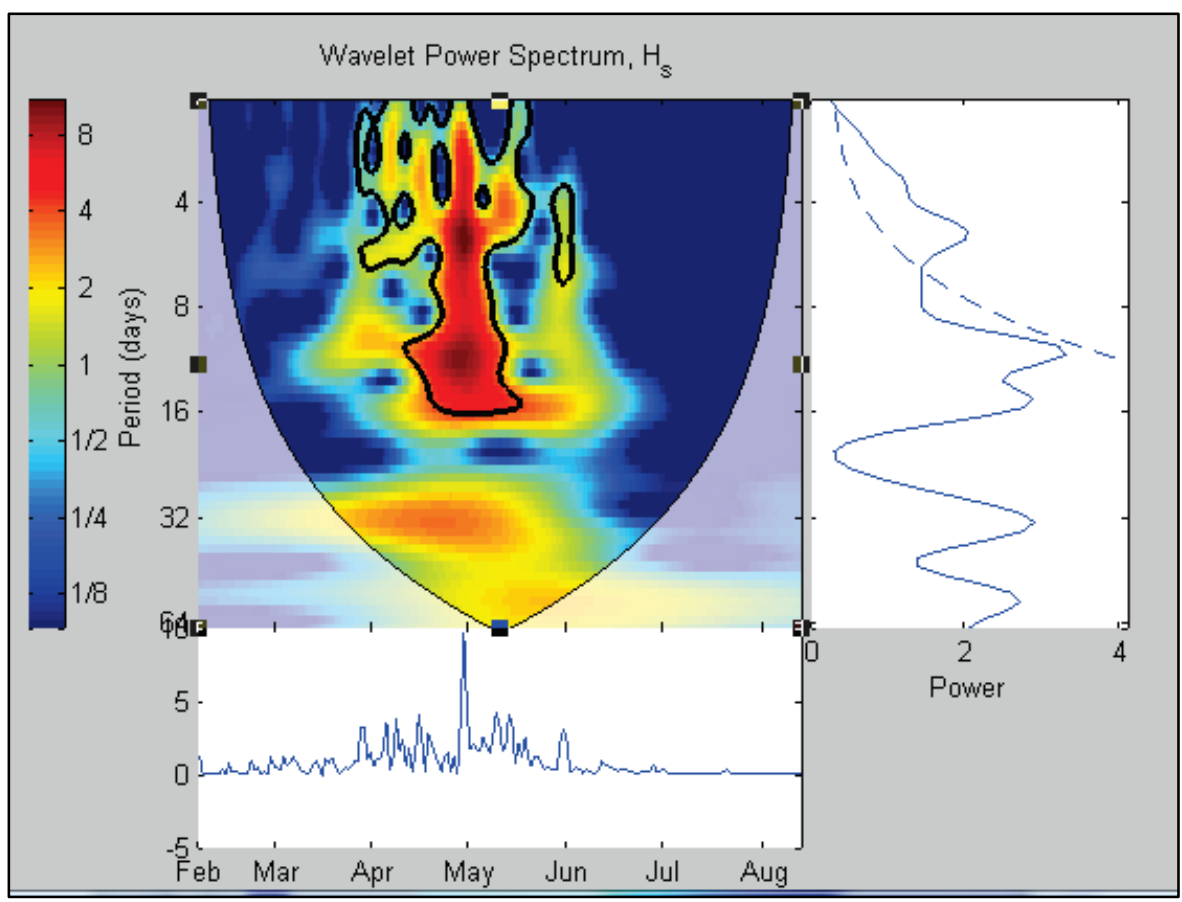

This explanation can be further explored by looking at the wavelet coherence spectra (Grinsted et al. 2004) between the wind stress magnitude and $H_{s}$ along the four cardinal directional components (Figure 18).

The northward and westward wind stress magnitude directional components show strong coherence during the middle months of the deployment. Though there is little variance late in the summer for wind stress or $H_{s}$ (see wavelet spectra above), the variables are still strongly coherent for these two directional components (i.e., what little variability in $H_{s}$ exists late in the summer can still be explained by wind stress variability). 
Figure 18. Wavelet coherence spectra between $H_{s}$ and northward (upper left), eastward (upper right), southward (lower left), and westward (lower right) directional components of the wind stress magnitude. In each plot, the color indicates the coherence, and the direction of the arrow indicates the nature of the phase relation. An arrow to the right indicates the two variables are in phase; a downward arrow indicates $H_{s}$ lags wind stress by $90^{\circ}$; a leftward arrow indicates the variables are $180^{\circ}$ out of phase; and an upward arrow indicates $H_{s}$ leads wind stress by $90^{\circ}$.

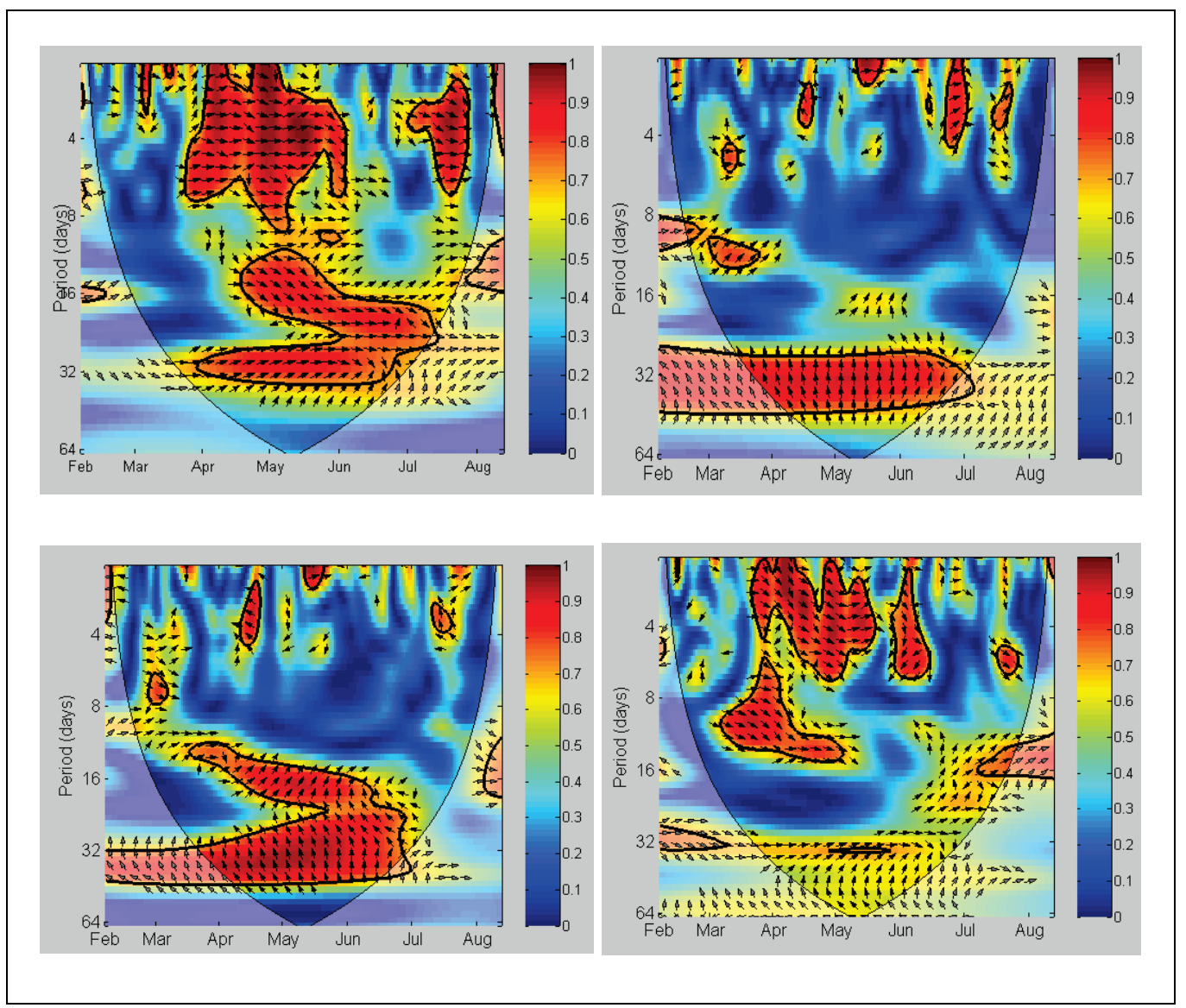

This can be further explored by looking at the amplitude response of the transfer function between each of the inputs and the output variable (Figure 19). This is akin to looking at the slope response in a regression model. Only in the wavelet model, if the slope response changes through time, it can be captured. Transfer function spectra for the four cardinal directional components of wind stress magnitude indicate that northward and westward wind stress are most effective in effecting a response in wave height. 
Figure 19. Amplitude and phase of transfer function between $H_{s}$ and northward (upper left), eastward (upper right), southward (lower left), and westward (lower right) directional components of the wind stress magnitude. In each plot, the color indicates the amplitude, and the direction of the arrow indicates the nature of the phase. An arrow to the right indicates the two variables are in phase; a downward arrow indicates $H_{s}$ lags wind stress by $90^{\circ}$; a leftward arrow indicates the variables are $180^{\circ}$ out of phase; and an upward arrow indicates $H_{s}$ leads wind stress by $90^{\circ}$.

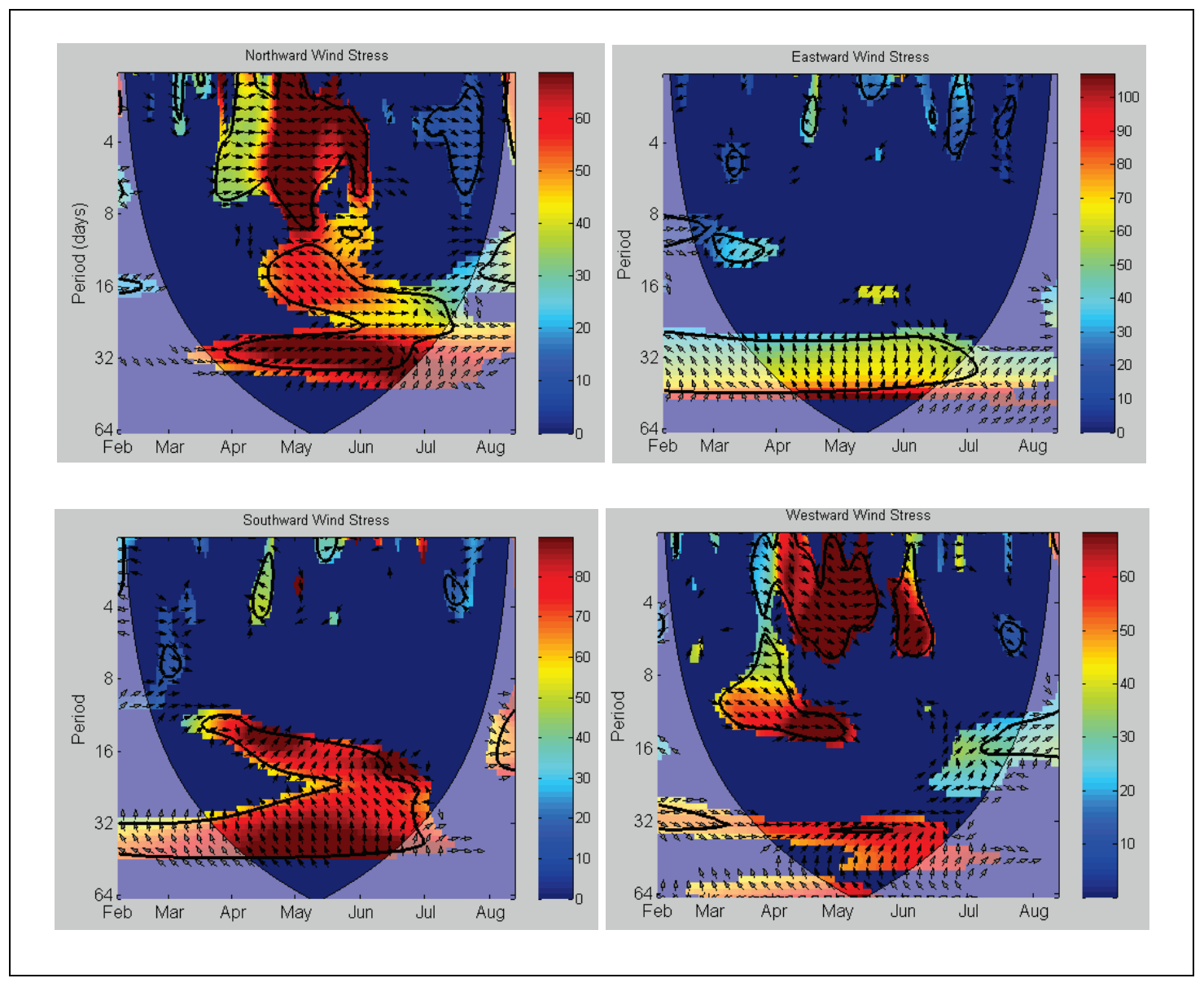

The transfer function amplitude indicates the strength of the response variable to a unit of input forcing. The lack of response to the eastward and southward wind stress that was observed in the coherence spectra is confirmed in that the response amplitude to wind stress along these directions is very low (compared to northward and westward). Second, though coherence in late summer (after vegetation becomes present) is high (see coherence spectra above), the response amplitude to wind forcing diminishes considerably (order of magnitude or more). This indicates that for a unit level of wind forcing, the wave response is greatly diminished toward the end of the summer when compared to earlier in the year (when vegetation was largely absent). 


\subsection{Hydrodynamics}

\subsubsection{Currents}

Current time series for each station is depicted in Figure 20. The plot includes a 15-day average to illustrate the low frequency flow. The majority of the kinetic energy lies in the tidal band, and current extremes generally decrease towards the interior stations. The currents peak in the March to May timeframe coincident with the spring freshet.

Figure 20. Time series of currents from the four island stations. St1 is near the western bank, and numbers progress eastward towards the island center.

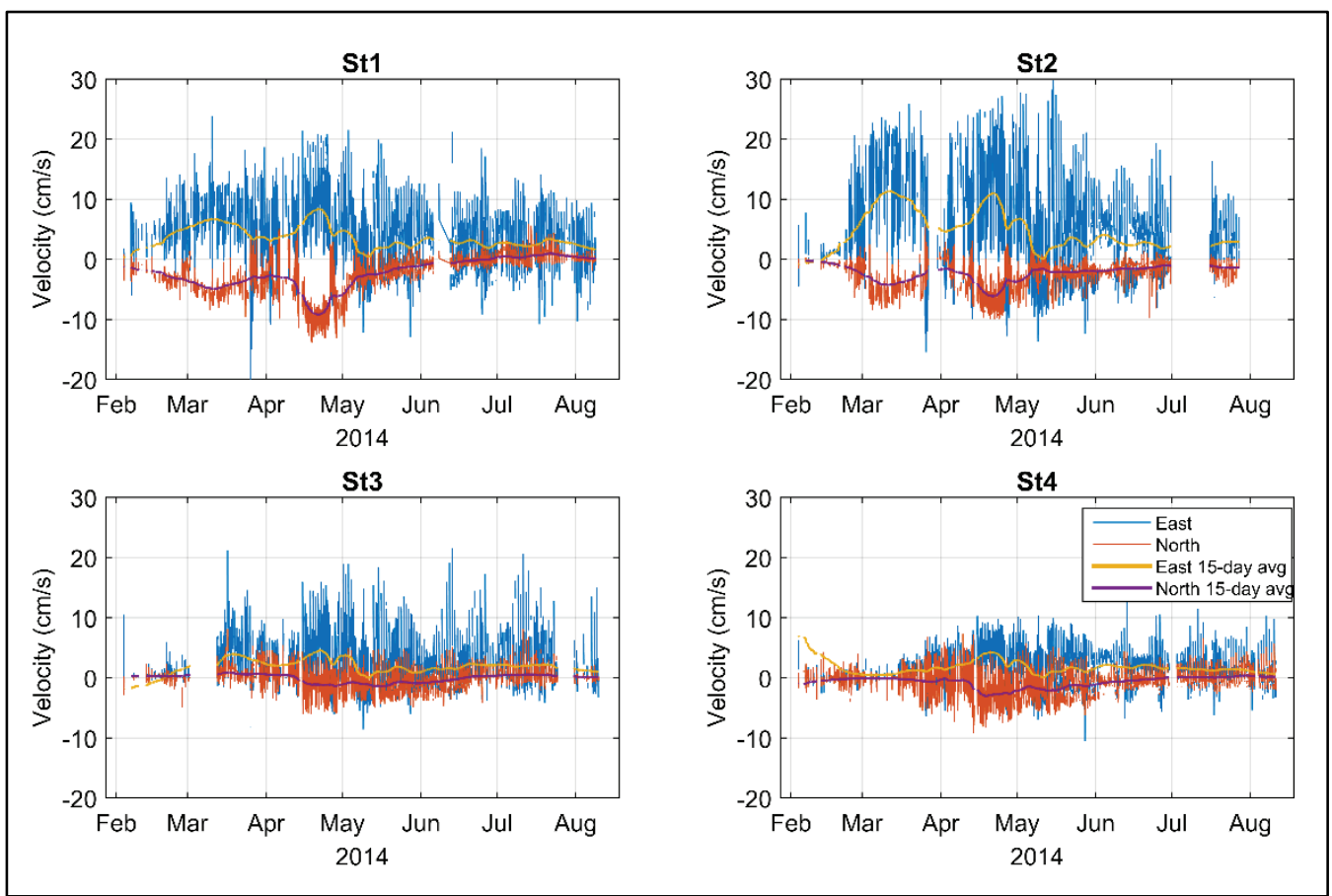

The low frequency flow at all the stations is directed towards the island interior (Figure 21). From the beginning of the record until mid-May, currents at St1 and St2 are oriented towards the southeast and then abruptly reduce in magnitude and slowly rotate more easterly. By the end of the record, St1 has rotated slightly towards the north. St3 is the most variable, oriented primarily towards the east but rotating from weakly north to the south and then to the north. Like St3, currents at St4 are weak but show more structure and agreement in terms of direction with St1 and St2. All stations show a steady decrease in magnitude starting at the end of April and continuing through May coincident with the reduction in WLO discharge. The general pattern shows cross-island flow from the channel over the levee and into the island interior. The flow is directed southeast 
towards the bay. Thus, the flow patterns suggest delivery of material carried in suspension from the adjacent channel to the island. During the peak flow season (March through May) St1 and St2 have stronger magnitudes indicating greater kinetic energy near the island edge and a reduction in energy at St3 and St4 towards the island center. This lateral gradient, in which currents weaken as the flow penetrates deeper into the island, reduces the flow's carrying capacity and increases the potential for sediment deposition.

Figure 21. Low-pass filtered current vectors. The arrows denote the magnitude and direction of the tidally averaged current in earth coordinates (up = north; right = east; down = south; left $=$ west).

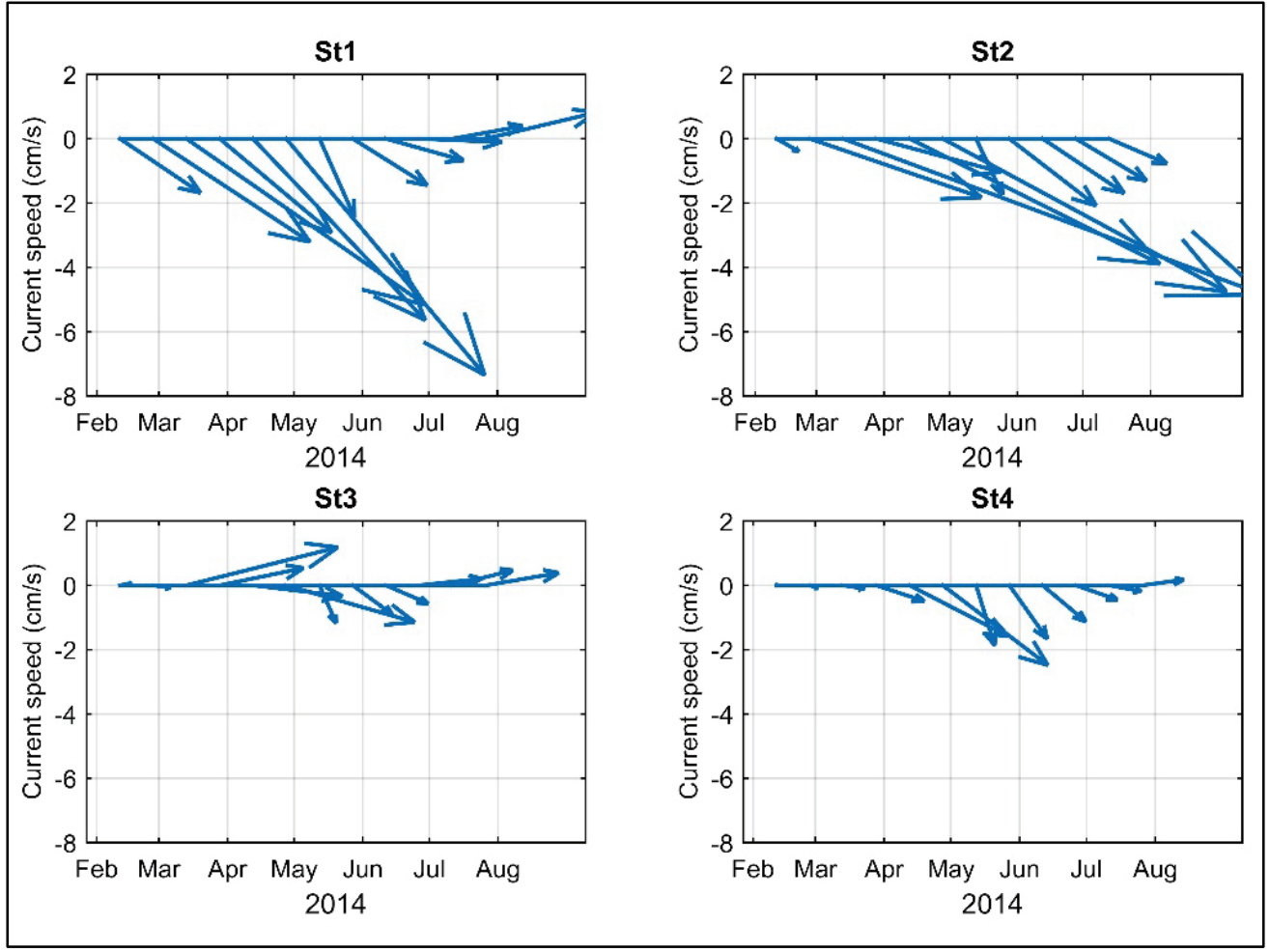

Monthly averaged current ellipses are reconstructed from the current time series using principal component analysis (Figure 22). The major and minor axes represent the current amplitude by decomposing the time signal into its variance components. The major axis signifies the direction of maximum variance, and the minor axis signifies the direction of next greatest variance with the constraint that it is orthogonal to the major axis. The eccentricity (distance between the center and one of the two foci) signifies the degree of rectilinear flow with a circle indicating progressive rotating flow equally in all directions. An ellipse with a relatively long major axis is indicative of near rectilinear flow as the current becomes 
more axial with less rotation. Overall, the amplitude increases initially, becomes strongest during the spring freshet, and then decreases throughout the remainder of the study. At St1, the major axis is aligned more with the mean flow during maximum discharge but then rotates towards an east/west direction in June and July. Station 2 maintains a northwest/southeast orientation throughout the study period. Station 4 is less polarized then the other three stations especially during the spring freshet. The flow at St1, St2, and St3 rotates to align with the east/west direction in June and July whereas St4 forms a north/south orientation. At all four stations, the ellipses become more polarized and smaller in June and July, when the island is covered with vegetation. 
Figure 22. Monthly averaged current ellipses. The vertical axis denotes north (+) and south (-) directed currents, and the horizontal axis denotes east and west currents. The arrows denote the monthly averaged mean flow vector.

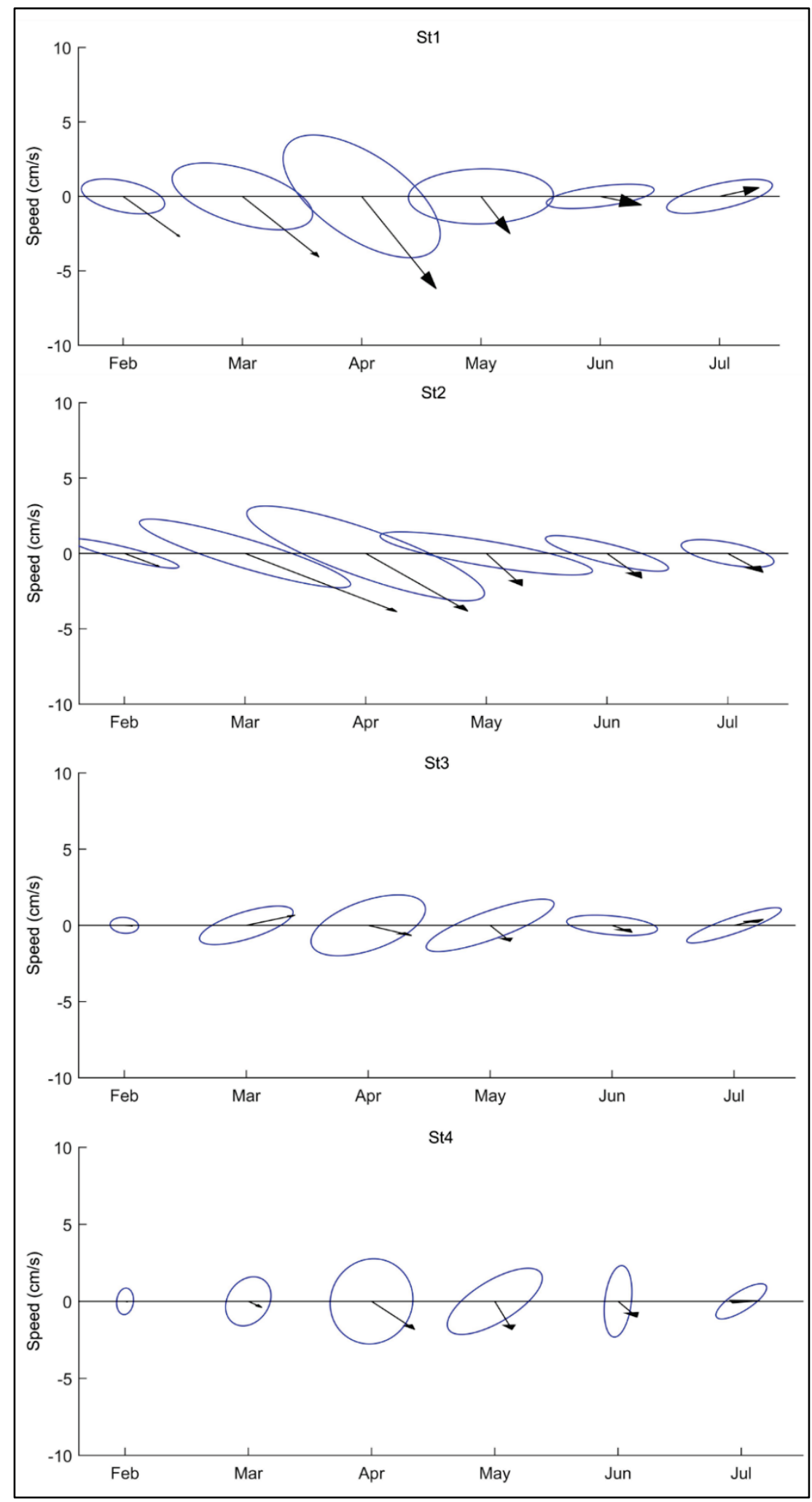




\subsubsection{Water level}

Water depth at each station is depicted in Figure 23. The absence of observations prior to May 10 at St4 is due to sensor malfunction. All records show a distinctive tidal signal modulated by the spring/neap cycle. For most tidal cycles, the island becomes subareal as indicated by zero water depths at low tide. Short-term fluctuations in the form of steady depth increases over a few days followed by similar decreases are associated with episodic wind events (frontal passages) that generate setup along the coast. The sharp increase in depth during the last week of April coincides with the peak WLO discharge; however, discharge alone does not account soley for the low-frequency variability as the falling limb of the spring freshet begins in late April and continues until the end of June. The 15-day average does not peak until late May, approximately 1 month after peak discharge. The low-frequency increase through the spring and decrease in the summer is consistent with the southerly winds associated with summer climate that cause setup along the coast.

Figure 23. Water depth measured at the four island stations.

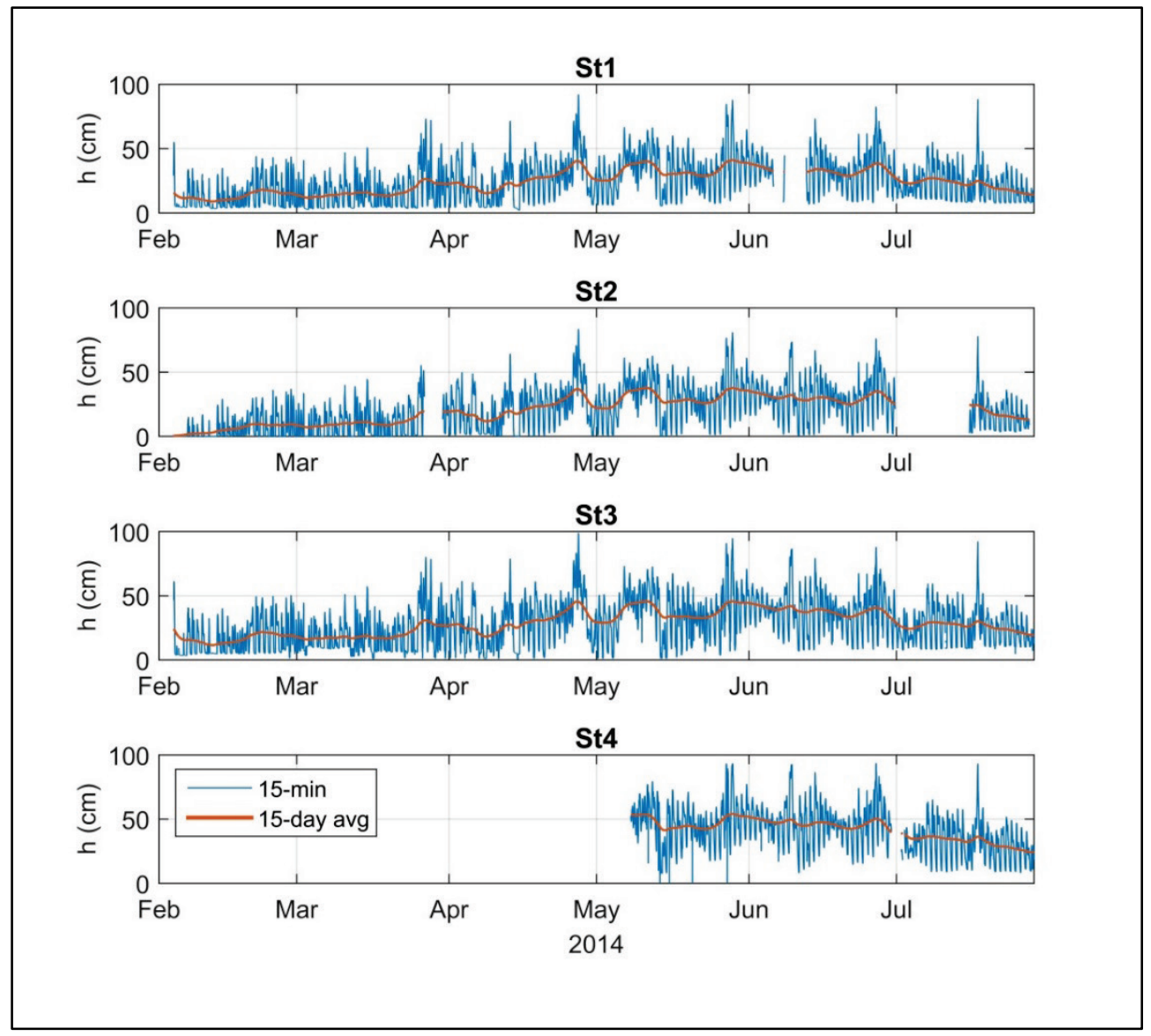




\subsubsection{Waves}

The significant wave height record is sparse containing significant gaps especially near the beginning and end (Figure 24). The gaps near the beginning of the record are primarily due to the wave staff drying at low tide. The largest waves coincide with the highest water levels, which occur during frontal passages accompanied by stronger winds. Wave activity also increases between mid-April and the end of May when average water levels are highest. Wave activity begins to decline in June and remains weak through the remainder of the record. By this time, the water surface over the island is covered by a thick canopy of Nelumbo lutea.

Figure 24. Significant wave height measured at the four island stations.

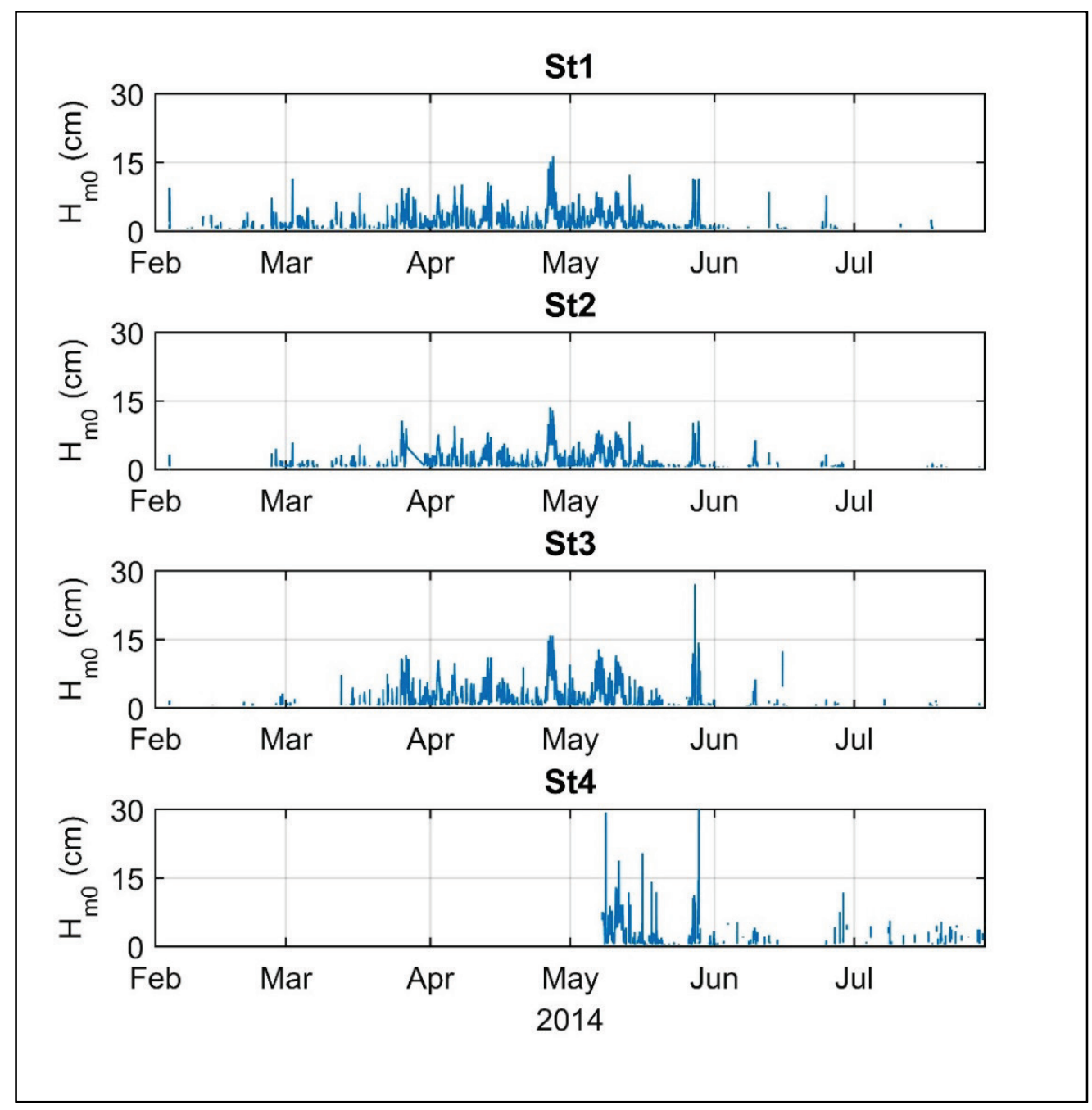




\subsection{Bottom stress estimates}

Time-averaged shear velocity at each station shows variation between the different methodologies and through time (Figure 25). Temporal variability results from the changing wave and current environment. Diurnal variations correspond to the tides in which tidal currents cause corresponding oscillations in boundary layer shear stress and associated $u *$ The correlation with the waves is less clear, but the TKE time and frequency domain results trend with wave height more than the other methods, as indicated by the higher correlation coefficient at all four stations (Table 1). The covariance time and frequency domain methods also trend with the waves but in general with a lower correlation coefficient. The inertial dissipation method shows an even lower correlation, and the BBLM has the lowest correlation coefficient indicating that this method does not trend closely with the waves.

Figure 25. Time-averaged shear velocity derived from the six different methodologies.

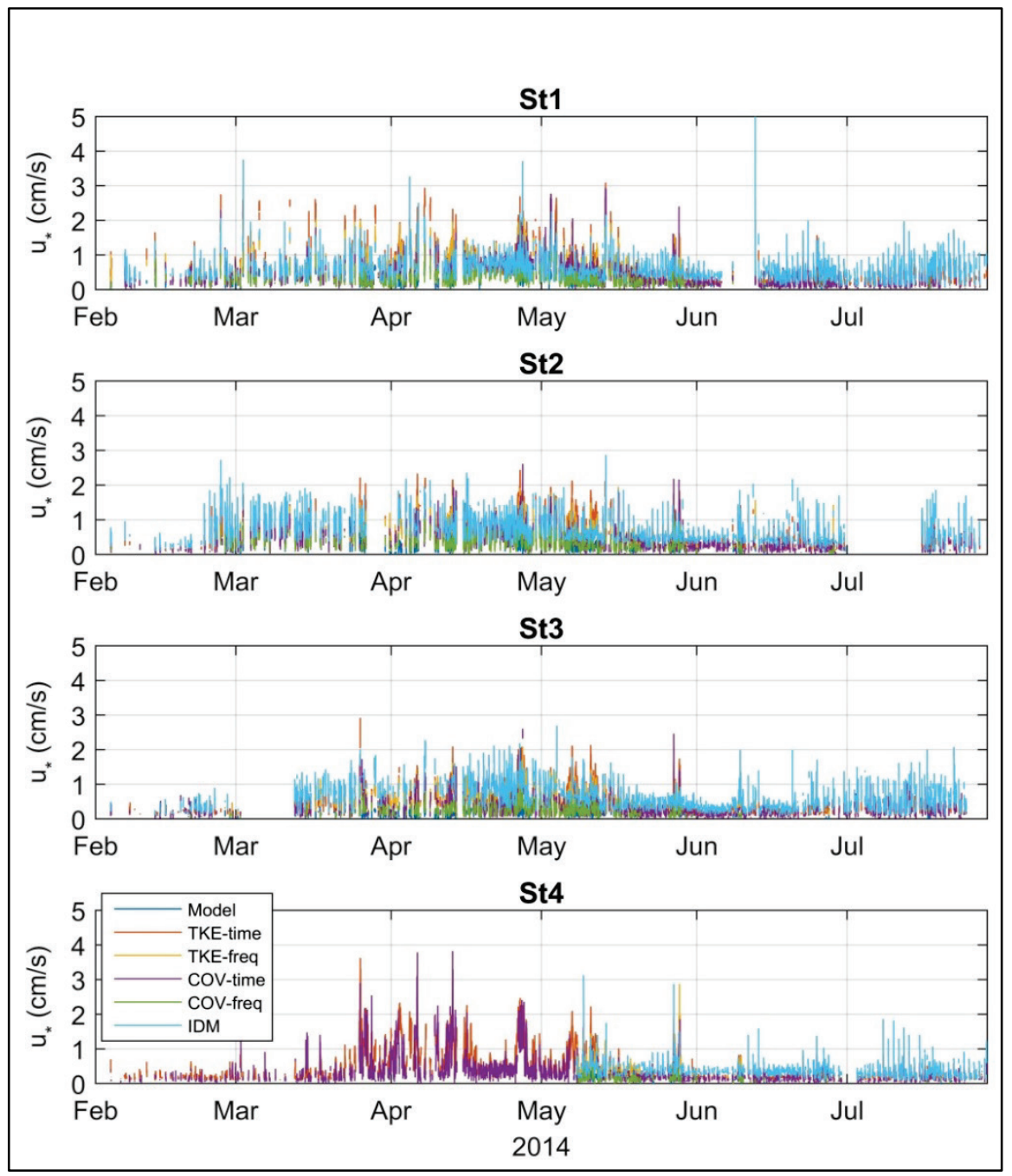


Table 1. Shear velocity statistics. Units are centimeters per second except for COR $H_{m 0}$, which is dimensionless. (BBLM - bottom boundary layer model; TKE - turbulence kinetic energy; COV - covariance; IDM - inertial dissipation method; COR - correlation coefficient denoting the correlation between $u *$ and $H_{m 0}$.)

\begin{tabular}{|c|c|c|c|c|c|c|c|}
\hline & & BBLM & TKE-time & TKE-freq & COV-time & COV-freq & IDM \\
\hline \multirow{4}{*}{ 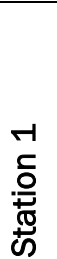 } & Mean & 0.30 & 0.85 & 0.71 & 0.58 & 0.34 & 0.68 \\
\hline & Max & 0.98 & 3.10 & 2.45 & 2.94 & 2.13 & 7.52 \\
\hline & Std. dev. & 0.16 & 0.48 & 0.34 & 0.35 & 0.22 & 0.37 \\
\hline & $\mathrm{COR} \mathrm{H}_{\mathrm{mo}}$ & 0.03 & 0.75 & 0.71 & 0.50 & 0.42 & 0.38 \\
\hline \multirow{4}{*}{$\begin{array}{l}N \\
\text { 工 } \\
\text { 은 } \\
\text { T⿱ } \\
\dot{\omega}\end{array}$} & Mean & 0.34 & 0.81 & 0.69 & 0.56 & 0.34 & 0.77 \\
\hline & Max & 1.21 & 2.43 & 1.95 & 2.61 & 1.28 & 2.87 \\
\hline & Std. dev. & 0.22 & 0.40 & 0.30 & 0.32 & 0.20 & 0.36 \\
\hline & $\mathrm{COR} H_{m 0}$ & -0.10 & 0.78 & 0.57 & 0.39 & 0.32 & 0.07 \\
\hline \multirow{4}{*}{ 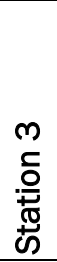 } & Mean & 0.18 & 0.69 & 0.60 & 0.37 & 0.25 & 0.80 \\
\hline & Max & 0.91 & 2.92 & 2.09 & 2.60 & 1.05 & 2.70 \\
\hline & Std. dev. & 0.11 & 0.37 & 0.29 & 0.28 & 0.16 & 0.36 \\
\hline & COR $H_{m 0}$ & -0.02 & 0.82 & 0.67 & 0.44 & 0.41 & 0.26 \\
\hline \multirow{4}{*}{ 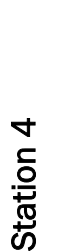 } & Mean & 0.17 & 0.53 & 0.46 & 0.27 & 0.17 & 0.47 \\
\hline & Max & 0.49 & 2.22 & 2.88 & 2.14 & 0.87 & 3.13 \\
\hline & Std. dev. & 0.07 & 0.38 & 0.28 & 0.22 & 0.12 & 0.26 \\
\hline & $\mathrm{COR} \mathrm{H}_{m 0}$ & 0.20 & 0.82 & 0.70 & 0.63 & 0.53 & 0.38 \\
\hline
\end{tabular}

The mean values are higher for the TKE and inertial dissipation methods compared to the BBLM and covariance (COV) methods. The BBLM has the lowest mean and maximum, respectively, of all the methods. The mean and maximum are higher at St1 and St2 compared to St3 and St4.

Monthly averaged $u^{*}$ reveals seasonal variations that tend to coincide with changes in environmental forcing (Figure 26). Only the TKE and COV time domain estimates are shown at St4 prior to May as the other methods require wave height spectra, which are not available during this time period. Shear velocity steadily increases until April, which coincides with the seasonal maximum river discharge and then steadily decreases until June as river discharge and average currents over the island are reduced. The lowest average $u^{*}$ occurs in June or July depending upon the 
methodology, with the inertial dissipation method (IDM) showing an average increase in July. The BBLM tends to track closely with the COVfrequency domain method at all four stations. The TKE time and frequency domain estimates also track closely at all four stations.

Figure 26. Monthly averaged shear velocity. Error bars denote $95 \%$ confidence limits. Legend represents curves at all stations but is displayed in only the last panel for clarity.

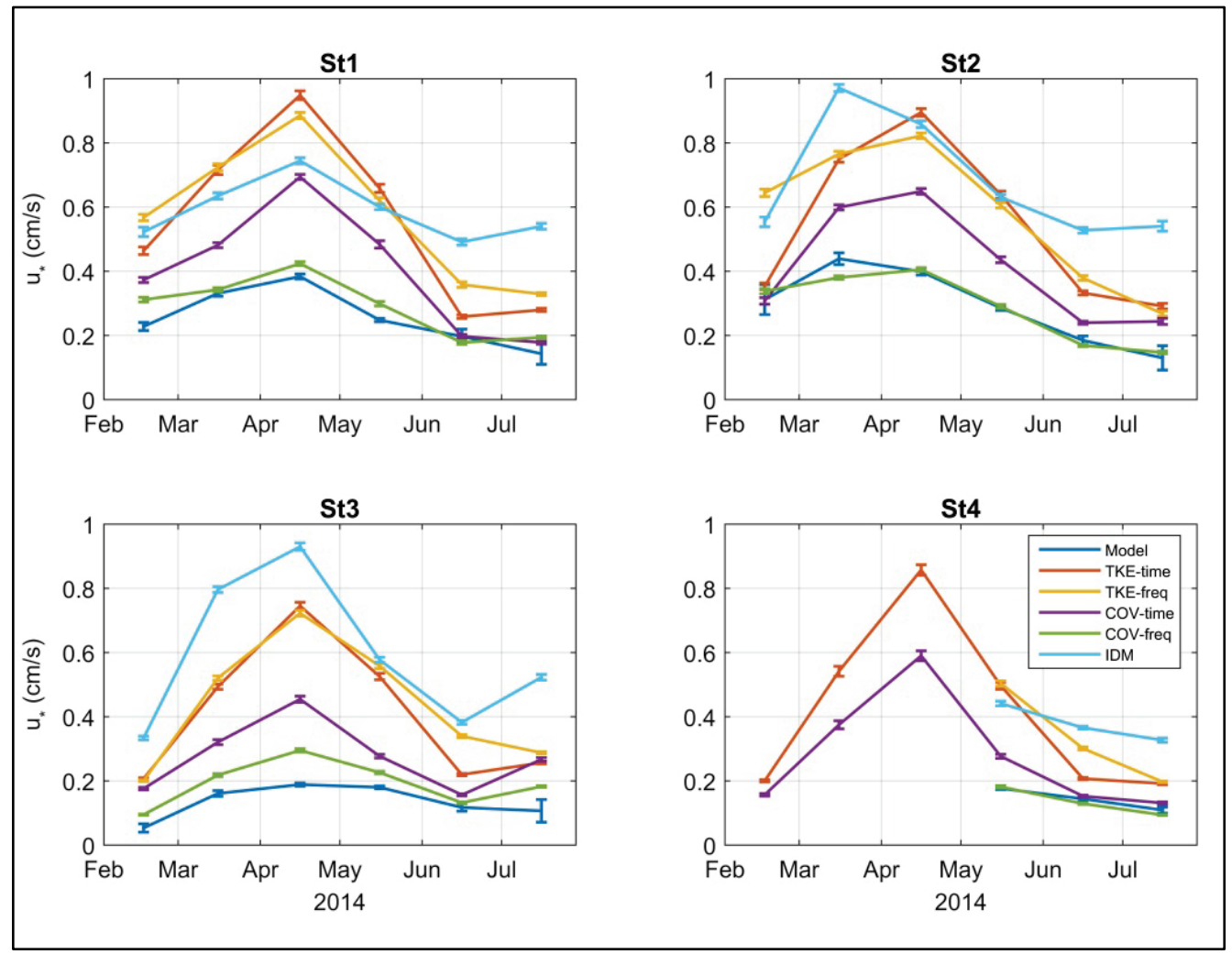

The maximum combined shear velocity $\left(u^{*} c w\right)$, which includes contributions from the waves, and the time-averaged shear velocity for the current $\left(u_{*}\right)$ derived from the BBLM show variability among stations and through time (Figure 27). In general, $u^{*} c w$ exceeds $u_{c}$ by a factor of two indicating that the wave stress dominates the current. However, some bursts show that $u^{*} c w$ is dominated by the current primarily at St1 and St2 between approximately April 15 and April 23. This is the period of maximum discharge and low waves so that the bottom stress contribution from the waves is relatively small. At St3 and St4, there is a clear indication that $u^{*} c w$ exceeds $u_{*}$ (by a factor or five or more) for the majority of burst. Beyond the June 1, the number of bursts that yield wave and current input parameters with sufficient quality to run the model is greatly reduced. This period is subjected to relatively weak wave conditions and generally lower average water levels over the island. The latter will reduce the number of quality 
bursts from which currents can be extracted as the ADV probe is exposed to air for a greater fraction of the tidal period. The former is likely caused by the dense growth of Nelumbo lutea, which reduces wind penetration and associated wave activity during the summer.

Figure 27. Time series depicting the time-averaged shear velocity and the maximum combined shear velocity for the wave and current predicted from the BBLM.
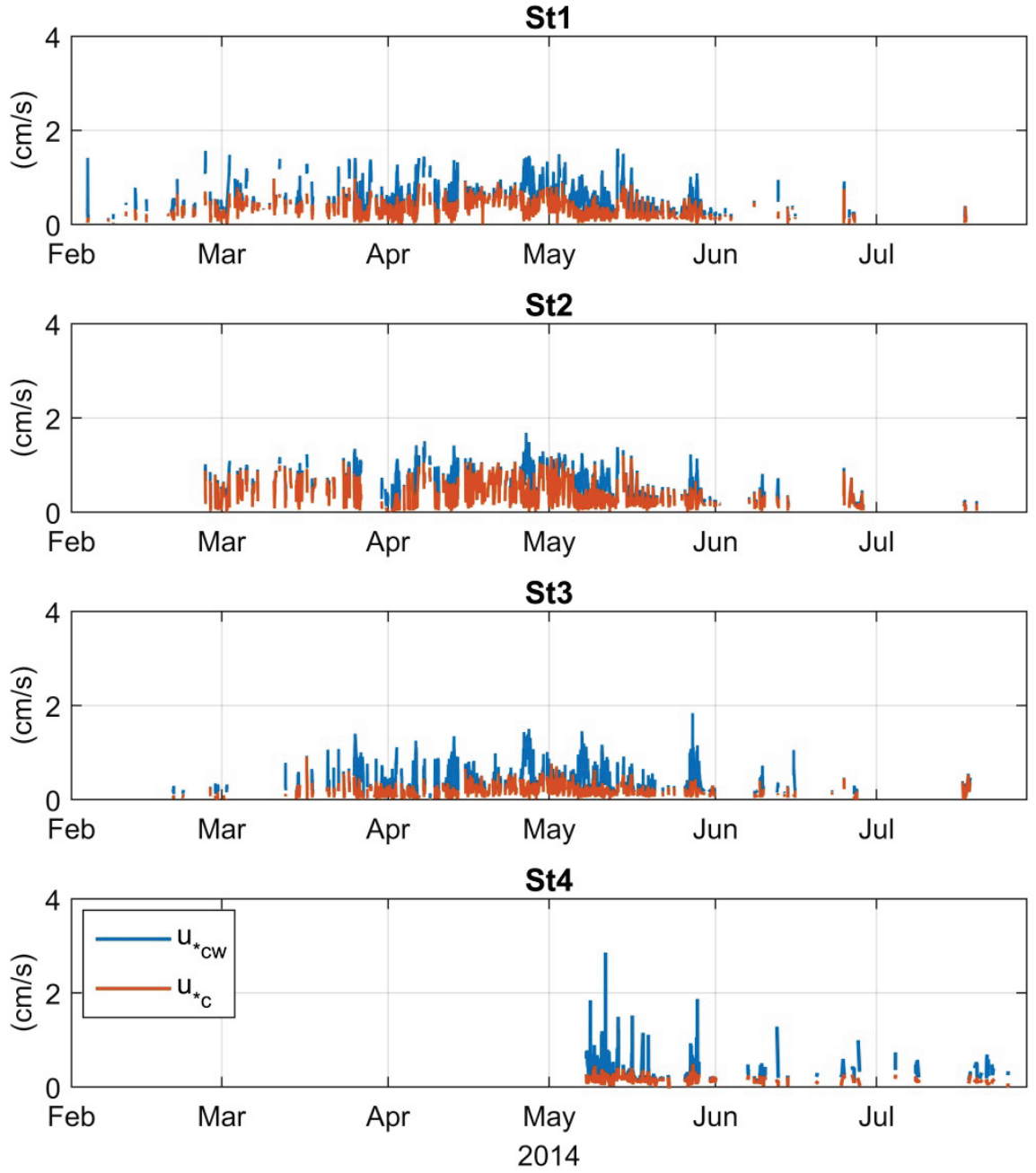

\subsection{Sediment characterization}

Sediment classification and type based on samples obtained near the platforms are fairly uniform (Table 2). Each site is dominated by silt followed by clay and small ( $\sim 5 \%)$ amounts of sand. Gravel comprised less than $0.1 \%$ of the samples measured and is not listed here. The D10 and 
D50 are fairly uniform with a mean of approximately 3 and 10 microns, respectively. The D9o varies among stations except for St3, which is almost three times larger in diameter.

Table 2. Grain size distribution and texture measured at each station.

\begin{tabular}{|l|c|c|c|c|c|c|}
\hline & \% clay & \% silt & \% sand & D10 & D50 & D90 \\
\hline Station 1 & 17 & 78 & 5 & 3.2 & 10.8 & 42.4 \\
\hline Station 2 & 17 & 78 & 5 & 3.2 & 10.2 & 39.5 \\
\hline Station 3 & 18 & 77 & 5 & 3.2 & 10.1 & 114.4 \\
\hline Station 4 & 18 & 76 & 5 & 3.1 & 9.5 & 37.7 \\
\hline
\end{tabular}

\subsubsection{Bed elevation change}

Bed elevation change obtained from feldspar plots indicates a net positive (deposition) change over the course of the 6-month deployment (Table 3). St1 and St2 show the greatest deposition of nearly $5 \mathrm{~cm}$. The results at St3 are inconclusive as the feldspar layer could not be clearly identified upon final examination.

Table 3. Feldspar plot sedimentation results for the six month deployment.

\begin{tabular}{|l|l|l|l|l|}
\hline Station & St1 & St 2 & St 3 & St 4 \\
\hline Mean $(\mathrm{mm})$ & $45.95 \pm 16.14$ & $46.18 \pm 13.24$ & $<2$ & $15.57 \pm 3.80$ \\
\hline
\end{tabular}

During low tide, the bed intermittently becomes exposed as water recedes into the subaqueous portion of the island closer to the bay. In order to capture the full range of water levels, the capacitance rods are installed with the lower end penetrating the bed. When the bed is exposed, the rods show a minimum depth that likely corresponds to the mud interface. If deposition or erosion occurs, the capacitance rods will show a change in the minimum depth during periods when the rods become exposed. Tracking this minimum produces a time series of bed height.

All stations show a net increase in bed elevation over the course of the deployment (Figure 28). The profile also shows periods of erosion/accretion that vary widely in amplitude and through the record. The results should be viewed as an approximation of actual bed change during the study as bed height is based on minimal depths recorded by the water level staffs and not a physical elevation measurement. The overall pattern does show accretion, which is in agreement with the feldspar results. 
Figure 28. Bed elevation change inferred from the capacitance rods. The rods can only be used to measure bed elevation when the bed is exposed.

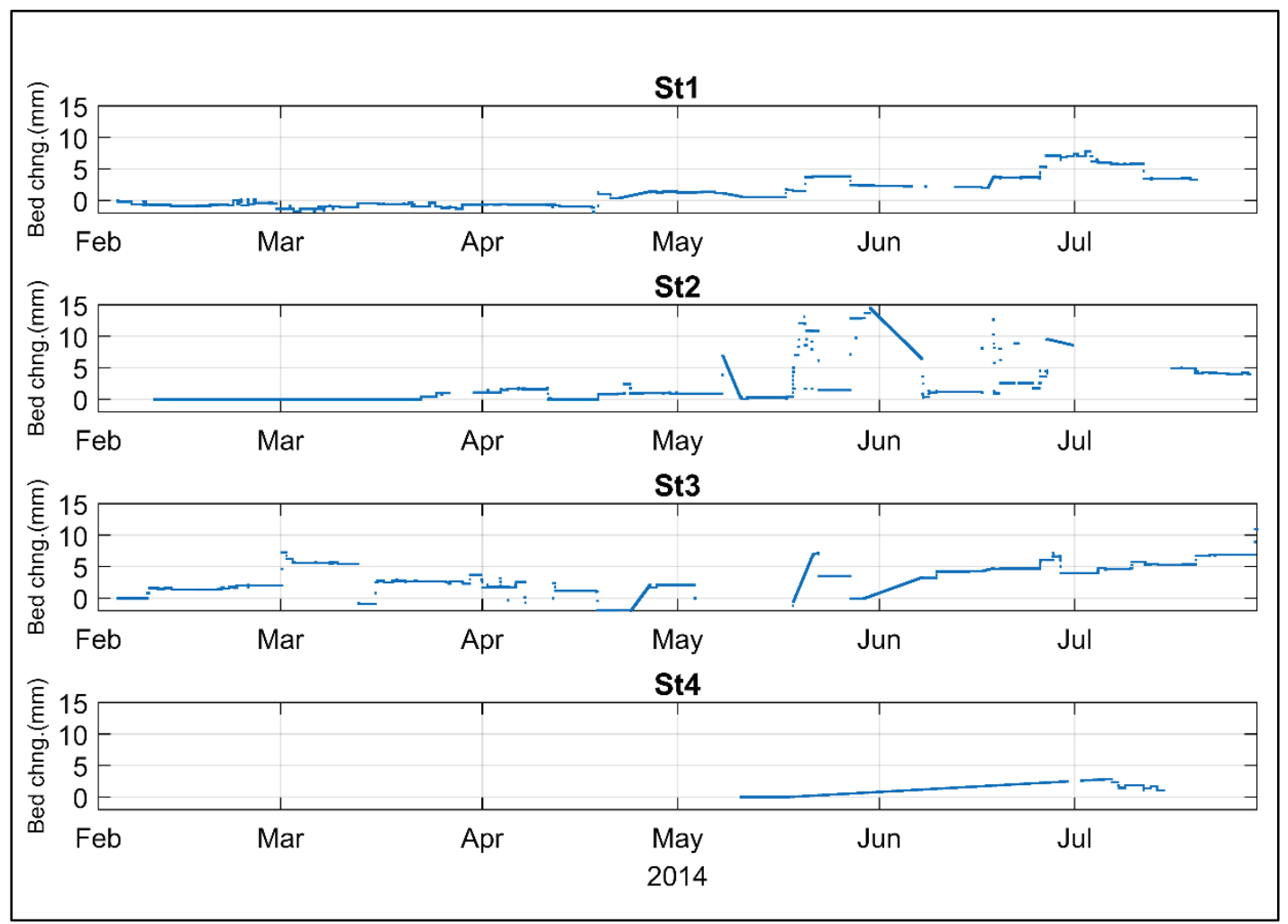

Modeled sediment concentration based on the OBS sensor data is variable at all stations and through time (Figure 29). The absence of data at St2 after the second week of May occurs due to the failure of the OBS, which is used to calibrate the modeled concentration time series. The record includes a number of spikes and dropouts, the latter of which corresponds to periods when the sensors become exposed and the concentration goes to zero. The long-term trends are seen in the filtered record and show higher concentrations during April and May that coincide with the period of maximum WLO discharge. Although sporadic, there are concentration spikes that exceed 1,000 mg/L. Except for isolated bursts, turbidity is generally highest in April and May coincident with the higher concentrations. 
Figure 29. Time series of sediment concentration including a 15-day low pass filtered to remove the tidal component.

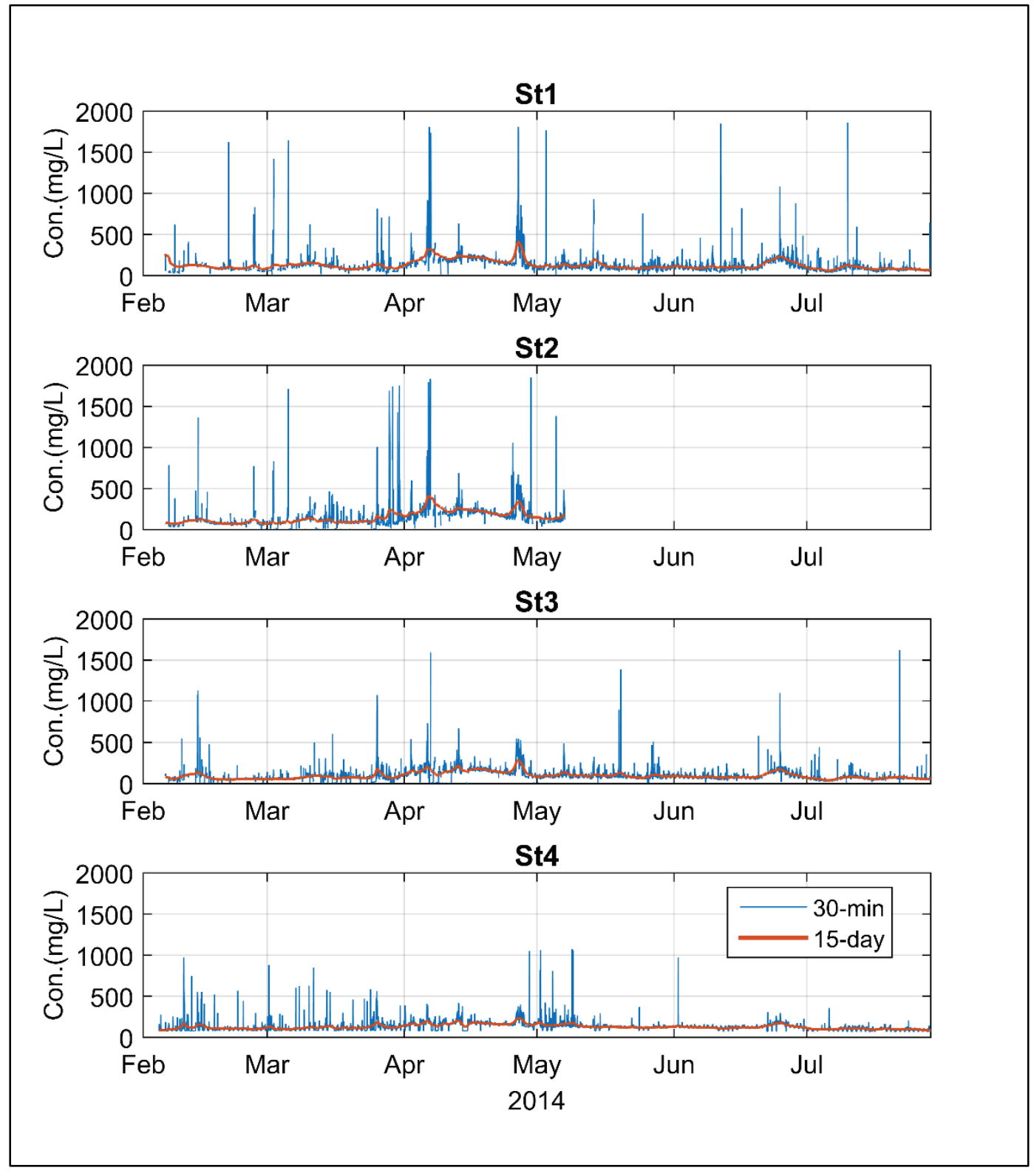

\subsubsection{Initiation of sediment motion}

The critical stress for the initiation of sediment motion $(=0.1 \mathrm{~Pa})$ as represented by the Shields parameter indicates that local sediment resuspension is variable and somewhat sparse (Figure 30). Less than 6\% of bursts per station exceed the critical threshold. There is also a seasonal trend in which the majority of bursts for which $\psi / \psi_{c r}>1$ occur between March and June. This includes the period of high discharge and increased wave activity. After June 1, $\psi$ at St1 and St2 is too low to initiate sediment 
motion. At St3 and St4, only one and two bursts, respectively, show a Shields parameter large enough to initiate sediment motion.

Sediment transport in combined flow is driven by the wave and current stress components. To first order in the momentum balance, the generally stronger wave stress mobilizes bed sediment and the current transports sediment. The relative contribution between the waves and current to the critical shear stress for the initiation of motion can be represented by the ratio $u^{*} w m / u^{*}{ }_{c}$. If $u^{*} w m / u^{*} c>1$, the waves dominate the currents and vice versa. The ratio $u^{*} w m / u^{*}$ for the measurements is always greater than one signifying that without the waves the currents are not energetic enough to initiate sediment motion (Figure 31).

Overall, the number of bursts for which $\psi$ exceeds the critical value is relatively small compared to the total record $(<6 \%)$. The relatively weak wave and current environment over the shallow island reduces the potential to resuspend bed sediments. However, fine-grained particles carried in suspension can penetrate the island interior and redeposit during slack tide. The results suggest that local resuspension is not a primary mechanism controlling sediment dynamics on the island.

Figure 30. Shields parameter and critical Shields parameter for the initiation of sediment motion.

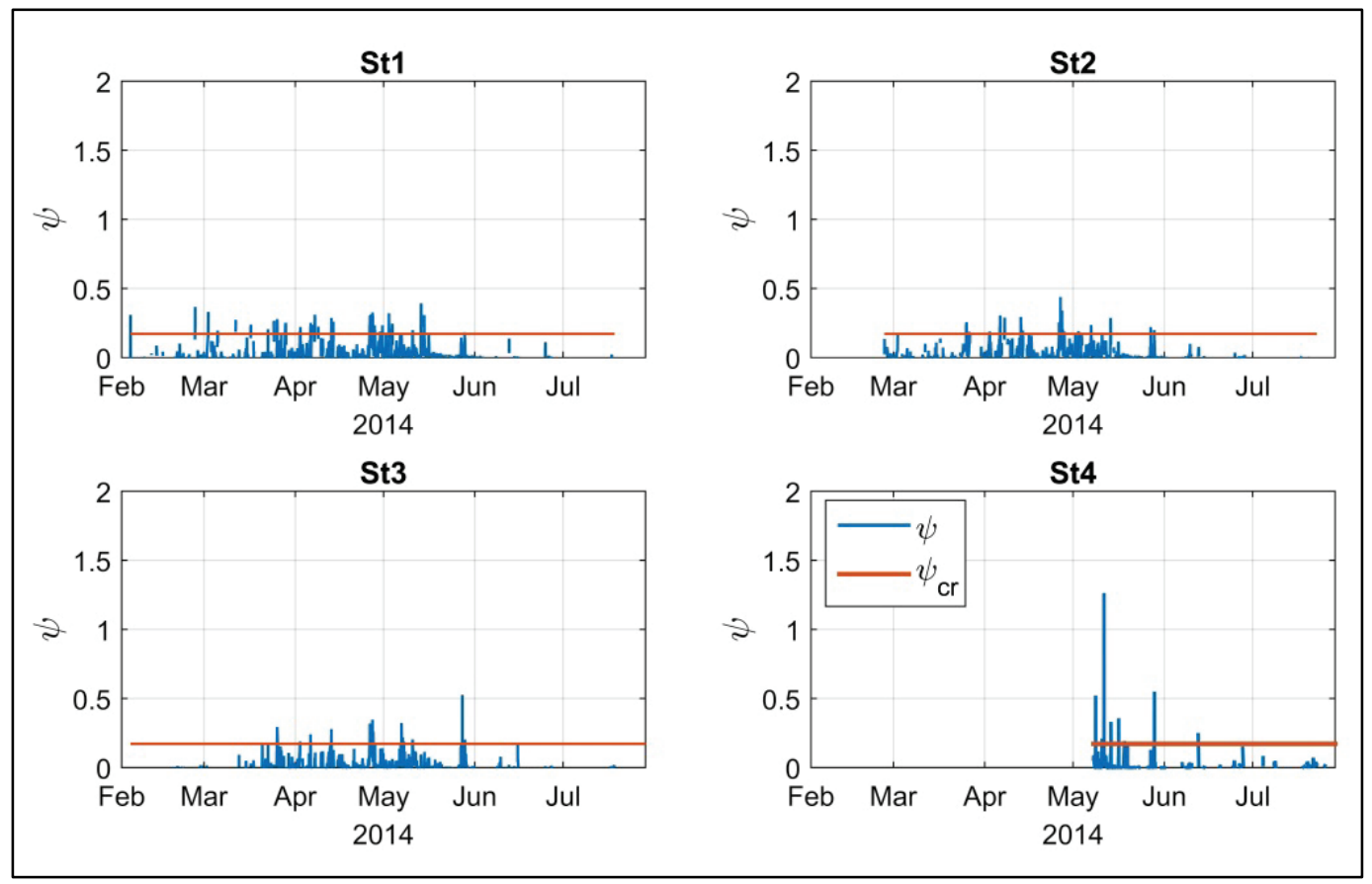


Figure 31. Ratio of maximum wave shear velocity and time-averaged shear velocity for the current. Dashed line is for clarity and signifies when the ratio is equal to one, and thus the wave and current contribute equally to the shear stress.

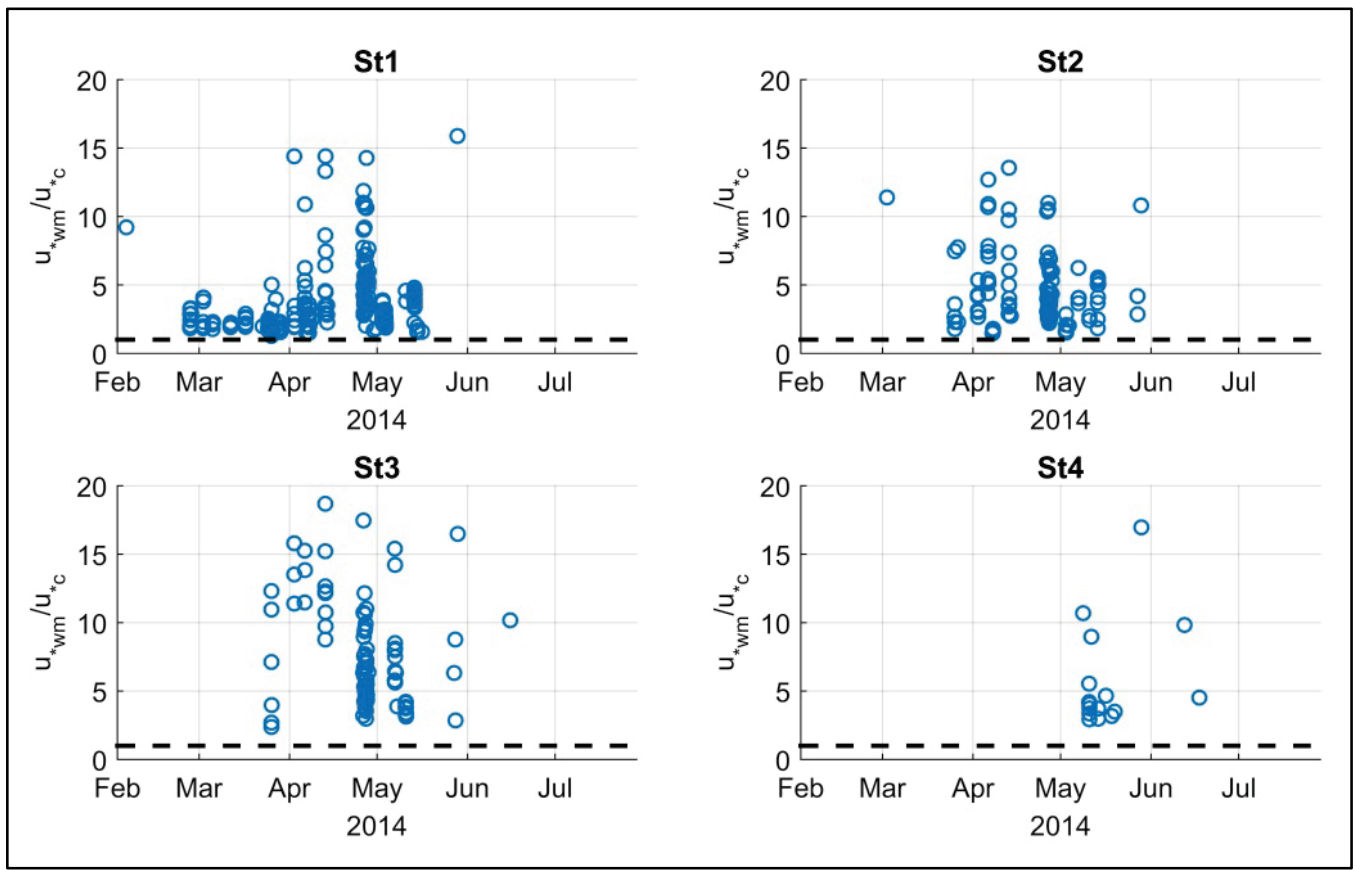

The BBLM sediment transport algorithm is designed for unconsolidated non-cohesive sediment concentration and transport predictions. Direct model/data comparisons are not possible as the sediment collected at the study site is primarily composed of fine silts and clays. The BBLM is designed to predict the bottom stress components responsible for sediment resuspension and transport independent of bed sediment physical characteristics. The sediment enters the equations through the critical shear stress, which is defined independent of the sediment physical characteristics based on erosion experiments conducted on sediment samples collected near the mouth of the Atchafalaya River previously discussed. Sediment transport models express concentration as a function of bed stress, which is written in terms of the square of the shear velocity $(u * 2)$. Under equilibrium conditions, concentration is positively correlated with $u^{* 2}$ as the upward turbulent flux balances particle settling. In combined flows, the total stress is the sum of the wave and current stress components as both contribute to the hydrodynamic forcing responsible for sediment resuspension.

A scatter plot of the filtered concentration versus the filtered $u^{*} c w^{2}$ indicates a positive correlation at all four stations (Figure 32). The data include only bursts in which the shear stress for the initiation of sediment 
motion exceeds the $0.1 \mathrm{~Pa}$ critical shear stress. A similar analysis using the time-averaged shear velocity, $u^{*}{ }^{2}$, produces negative correlation coefficients at St1 and St2 and lower correlations at St3 and St4. Only when the combined stress is used to represent the turbulence does the analysis produce positive correlations at all stations. The combined stress is dominated by the waves during periods when the Shields parameter exceeds the minimum required to initiate sediment motion reinforcing the idea that the wave contribution is required to resuspend sediments and that local equilibrium between concentration and the hydrodynamics is possible only when waves are present. The currents alone do not produce bed shear stresses large enough to resuspend sediment.

Figure 32. Concentration versus square of combined wave and current shear velocity. The correlation coefficient $(r)$ is determined from linear regression.

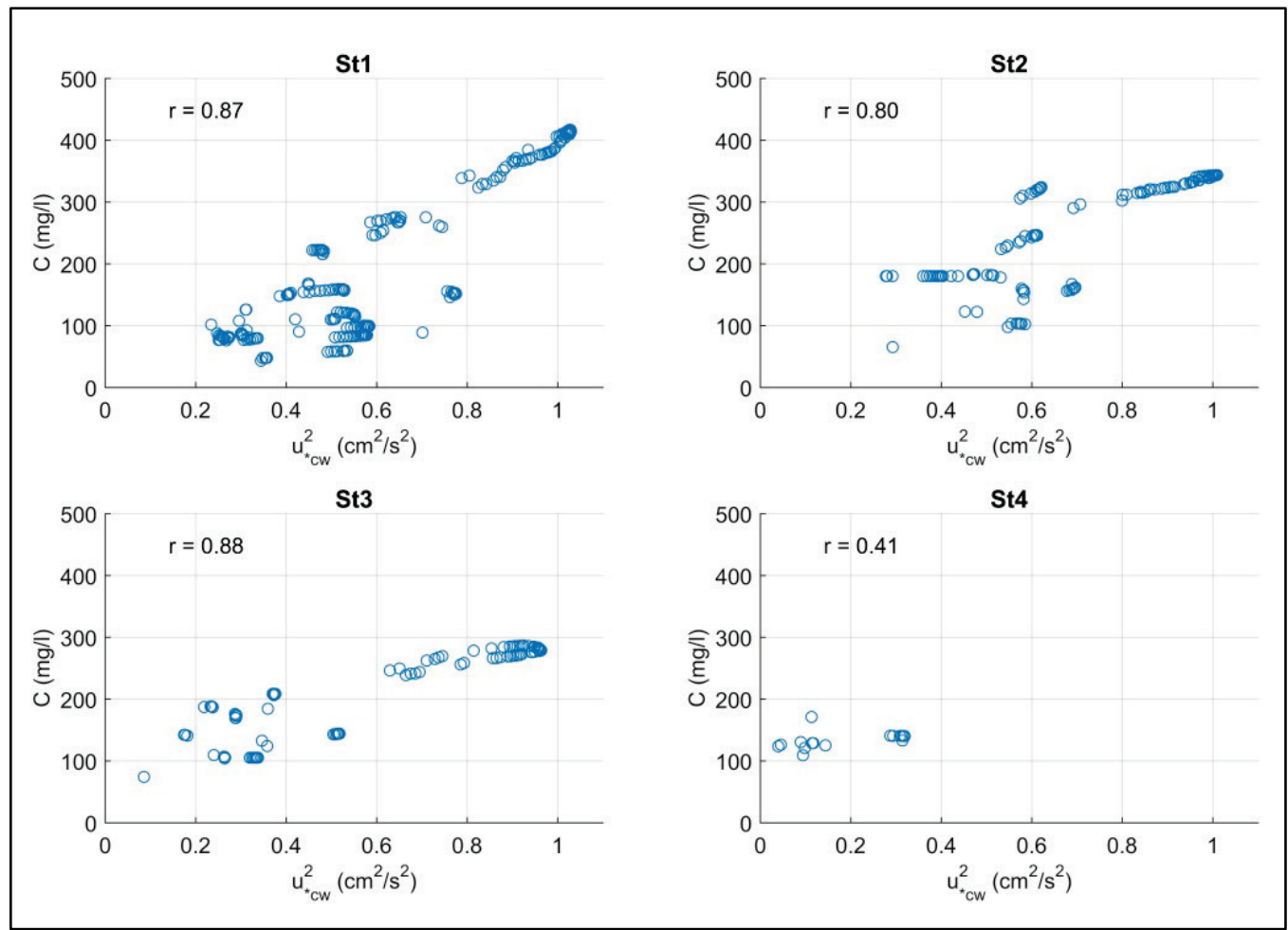

\subsubsection{Micro-scale turbulence and floc size}

The monthly averaged shear parameter is variable at each station with a distinctive seasonal trend (Figure 33). The shear velocity used to calculate dissipation is determined from the BBLM and is why there are no estimates at St3 prior to May. The shear parameter increases to a maximum during the spring freshet and then decreases throughout the remainder of the study period. The shear parameter is much larger at St1 and St2 during the spring freshet but is similar to St3 and St 4 in July. 
Figure 33. Monthly averaged shear parameter. Error bars denote $95 \%$ confidence limits.

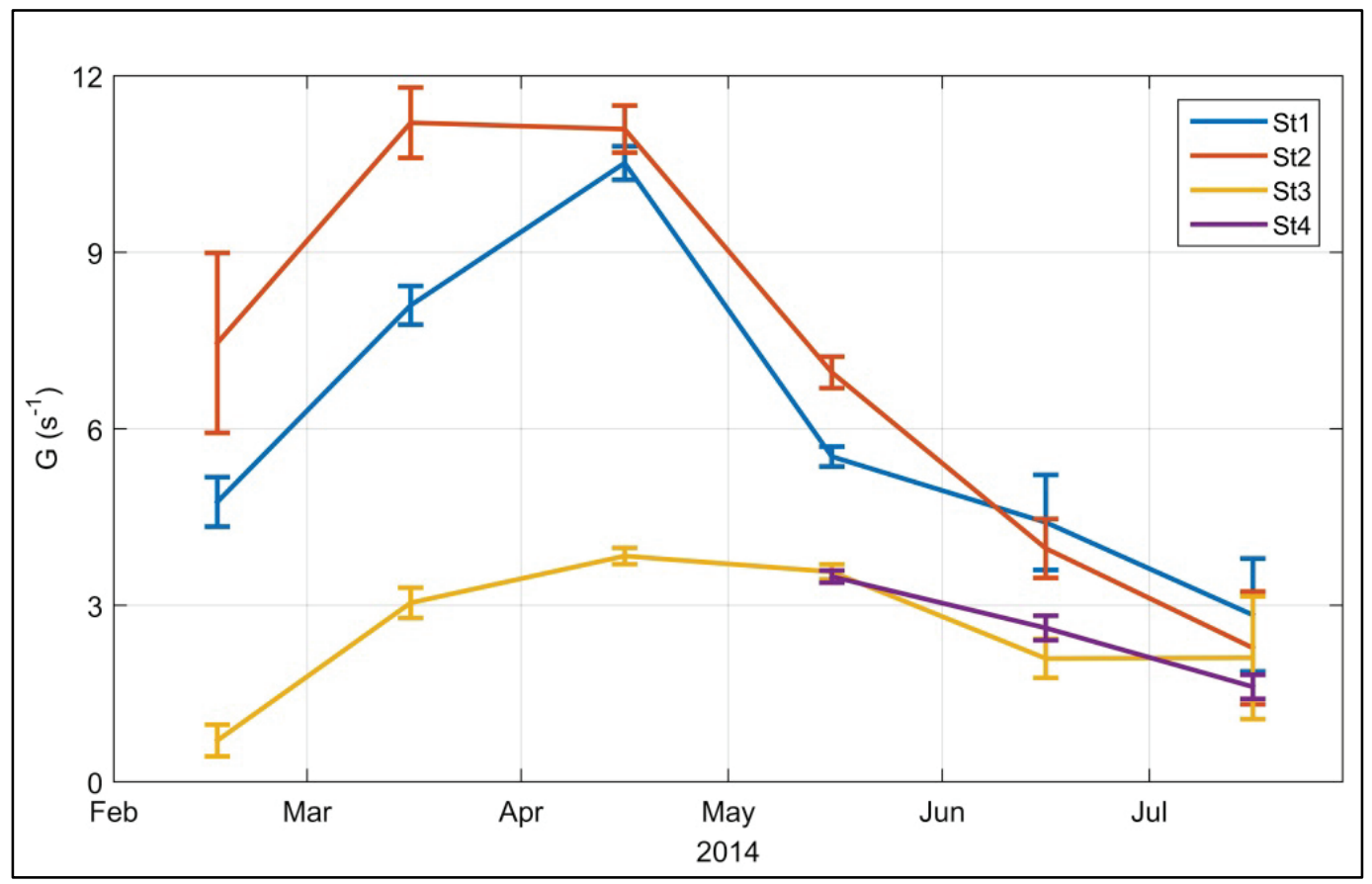

The Kolmogorov micro-scale shows an opposite trend with the lowest values occurring during the spring freshet (Figure 34). Assuming $\lambda_{0}$ is a representative measure of the maximum floc size, the water column can support flocs on the order of 600 to 1,000 microns at St1, St2, and St4. The largest flocs occur in the winter and summer with a reduction in size during the spring freshest. St3 can support much larger flocs prior to the spring freshet, but the results have large error bars corresponding to greater variance and a higher level of uncertainty. The seasonal trend at St3 follows the other stations with the smallest size during April and May. Overall, St1 and St2 show higher shear (through $G$ ) and characteristically smaller floc sizes compared to the St3 and St4, which are located farther from the island edge. 
Figure 34. Monthly averaged Kolmogorov micro-scale. Error bars denote $95 \%$ confidence limits.

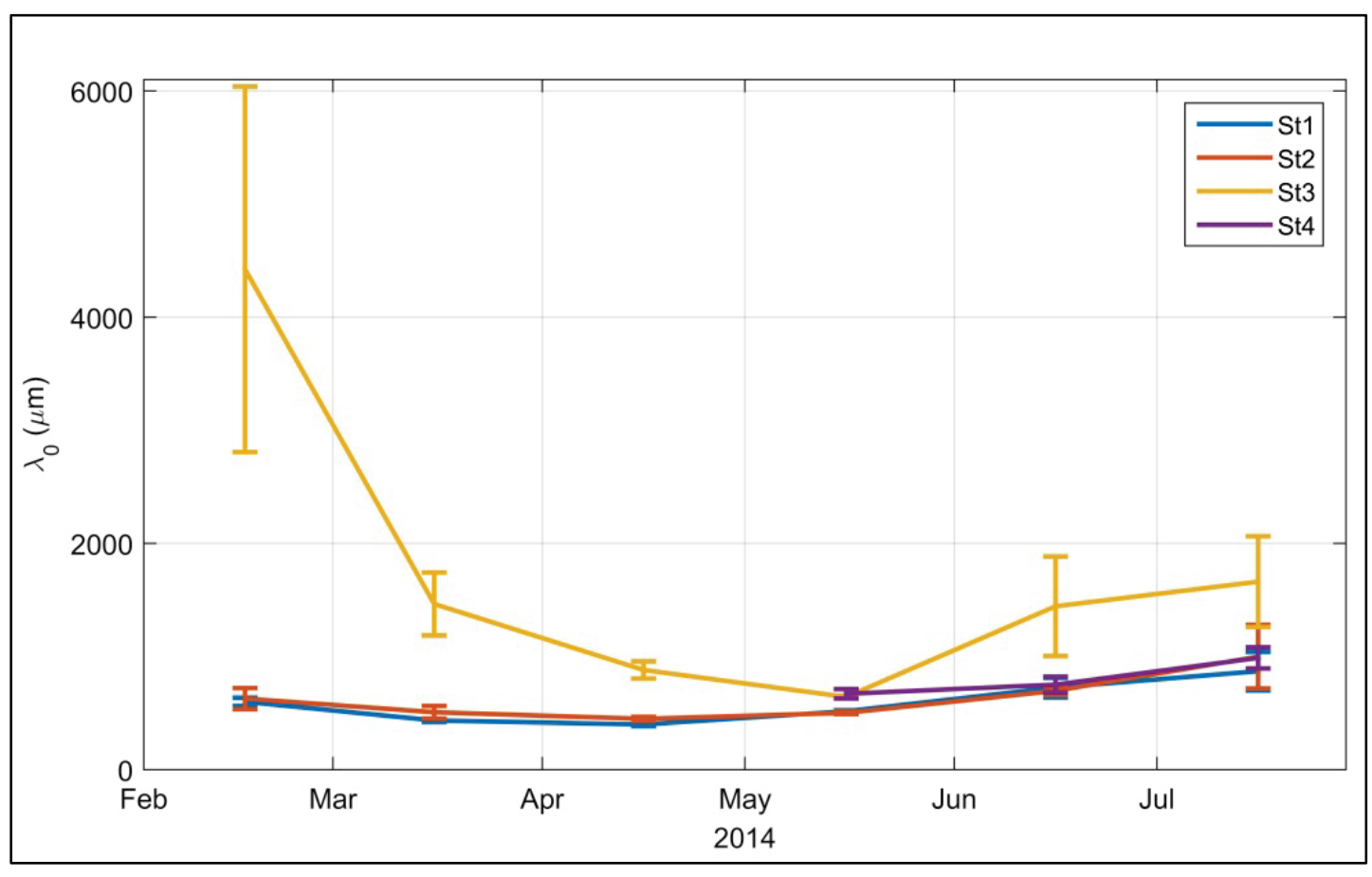




\section{Conceptual Site Model}

\subsection{Hydrodynamic forcing}

The climatology of the southwestern Louisiana coast can be described by persistent southeasterly winds in spring and summer and variable winds associated with frontal systems in the fall and winter (Walker and Hammack 2000). Maximum winds are higher in the winter but are generally shorter in duration consistent with synoptic cold fronts in the 3to 7-day band. Spectral analysis showed higher frequency fluctuations in the mesoscale band (sea breeze) that are also common to this region (Smith et al. 2005).

The prevailing southeast winds lead to coastal setup in the spring, which gives rise to higher average water elevations along the coast. Elevated water levels increase island inundation allowing offshore waves to more easily penetrate the interior regions. The shallow island depths filter the longer waves including ocean swell and infragravity motions, which is consistent with the $3-5 \mathrm{~s}$ waves measured at the platforms. Higher average water levels translate to fewer instances of drying during low tide, so a greater number of wave events are possible. Total number of wave observations is greatest in April and May coincident with higher water levels at the Mike Island stations. The southeasterly winds and associated elevated water levels persist through June, but the number of observed bursts with waves drops significantly in June and July.

Current variability follows a pattern that is consistent with the larger-scale environmental forcing. In winter and summer, current ellipses at St1 and St2 are oriented in a more east/west direction. During the flood season, the magnitude increases with a rotation towards the southeast suggesting the overland flow is influenced by the adjacent channel when the banks overflow. Currents are reduced at St 3 and show a more northeast/southwest orientation during the flood season. The currents at St 4 are even more variable and except for the longer major axis during the flood season, are not oriented with the adjacent channel flow.

In May the monthly averaged current at all stations is at a high angle to the major axis of the ellipse suggesting tidal currents enhance lateral dispersion of a primarily southeasterly directed flow. Water levels are still above average owing to the southeasterly winds, yet discharge is reduced 
so there is less net flow from the adjacent channel. The effect of the tide increases producing a stronger east/west oriented flow. However, WLO discharge is reduced but not absent producing the weak southsoutheasterly flow.

The reduction in magnitude with distance from the island edge implies a sheltering effect in which friction reduces currents in the interior compared to the fringe, where the lateral flux of channel momentum is strongest. The reduction in magnitude at all stations in June and July coincides with the emergence and proliferation of vegetation and a reduction in average water level. Eddy shedding around submerged stems of $S$. alterniflora has been shown to increases turbulence and reduce flow velocities (Christiansen et al. 2000; Leonard and Luther 1995), which is consistent with the measurements at Mike Island. The lower average water levels limit exchange between the island interior and adjacent channels as the banks are only overtopped above midtide.

\subsection{Role of vegetation}

The analysis suggests aquatic vegetation plays several primary roles that affect the hydrodynamics and in particular, the wave activity. In February and March, wave height and the number of bursts with waves is diminished likely due to widespread distribution of decayed organic matter accumulated within the quasi-sheltered island interior. During the initial phase of the instrument deployment, the field team observed large rafts of water hyacinth (Eichhornia crassipes) floating on the surface resulting from seasonal dieback during the previous year. It is hypothesized that the thick cover dampens wave activity and explains the lower wave height and the low number of bursts with waves despite the fact that winter storms can generate waves that would normally be present over the island. Lower average water depths lead to greater instances of drying at low tide, which also limits wave propagation into the island interior and further contributes to the low number of bursts with waves.

Wave activity after June 1 is significantly reduced and more sporadic. Video time series documents the emergence of Nelumbo lutea in the spring followed by proliferation in June and July. Vegetation is known to reduce surface wind stress over erodible land surfaces (Stockton and Gillette 1990), so it is reasonable to expect a similar effect over water with extensive vegetation cover. The reduced capacity of the wind stress to transfer momentum to the water surface impedes local wave generation. 
Likewise, waves generated on the open coast propagate into the vegetated region and encounter increased damping. Both the lower average water depths, which lead to drying at low tide, combined with the dense canopy of Nelumbo lutea contribute to the reduced number of bursts with waves.

\subsection{Sediment dynamics}

The results indicate that waves play a leading role in generating local resuspension. The positive correlation between $u^{*} c w^{2}$ and concentration suggests a local balance between upward sediment flux and gravitational settling. The positive correlation is only achieved when (1) only bursts for which $\psi / \psi_{c r}>1$ are considered and (2) the contribution from the waves is included in the bottom stress calculation. The first condition implies local resuspension as concentrations increase in proportion to $\psi$ once the initiation criteria has been exceeded. The second condition implies that the wave contribution is required to produce a positive correlation. When the regression analysis is performed with $u^{*}{ }^{2}$ representing the bottom stress, the correlation is negative at St1 and St2 and lower at St3 and St4. The lack of correlation implies the current alone is insufficient in generating large enough bottom stress to maintain local resuspension. When $u^{*} c w^{2}$ is used, the concentration increases linearly as measured by the degree of correlation through the regression coefficient. Furthermore, bursts for which $\psi / \psi_{c r}>1, u^{*} w^{2}$ is greater than $u^{*} c^{2}$ indicating that the wave contributes the majority to the total bottom stress.

The analysis reveals that bed sediment is comprised mostly of silt and clay with a D50 of approximately 10 microns, and it is consistent with other regional studies that these particles are carried in suspension as flocs (Lo et al. 2014). Kolmogorov micro-scale estimates indicate the water column can sustain flocs on the order of 600-1,000 microns at St1, St2, and St4, and potentially larger flocs at St3. The ability for the flocs to persist is controlled by the shearing force necessary to disrupt the bonding strength as measured by $G$. The results indicate that larger flocs are more likely to persist in June and July when $G$ is smallest. The presence of vegetation increases friction thereby reducing net flow and associated turbulence stresses as measured by $u^{*}$ and reduced TKE dissipation as measured by the IDM stress estimate and $G$. Reduced turbulence permits larger flocs but lower overall concentrations as maximum turbulence levels are reduced and cannot support higher concentrations in the water column. 
Larger flocs have higher settling velocities (Manning and Dyer 1999), which promotes deposition and bed elevation growth.

\subsection{Morphological discussion}

The results indicate multiple regimes of sediment delivery to WLD islands based on seasonal differences in climate and biological activity. In winter, the primary delivery mechanism is WLO discharge, tidal flow and occasional storm-induced currents. Low-frequency currents are directed towards the island interior and are weaker. Tidally influenced currents are also relatively weak during this time period due to overall lower water levels, which increases friction and reduces the exchange flow. Sediment delivery is primarily from the adjacent channel with limited stirring by waves, as broadly distributed rafts of decaying Eichhornia crassipes dampen wave activity. Monthly averaged sediment concentrations are slightly below the deployment average ranging from 70 to $120 \mathrm{mg} / \mathrm{L}$ in February and March. The weaker waves and currents reduce turbulence increasing the likelihood of larger flocs with higher settling velocities thus promoting deposition.

During the spring freshet, increased discharge from WLO flushes the WLD removing the surface detrital layer. The greater discharge raises water levels in the channel that spills over the banks and increases the exchange flow. The channel flow originates from the WLO and ultimately the Mississippi River, which comprises high concentrations of fine-grained terrigenous sediments (Roberts et al. 1997). Combined with the increased wave activity and stronger currents, concentrations are highest in April. The increased stress associated with the stronger currents and waves reduces the characteristic floc size and associated settling velocity. Furthermore, the model results imply greater resuspension, which would affect fresh deposits to a greater degree than older, more compacted material. While concentrations are higher, the hydrodynamic environment combined with lower settling velocities and weakly compacted fresh deposits that are easily eroded may permit some bypassing of fine-grained sediment over the island. Deposition rates as determined from the wave staffs vary widely during this time, and with the exception of St1, there is no clear increase in bed elevation during the spring freshet.

By late spring, discharge is reduced, and southeasterly winds produce setup within the WLD allowing waves to penetrate the island interior. In conjunction with higher water levels, vegetation emerges and begins to 
blanket the island interior. Sediment delivery is primarily via tidally influenced currents, and over time, deposits become increasingly sheltered from the effects of waves. Floc size and settling velocity are presumably increased due to reduced stress. Monthly averaged concentrations in May and June are consistent with the deployment average as WLO discharge and the exchange flow are reduced.

By late summer, the southeasterly winds relax reducing the setup along the coast and average water levels over the island. Low-frequency currents are reduced likely due to increased friction in the dense sediment canopy and shallower depths. The simultaneous reduction in wave activity suggests sediment deposits are less likely to be disturbed until the fall die out when vegetation is less abundant and can no longer shelter the island from waves. Monthly averaged shear stress is below the deployment average, and floc size and settling velocity are presumably higher encouraging deposition and bed growth. St3 and St4 show a net increase in bed elevation through June and July suggesting deposition. 


\section{Conclusions}

This TR provides a summary of a field data collection effort carried out between February and August 2014 at WLD. Four platforms were instrumented with wave, tide, current, and sediment concentration sensors to measure the hydrodynamic and sediment transport processes in one of only a few global deltas that are actively accreting sediment. The platforms formed a linear array from the island edge to approximately 100 $\mathrm{m}$ into the interior, providing an examination of the fine-scale spatial variations between the edge and interior of an interdistributary island. The results indicated complex interactions between climatology, discharge, and vegetation to create conditions favorable for delta building.

The main conclusions are summarized as follows:

- River discharge from WLO delivers high concentrations of suspended sediment to the channels. The currents show a combination of tidal flow and low-frequency motion, the latter of which is directed towards the island interior and is strongest during the spring freshet. Delivery from WLO is regulated by water elevation, as periods outside the spring flood season show frequent drying at low tide reducing the exchange. Higher water levels overflow the levees and combined with the current, deliver sediment to the island interior. Based on the current measurements, this is the primary source of sediment delivery throughout the study.

- During late spring, discharge is reduced, but setup along the coast due to persistent southeasterly winds maintains higher than average water levels allowing waves to penetrate the island interior and greater exchange between the island and adjacent channel. Waves increase sediment resuspension, which is redistributed over the island via tidal currents.

- The emergence of Nelumbo lutea in May produces a thick canopy over the island interior, damping wave activity. Flow is primarily tidal, and sediment resuspension due to waves is reduced. Water levels are lower than the deployment average, reducing exchange flow and the tidal currents' capacity to deliver sediment to the island interior. However, concentrations of suspended sediment are carried by the flow, where they are likely deposited as thin, easily erodible surface layers. The combination of greater vegetation to reduce current magnitude and the lack of waves acts to further sequester sediment. Over time, these 
layers may become more consolidated, and by the time the vegetation dieback occurs in the fall and the waves reappear, the more erosionresistant bed would bolster delta growth. Vegetation may serve as a critical component of wetland restoration projects by accelerating land building and facilitating erosion protection. 


\section{References}

American Society for Testing Materials (ASTM). 1997. Standard Test Methods for Determining Sediment Concentration in Water Samples (ASTM designation: D 3977-97). West Conshohocken, PA: American Society for Testing and Materials.

Anderson, M. E., and J. Smith. 2014. "Wave Attenuation by Flexible, Idealized Salt Marsh Vegetation." Coastal Engineering 83: 82-92.

Augustin, L. N., J. L. Irish, P. Lynett. 2009. "Laboratory and Numerical Studies of Wave Damping by Emergent and Near-Emergent Wetland Vegetation." Coastal Engineering 56: 332-340. http://www.sciencedirect.com/science/article/pii/S0272771400905481.

Bendat, J. S., and A. G. Piersol. 1986. Random Data Analysis and Measurement Techniques. $2^{\text {nd }}$ ed. New Jersey: J. Wiley \& Sons. http://www.worldcat.org/title/random-data-analysis-and-measurementprocedures/oclc/455952078? referer=di\&ht=edition.

Cahoon, D. R., P. F. Hensel, T. Spencer, D. J. Reed, K. L. McKee, and N. Saintilan. 2006. Coastal Wetland Vulnerability to Relative Sea-Level Rise: Wetland Elevation Trends and Process Controls, Wetlands and Natural Resource Management. New York City: Springer.

Carle, M. V., C. E. Sasser, and H. H. Roberts. 2015. "Accretion and Vegetation Community Change in the Wax Lake Delta Following Historic 2011 Mississippi River Flood." J. Coastal Res. 31: 569-587.

Christiansen, T., P. Wiberg, and T. Milligan. 2000. "Flow and Sediment Transport on a Tidal Salt Marsh Surface." Estuarine, Coastal and Shelf Science 50(3): 315-331. http://www.sciencedirect.com/science/article/pii/S0272771400905481.

Coastal Engineering Research Center (CERC). 1984. Shore Protection Manual-Volume I. 4th ed. Vicksburg, MS: Waterways Experiment Station.

Cooper, N. J. 2005. "Wave Dissipation across Intertidal Surfaces in the Wash Tidal Inlet, Eastern England." Journal of Coastal Research 1: 28-40. http://www.jstor.org/stable/4299388.

Costanza, R., O. Pérez-Maqueo, M. L. Martinez, P. Sutton, S. J. Anderson, and K. Mulder. 2008. "The Value of Coastal Wetlands for Hurricane Protection." AMBIO: A Journal of the Human Environment 37(4): 241-248. http://www.bioone.org/doi/abs/10.1579/00447447(2008)37\%5B241\%3ATVOCWF\%5D2.0.C0\%3B2.

Daubechies, I. 1990. "The Wavelet Transform, Time-Frequency Localization and Signal Analysis." Information Theory, IEEE Transactions on Information Theory 36(5): 961-1005. http://ieeexplore.iee.org/stamp/stamp.jsp?tp=\&arnumber=57199. 
Edmonds, D., and R. Slingerland. 2007. "Mechanics of River Mouth Bar Formation: Implications for the Morphodynamics of Delta Distributary Networks." Journal of Geophysical Research: Earth Surface (2003-2012) 112(FO2034). http://onlinelibrary.wiley.com/doi/10.1029/2006JF000574/epdf.

Edmonds, D. A., C. Paola, D. C. Hoyal, and B. A. Sheets. 2011. "Quantitative Metrics That Describe River Deltas and Their Channel Networks." Journal of Geophysical Research: Earth Surface (2003-2012) 116(FO4022). http://onlinelibrary.wiley.com/doi/10.1029/2010JF001955/epdf.

Fisk, H. N. 1952. Geological Investigation of the Atchafalaya Basin and the Problem of Mississippi River Diversion. Vicksburg, MS: U.S. Army Corps of Engineers, Waterways Experiment Station.

Garrett, C., and B. Toulany. 1982. "Sea Level Variability Due to Meteorological Forcing in the Northeast Gulf of St. Lawrence." Journal of Geophysical Research: Oceans 87(C3): 1968-1978. http://onlinelibrary.wiley.com/doi/10.1029/JC087iC03p01968/epdf.

Gedan, K. B., M. L. Kirwan, E. Wolanski, E. B. Barbier, and B. R. Silliman. 2011. "The Present and Future Role of Coastal Wetland Vegetation in Protecting Shorelines: Answering Recent Challenges to the Paradigm." Climatic Change 106(1): 7-29. http://link.springer.com/article/10.1007/s10584-010-0003-7.

Grinsted, A., J. C. Moore, and S. Jevrejeva. 2004. "Application of the Cross Wavelet Transform and Wavelet Coherence to Geophysical Time Series." Nonlinear Processes in Geophysics 11: 561-566.

Hall, T. F., and W. T. Penfound. 1944. "The Biology of the American Lotus, Nelumbo lutea" (Wild.) Pers. American Midland Naturalist 31(3): 744-758. http://www.jstor.org/stable/2421417.

Hiatt, M., and P. Passalacqua. 2015. "Hydrological Connectivity in River Deltas: The First-Order Importance of Channel-Island Exchange." Water Resources Research 51(4): 2264-2282. http://onlinelibrary.wiley.com/doi/10.1002/2014WR016149/full.

Jevrejeva, S., J. Moore, and A. Grinsted. 2003. "Influence of the Arctic Oscillation and El Niño-Southern Oscillation (ENSO) on Ice Conditions in the Baltic Sea: The Wavelet Approach." Journal of Geophysical Research: Atmospheres 108(D21). http://onlinelibrary.wiley.com/doi/10.1029/2003JD003417/epdf.

Jevrejeva, S., J. Moore, P. Woodworth, and A. Grinsted. 2005. "Influence of Large-Scale Atmospheric Circulation on European Sea Level: Results Based on the Wavelet Transform Method." Tellus A 57(2): 183-193. http://onlinelibrary.wiley.com/doi/10.1111/j.1600-0870.2005.00090.x/abstract.

Kayano, M. T., and R. V. Andreoli. 2006. "Relationships between Rainfall Anomalies over Northeastern Brazil and the El Nino-Southern Oscillation." Journal of Geophysical Research: Atmospheres 111(D13101). http://onlinelibrary.wiley.com/doi/10.1029/2005JD006142/epdf. 
Kim, S. C., C. T. Friedrichs, J. P. Y. Maa, and L. D. Wright. 2000. "Estimating Bottom Stress in Tidal Boundary Layer from Acoustic Doppler Velocimeter Data." Journal of Hydraulic Engineering-ASCE 126(6): 399-406. http://ascelibrary.org/doi/abs/10.1061/(ASCE)0733-9429(2000)126\%3A6(399).

Kim, W., D. Mohrig, R. Twilley, C. Paola, and G. Parker. 2009. "Is It Feasible to Build New Land in the Mississippi River Delta?" Eos, Transactions American Geophysical Union 90(52): 373-374. http://onlinelibrary.wiley.com/doi/10.1029/2009E0420001/abstract.

Kolmogorov, A. N. 1941. "The Local Structure of Turbulence in Incompressible Viscous Fluid for Very Large Reynolds Numbers." Doklady Akademiia Nauk SSSR 30: 301-305. http://adsabs.harvard.edu/abs/1941DoSSR..30..301K.

Labat, D., Y. Goddéris, J. L. Probst, J. L. Guyot. 2004. "Evidence for Global Runoff Increase Related to Climate Warming." Advances in Water Resources 27(6): 631-642. http://www.sciencedirect.com/science/article/pii/S0309170804000478.

Leonard, L. A., and M. E. Luther. 1995. "Flow Hydrodynamics in Tidal Marsh Canopies." Limnology and Oceanography 40(8): 1474-1484. http://onlinelibrary.wiley.com/doi/10.4319/lo.1995.40.8.1474/full.

Lo, E. L., S. J. Bentley, Sr., and K. Xu. 2014. "Experimental Study of Cohesive Sediment Consolidation and Resuspension Identifies Approaches for Coastal Restoration: Lake Lery, Louisiana." Geo-Marine Letters 34(6): 499-509. http://link.springer.com/article/10.1007/s00367-014-0381-3.

Manning, A. J., and K. R. Dyer. 1999. "A Laboratory Examination of Floc Characteristics with Regard to Turbulent Shearing." Marine Geology 160(1,2): 147-170. http://www.sciencedirect.com/science/article/pii/S0025322799000134.

Nepf, H. M. 2012. "Flow and Transport in Regions with Aquatic Vegetation." Annual Review of Fluid Mechanics 44: 123-142.

Neumeier, U., and C. L. Amos. 2006. "The Influence of Vegetation on Turbulence and Flow Velocities in European Salt-Marshes." Sedimentology 53(2): 259-277. http://onlinelibrary.wiley.com/doi/10.1111/j.1365-3091.2006.00772.x/abstract.

Nicholls, R. J., and A. Cazenave. 2010. "Sea-Level Rise and Its Impact on Coastal Zones." Science 328(5985): 1517-1520. http://science.sciencemag.org/content/328/5985/1517.

Novakowski, K. I., R. Torres, L. R. Gardner, and G. Voulgaris. 2004. "Geomorphic Analysis of Tidal Creek Networks." Water Resources Research 40(Wo5401). http://onlinelibrary.wiley.com/doi/10.1029/2003WR002722/epdf.

O'Connor, M. T., and K. B. Moffett. 2015. "Groundwater Dynamics and Surface WaterGroundwater Interactions in a Prograding Delta Island, Louisiana, USA." Journal of Hydrology 524: 15-29.

Pawlowicz, R., B. Beardsley, and S. Lentz. 2002. "Classical Tidal Harmonic Analysis Including Error Estimates in MATLAB Using T_TIDE." Computers \& Geosciences 28(8): 929-937. http://www.sciencedirect.com/science/article/pii/S0098300402000134. 
Pope, N., J. Widdows, and M. Brinsley. 2006. "Estimation of Bed Shear Stress Using the Turbulent Kinetic Energy Approach-A Comparison of Annular Flume and Field Data." Continental Shelf Research 26(8): 959-970. http://www.sciencedirect.com/science/article/pii/S0278434306000689.

Roberts, H., J. Coleman, S. Bentley, and N. Walker. 2003. "An Embryonic Major Delta Lobe: A New Generation of Delta Studies in the Atchafalaya-Wax Lake Delta System." Gulf Coast Association of Geological Societies Transactions, 53: 690703.

http://archives.datapages.com/data/gcags/data/053/053001/0690.htm.

Roberts, H., N. Walker, R. Cunningham, G. Kemp, and S. Majersky. 1997. "Evolution of Sedimentary Architecture and Surface Morphology: Atchafalaya and Wax Lake Deltas, Louisiana (1973-1994)." Gulf Coast Association of Geological Societies Transactions 47: 477-484. http://archives.datapages.com/data/gcags/data/047/047001/0477.htm.

Roberts, H. H. 1998. "Delta Switching: Early Responses to the Atchafalaya River Diversion." Journal of Coastal Research 3: 882-899. http://www.jstor.org/stable/4298842.

Salehi, M., and K. Strom. 2012. "Measurement of Critical Shear Stress for Mud Mixtures in the San Jacinto Estuary under Different Wave and Current Combinations." Continental Shelf Research 47: 78-92.

Shaw, J. B., and D. Mohrig. 2014. "The Importance of Erosion in Distributary Channel Network Growth, Wax Lake Delta, Louisiana, USA." Geology 42: 31-34.

Shaw, J. B., D. Mohrig, and S. K. Whitman. 2013. "The Morphology and Evolution of Channels on the Wax Lake Delta, Louisiana, USA." Journal of Geophysical Research: Earth Surface 118: 1562-1584.

Shaw, W. J., and J. H. Trowbridge. 2001. "The Direct Estimation of Near-Bottom Turbulent Fluxes in the Presence of Energetic Wave Motions." Journal of Atmospheric and Oceanic Technology 18: 1540-1557.

Smith, J. R., H. E. Fuelberg, and A. I. Watson. 2005. "Warm Season Lightning Distributions over the Northern Gulf of Mexico Coast and Their Relation to Synoptic-Scale and Mesoscale Environments." Weather and Forecasting 20: 415-438.

Snedden, G. A., J. E. Cable, C. Swarzenski, and E. Swenson. 2007. "Sediment Discharge into a Subsiding Louisiana Deltaic Estuary through a Mississippi River Diversion." Estuarine, Coastal and Shelf Science 71(1,2): 181-193. http://www.sciencedirect.com/science/article/pii/S027277140600312X.

Stapleton, K., and D. Huntley. 1995. "Seabed Stress Determinations Using the Inertial Dissipation Method and the Turbulent Kinetic Energy Method." Earth Surface Processes and Landforms 20(9): 807-815. http://onlinelibrary.wiley.com/doi/10.1002/esp.3290200906/abstract.

Stockton, P., and D. Gillette. 1990. "Field Measurement of the Sheltering Effect of Vegetation on Erodible Land Surfaces." Land Degradation \& Development 2(2): 77-85. http://onlinelibrary.wiley.com/doi/10.1002/Idr.3400020202/abstract. 
Temmerman, S., T. Bouma, G. Govers, Z. Wang, M. De Vries, and P. Herman. 2005. "Impact of Vegetation on Flow Routing and Sedimentation Patterns: ThreeDimensional Modeling for a Tidal Marsh." Journal of Geophysical Research: Earth Surface (2003-2012) 110(F04019). http://onlinelibrary.wiley.com/doi/10.1029/2005JF000301/abstract.

Torrence, C., and P. J. Webster. 1999. "Interdecadal Changes in the ENSO-Monsoon System." Journal of Climate 12: 2679-2690.

Torres, R., and R. Styles. 2007. "Effects of Topographic Structure on Salt Marsh Currents." Journal of Geophysical Research: Earth Surface (2003-2012) 112(Fo2023). http://onlinelibrary.wiley.com/doi/10.1029/2006JF000508/full.

Walker, N. D., and A. B. Hammack. 200o. "Impacts of Winter Storms on Circulation and Sediment Transport: Atchafalaya-Vermilion Bay Region, Louisiana, USA." Journal of Coastal Research 16(4): 996-1010. http://www.jstor.org/stable/4300118.

Wamsley, T. V., M. A. Cialone, J. M. Smith, J. H. Atkinson, and J. D. Rosati. 2010. "The Potential of Wetlands in Reducing Storm Surge." Ocean Engineering 37(1): 5968. http://www.sciencedirect.com/science/article/pii/S002980180900184X.

Welch, P. D. 1967. "The Use of Fast Fourier Transform for the Estimation of Power Spectra: A Method Based on Time Averaging over Short, Modified Periodograms." IEEE Transactions on Audio and Electroacoustics 15(2): 70-73. http://ieeexplore.ieee.org/xpl/articleDetails.jsp?arnumber=1161901.

Winterwerp, J. C. 1998. "A Simple Model for Turbulence Induced Flocculation of Cohesive Sediment." Journal of Hydraulic Research 36(3): 309-326. http://www.tandfonline.com/doi/abs/10.1080/00221689809498621.

Winterwerp, J. C., and W. G. Van Kesteren. 2004. Introduction to the Physics of Cohesive Sediment Dynamics in the Marine Environment. Amsterdam, The Netherlands: Elsevier.

Wright, L. 1977. "Sediment Transport and Deposition at River Mouths: A Synthesis." Geological Society of America Bulletin 88(6): 857-868.

http://gsabulletin.gsapubs.org/content/88/6/857. 


\section{Appendix A: Time Series of Wax Lake Hydrological Measurements}

Appendix A lists the time series of (a) WLO discharge, (b) wind speed, (c) wind direction, (d) water level, (e) wave height, (f) wave period, and (g) current velocity for each month beginning in February. Figures 35-40 are for Station 1; Figures 41-46 are for Station 2; Figures 47-52 are for Station 3; and Figures 53-58 are for Station 4. 
Figure 35. Data for 5 February to 1 March 2014 for Wax Lake Remote Station 1 where a) Wax Lake Discharge $\left(\mathrm{m}^{3} / \mathrm{s}\right)$, b) Wind Speed $(\mathrm{m} / \mathrm{s}), \mathrm{c}$ ) Wind Direction (degrees), d) Water Level (blue -local, red-Buoy AMRL1, cm), e) Wave Height (cm), f) Wave Period (s), and g) Velocity (rednorth, green-east, blue-vertical, $\mathrm{cm} / \mathrm{s})$.

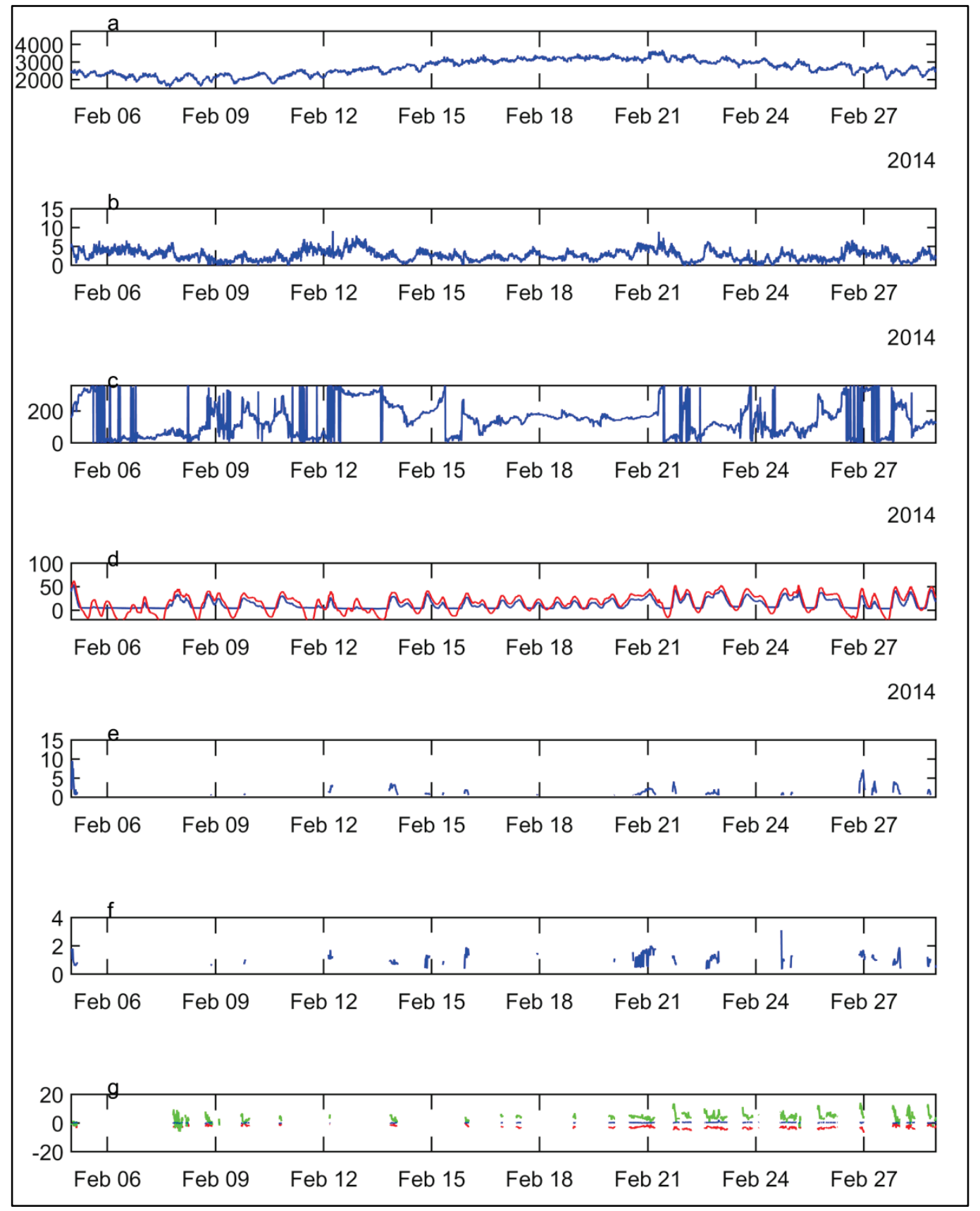


Figure 36. Data for 1 March to 1 April 2014 for Wax Lake Remote Station 1 where a) Wax Lake Discharge $\left.\left(\mathrm{m}^{3} / \mathrm{s}\right), \mathrm{b}\right)$ Wind Speed $(\mathrm{m} / \mathrm{s})$, c) Wind Direction (degrees), d) Water Level (blue -local, red-Buoy AMRL1, cm), e) Wave Height (cm), f) Wave Period (s), and g) Velocity (rednorth, green-east, blue-vertical, cm/s).

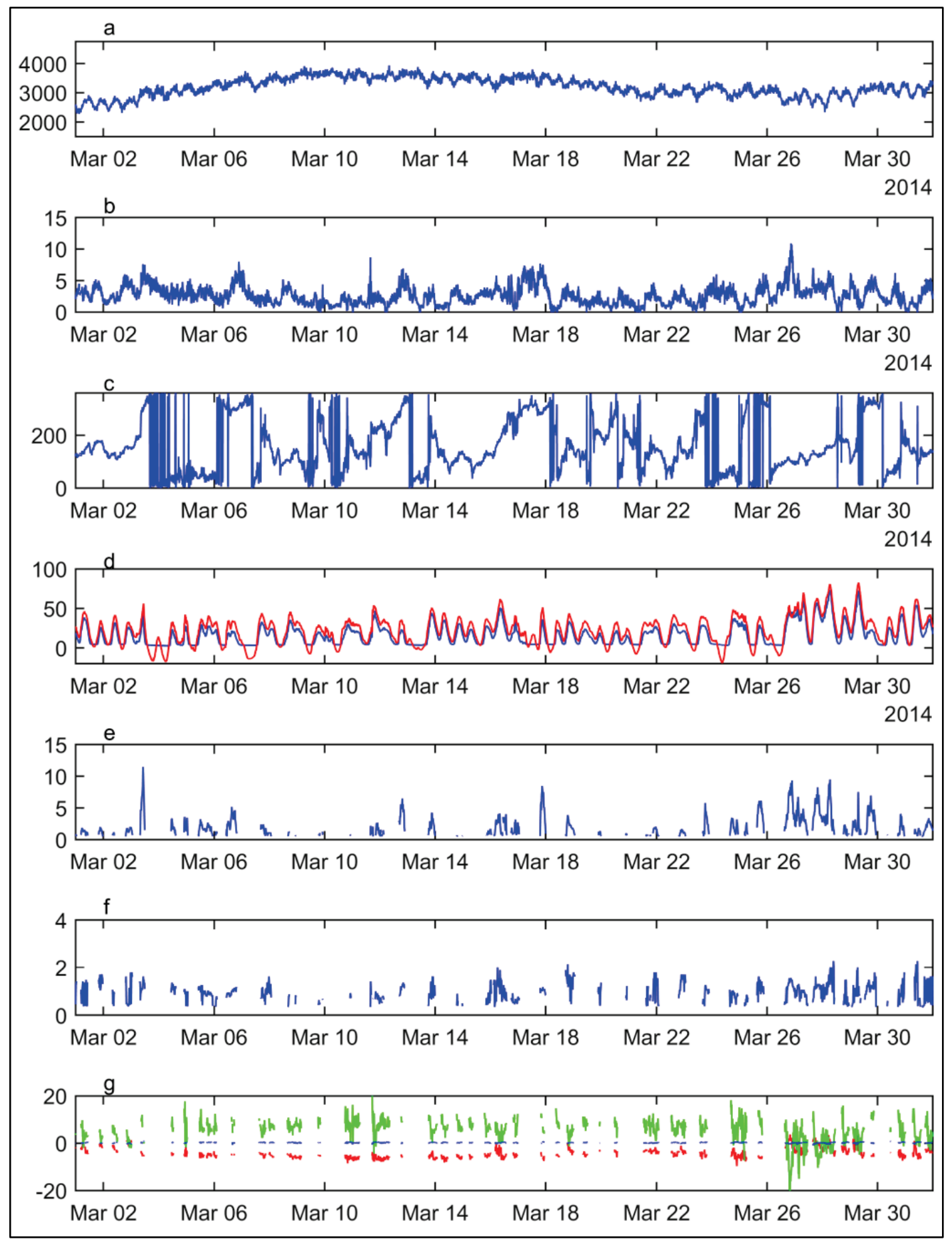


Figure 37. Data for 1 April to 1 May 2014 for Wax Lake Remote Station 1 where a) Wax Lake Discharge $\left(\mathrm{m}^{3} / \mathrm{s}\right)$, b) Wind Speed $(\mathrm{m} / \mathrm{s})$, c) Wind Direction (degrees), d) Water Level (blue local, red-Buoy AMRL1, cm), e) Wave Height (cm), f) Wave Period (s), and g) Velocity (rednorth, green-east, blue-vertical, $\mathrm{cm} / \mathrm{s}$ ).

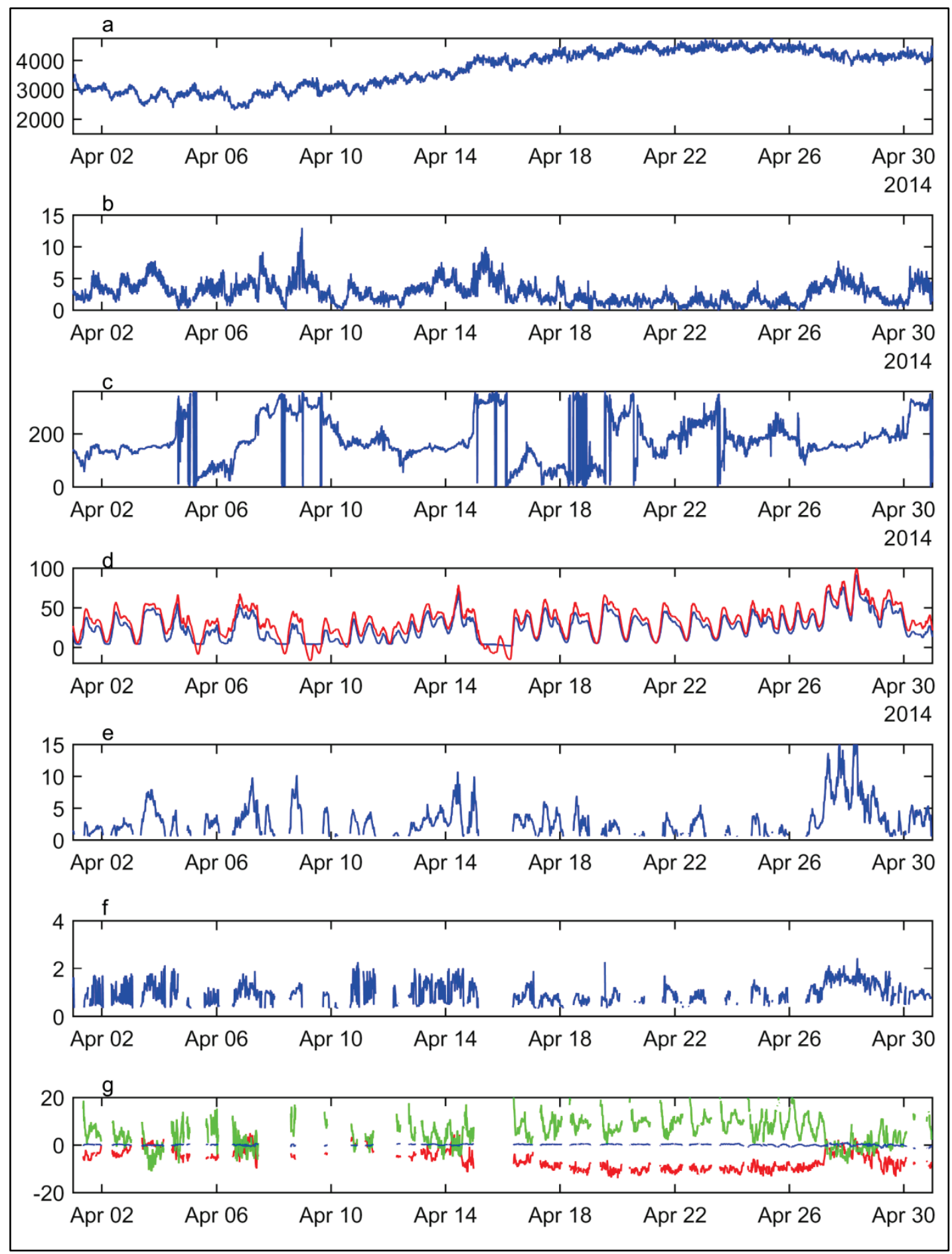


Figure 38. Data for 1 May to 1 June 2014 for Wax Lake Remote Station 1 where a) Wax Lake Discharge $\left(\mathrm{m}^{3} / \mathrm{s}\right)$, b) Wind Speed $(\mathrm{m} / \mathrm{s})$, c) Wind Direction (degrees), d) Water Level (blue local, red-Buoy AMRL1, cm), e) Wave Height (cm), f) Wave Period (s), and g) Velocity (rednorth, green-east, blue-vertical, cm/s).

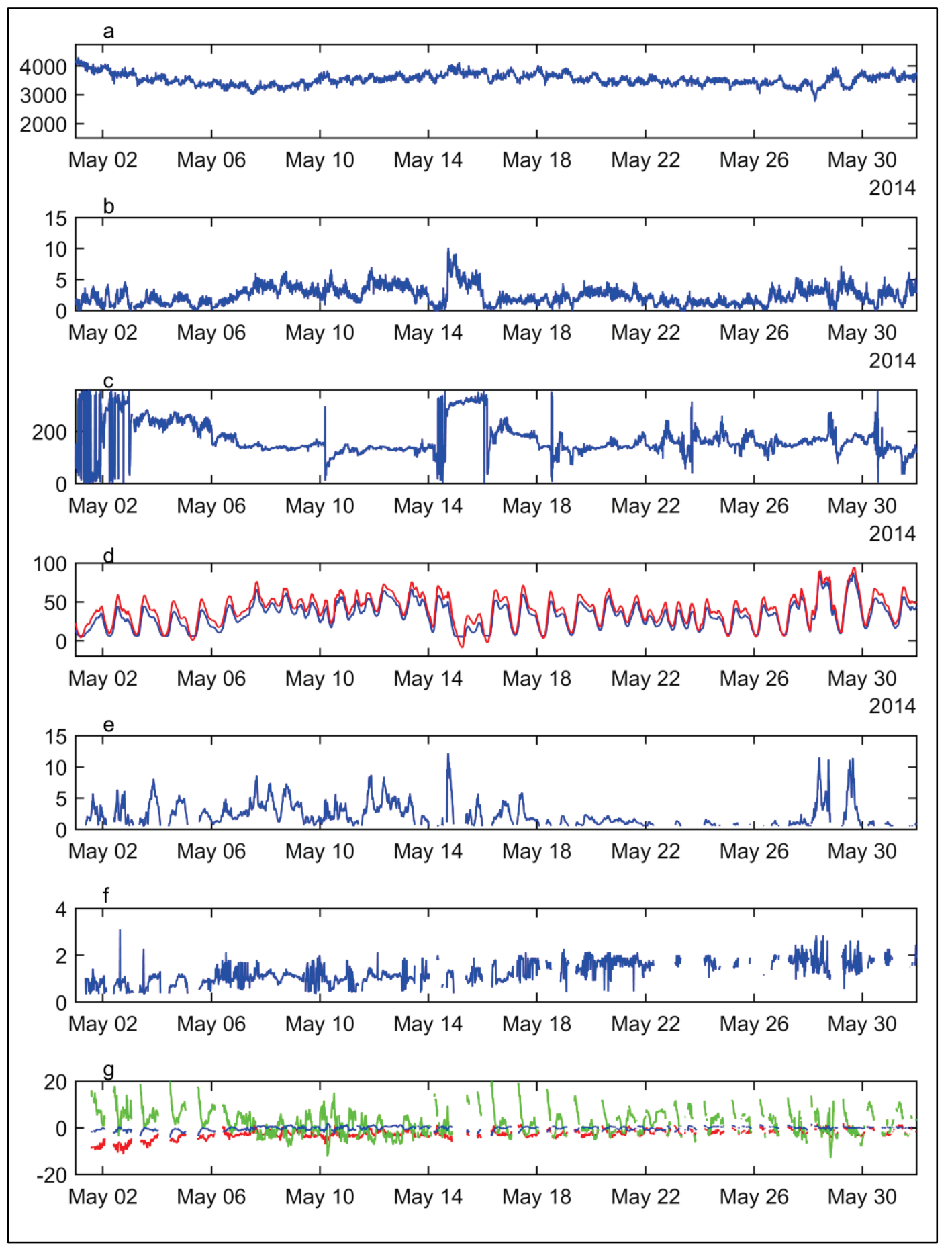


Figure 39. Data for 1 June to 1 July 2014 for Wax Lake Remote Station 1 where a) Wax Lake Discharge $\left(\mathrm{m}^{3} / \mathrm{s}\right)$, b) Wind Speed $(\mathrm{m} / \mathrm{s})$, c) Wind Direction (degrees), d) Water Level (blue local, red-Buoy AMRL1, cm), e) Wave Height (cm), f) Wave Period (s), and g) Velocity (rednorth, green-east, blue-vertical, $\mathrm{cm} / \mathrm{s}$ ).

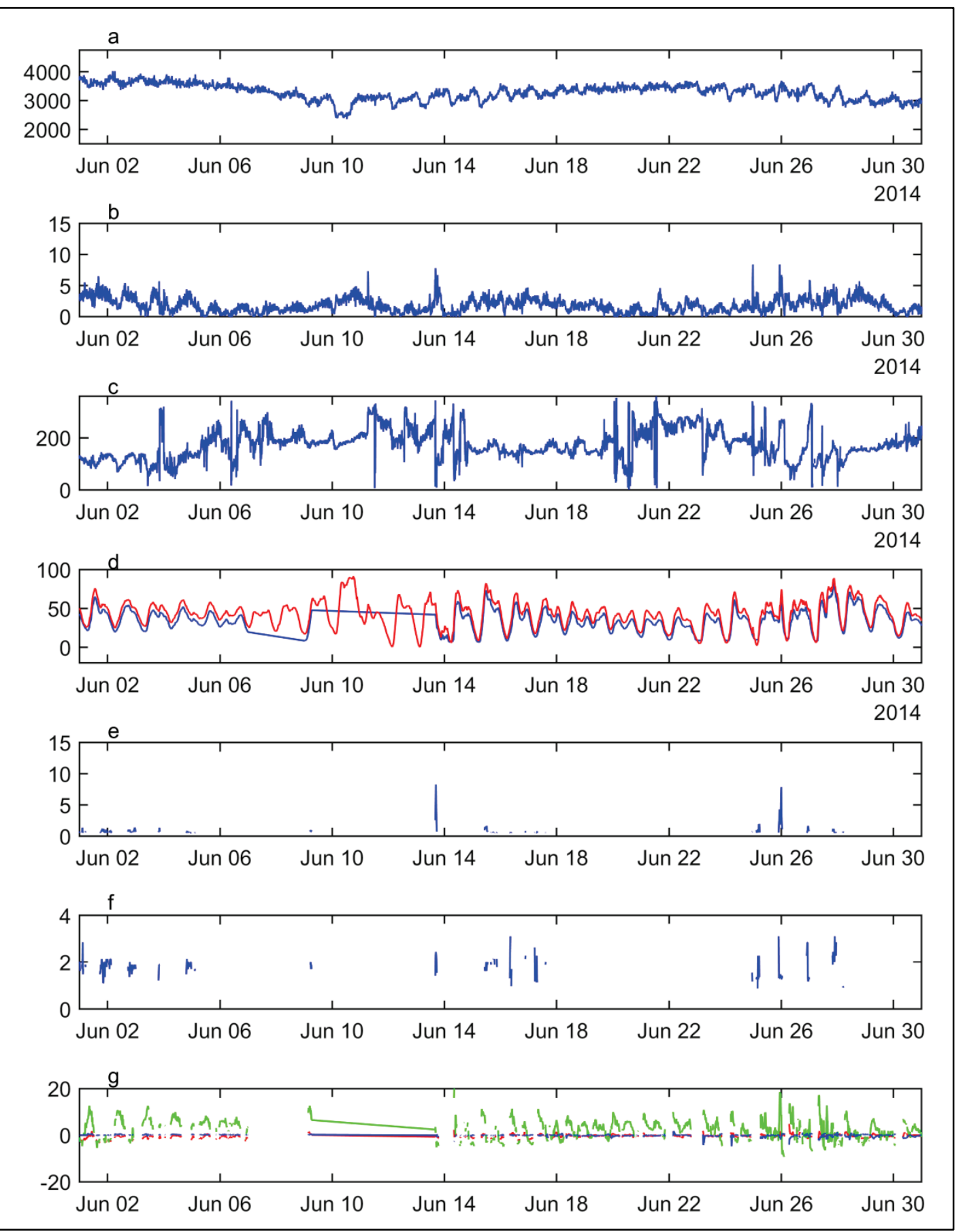


Figure 40. Data for 1 July to 1 August 2014 for Wax Lake Remote Station 1 where a) Wax Lake Discharge $\left(\mathrm{m}^{3} / \mathrm{s}\right)$, b) Wind Speed $(\mathrm{m} / \mathrm{s}), \mathrm{c}$ ) Wind Direction (degrees), d) Water Level (blue -local, red-Buoy AMRL1, cm), e) Wave Height (cm), f) Wave Period (s), and g) Velocity (rednorth, green-east, blue-vertical, $\mathrm{cm} / \mathrm{s}$ ).
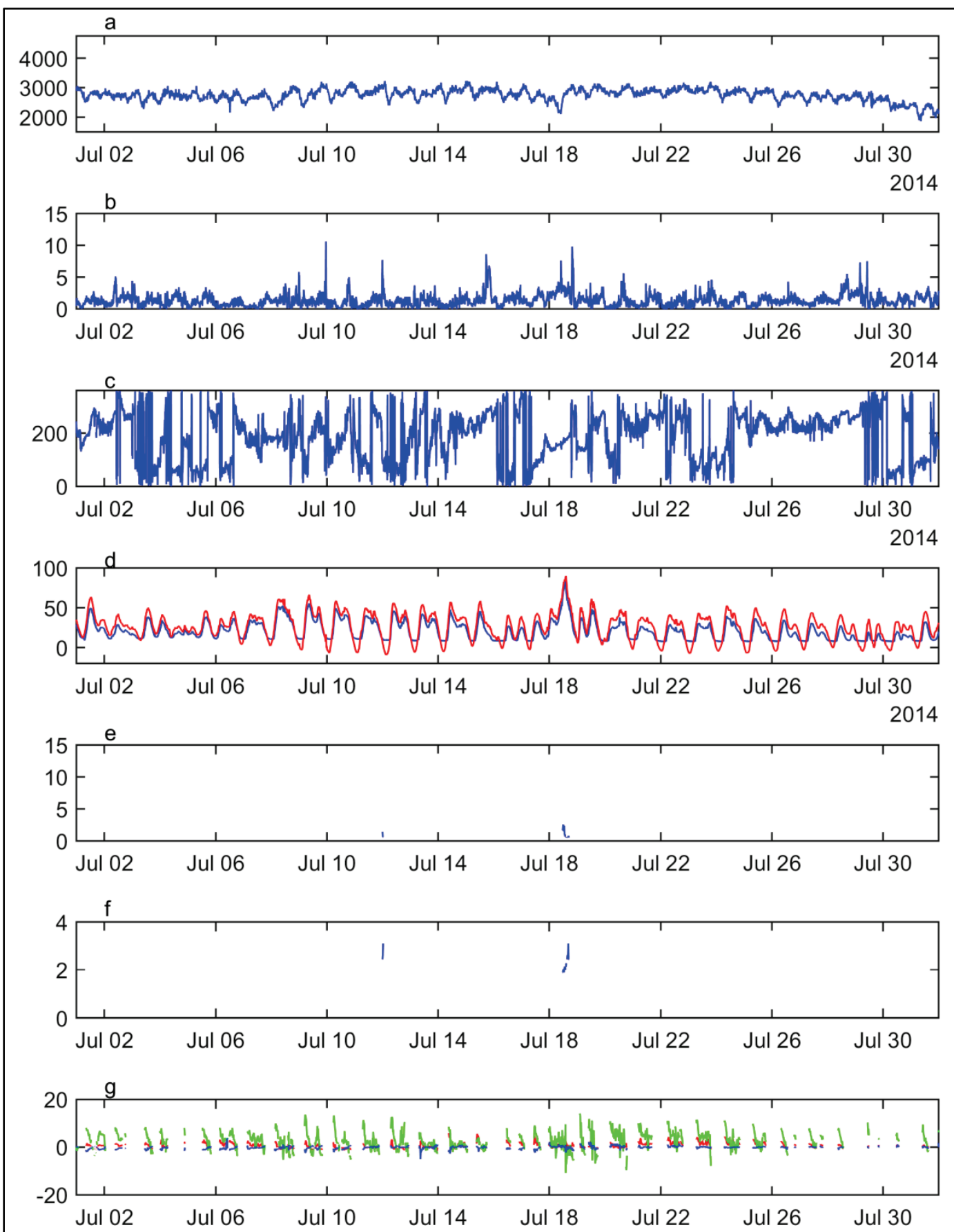
Figure 41. Data for 5 February to 1 March 2014 for Wax Lake Remote Station 2 where a) Wax Lake Discharge $\left(\mathrm{m}^{3} / \mathrm{s}\right)$, b) Wind Speed $(\mathrm{m} / \mathrm{s}), \mathrm{c}$ ) Wind Direction (degrees), d) Water Level (blue -local, red-Buoy AMRL1, cm), e) Wave Height (cm), f) Wave Period (s), and g) Velocity (rednorth, green-east, blue-vertical, $\mathrm{cm} / \mathrm{s})$.

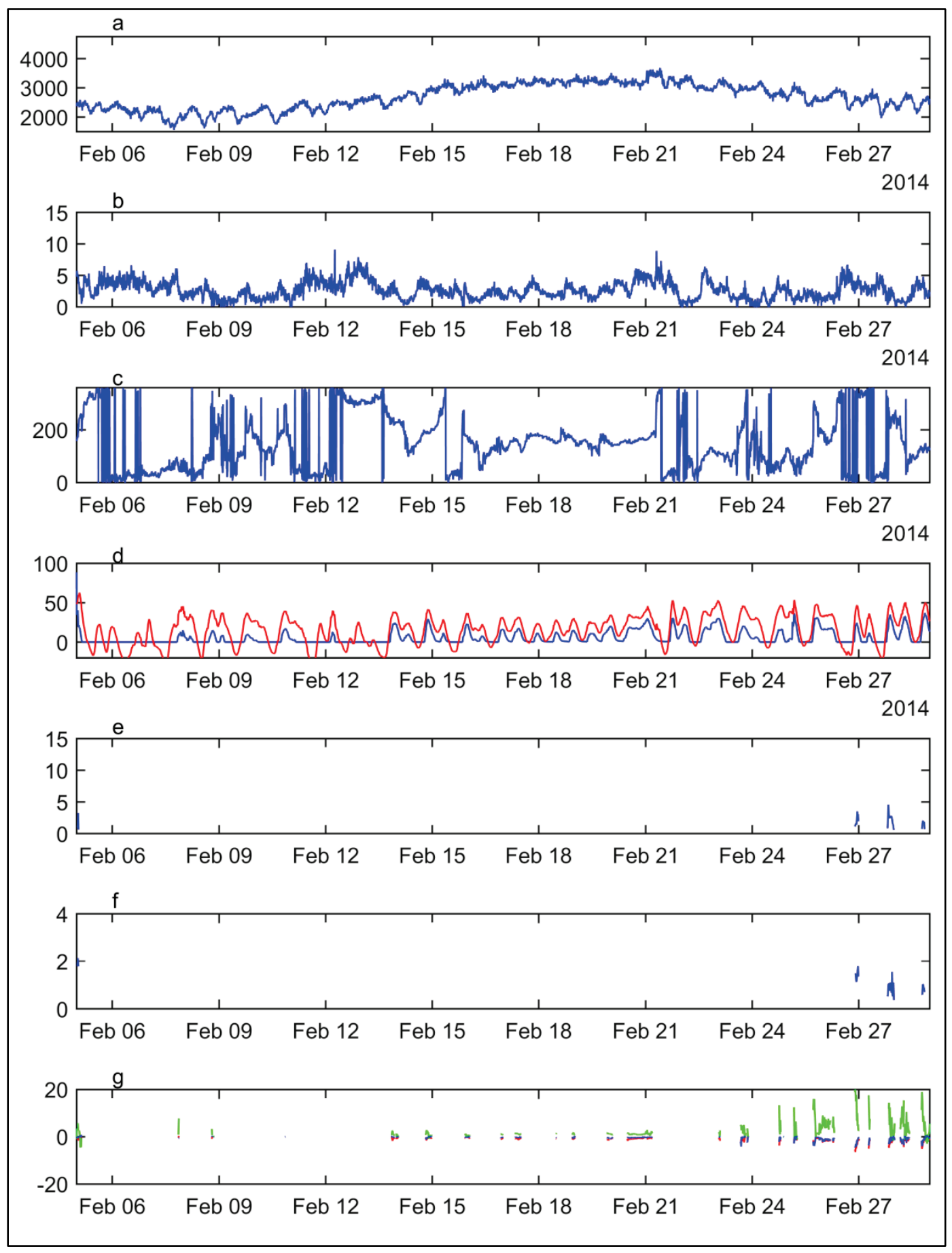


Figure 42. Data for 1 March to 1 April 2014 for Wax Lake Remote Station 2 where a) Wax Lake Discharge $\left(\mathrm{m}^{3} / \mathrm{s}\right)$, b) Wind speed $\left.(\mathrm{m} / \mathrm{s}), \mathrm{c}\right)$ Wind Direction (degrees), d) Water Level (blue -local, red-Buoy AMRL1, cm), e) Wave Height (cm), f) Wave Period (s), and g) Velocity (rednorth, green-east, blue-vertical, cm/s).

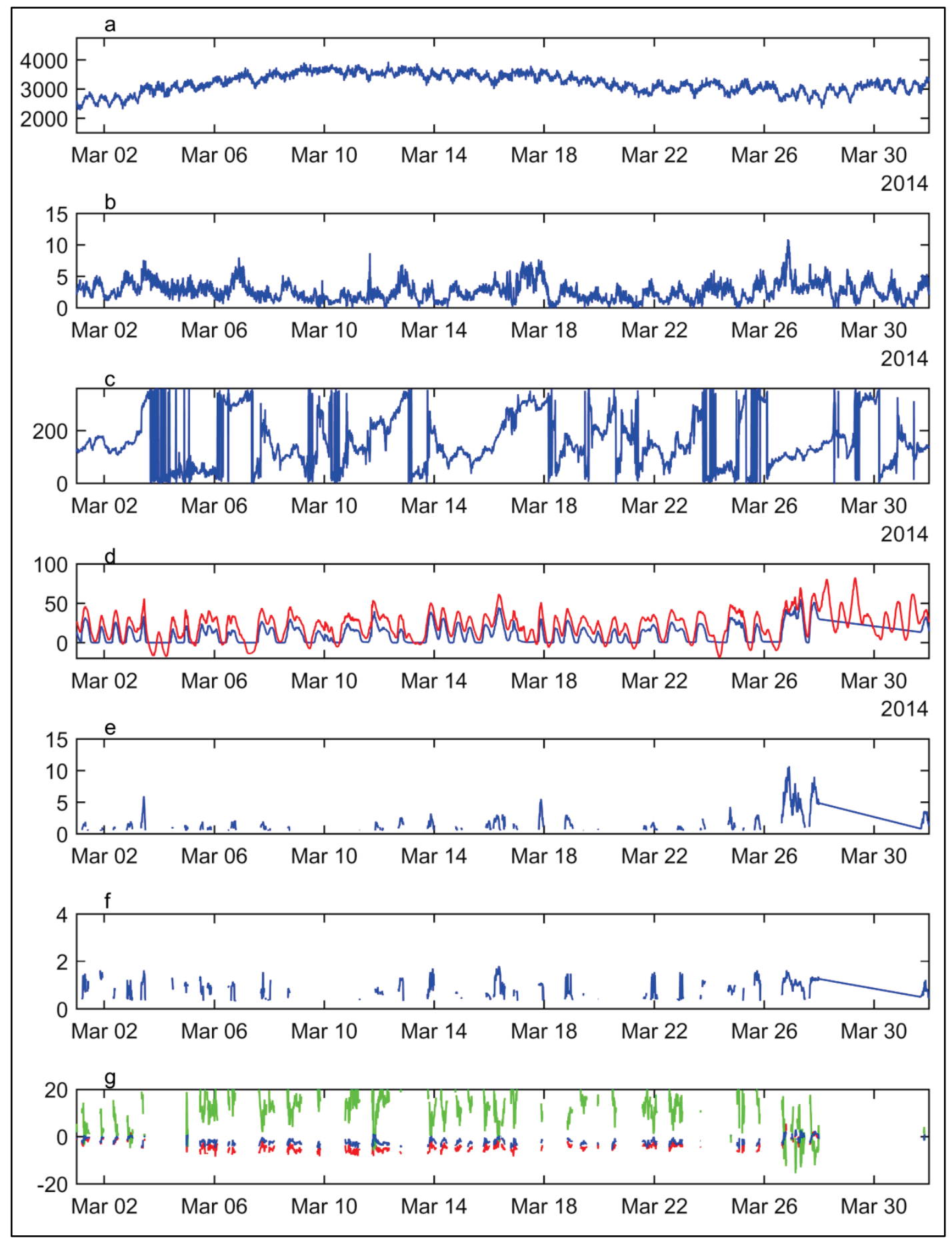


Figure 43. Data for 1 April to 1 May 2014 for Wax Lake Remote Station 2 where a) Wax Lake Discharge $\left(\mathrm{m}^{3} / \mathrm{s}\right)$, b) Wind Speed $(\mathrm{m} / \mathrm{s})$, c) Wind Direction (degrees), d) Water Level (blue local, red-Buoy AMRL1, cm), e) Wave Height (cm), f) Wave Period (s), and g) Velocity (rednorth, green-east, blue-vertical, $\mathrm{cm} / \mathrm{s}$ ).

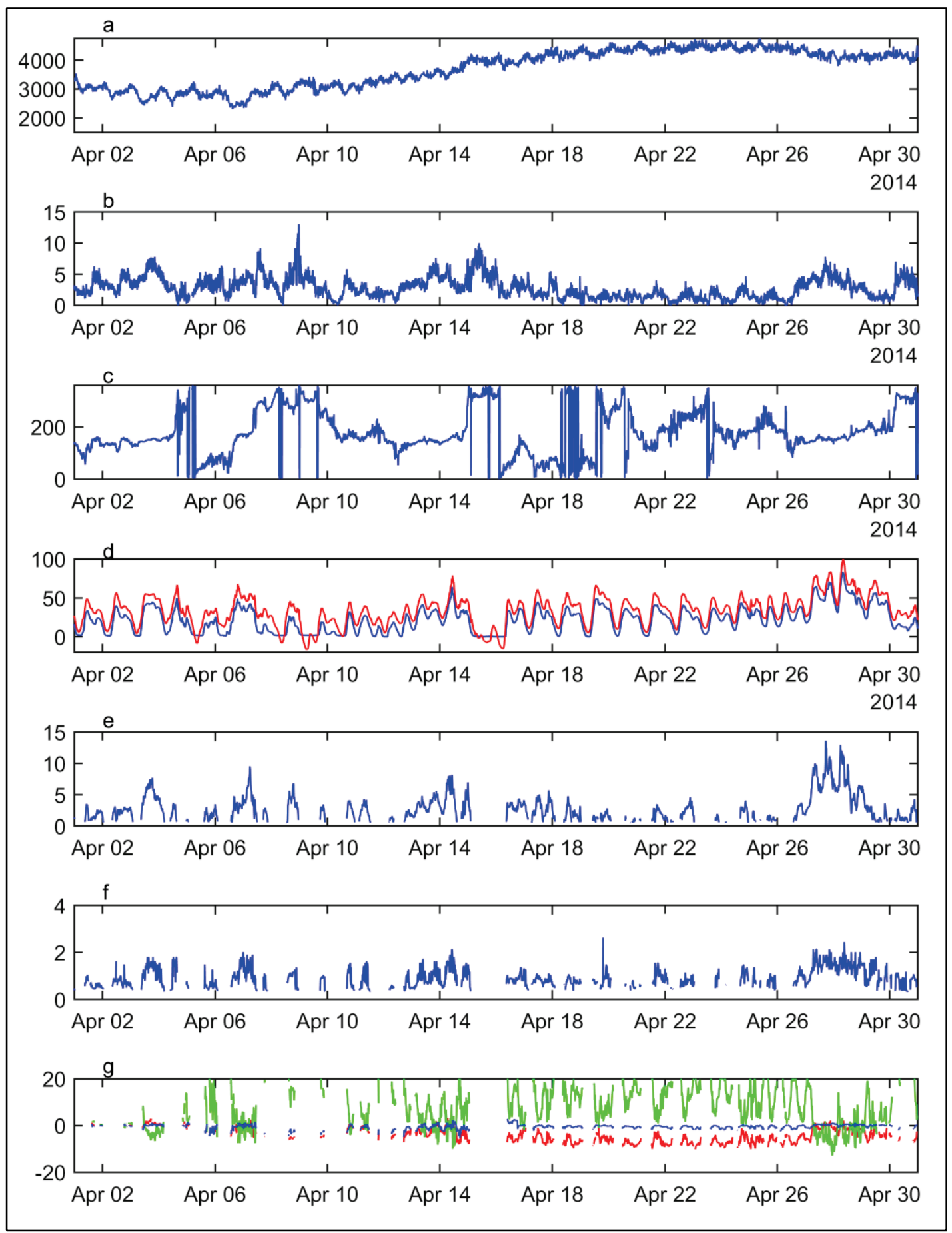


Figure 44. Data for 1 May to 1 June 2014 for Wax Lake Remote Station 2 where a) Wax Lake Discharge $\left(\mathrm{m}^{3} / \mathrm{s}\right)$, b) Wind Speed $(\mathrm{m} / \mathrm{s})$, c) Wind Direction (degrees), d) Water Level (blue local, red-Buoy AMRL1, cm), e) Wave Height (cm), f) Wave Period (s), and g) Velocity (rednorth, green-east, blue-vertical, $\mathrm{cm} / \mathrm{s}$ ).

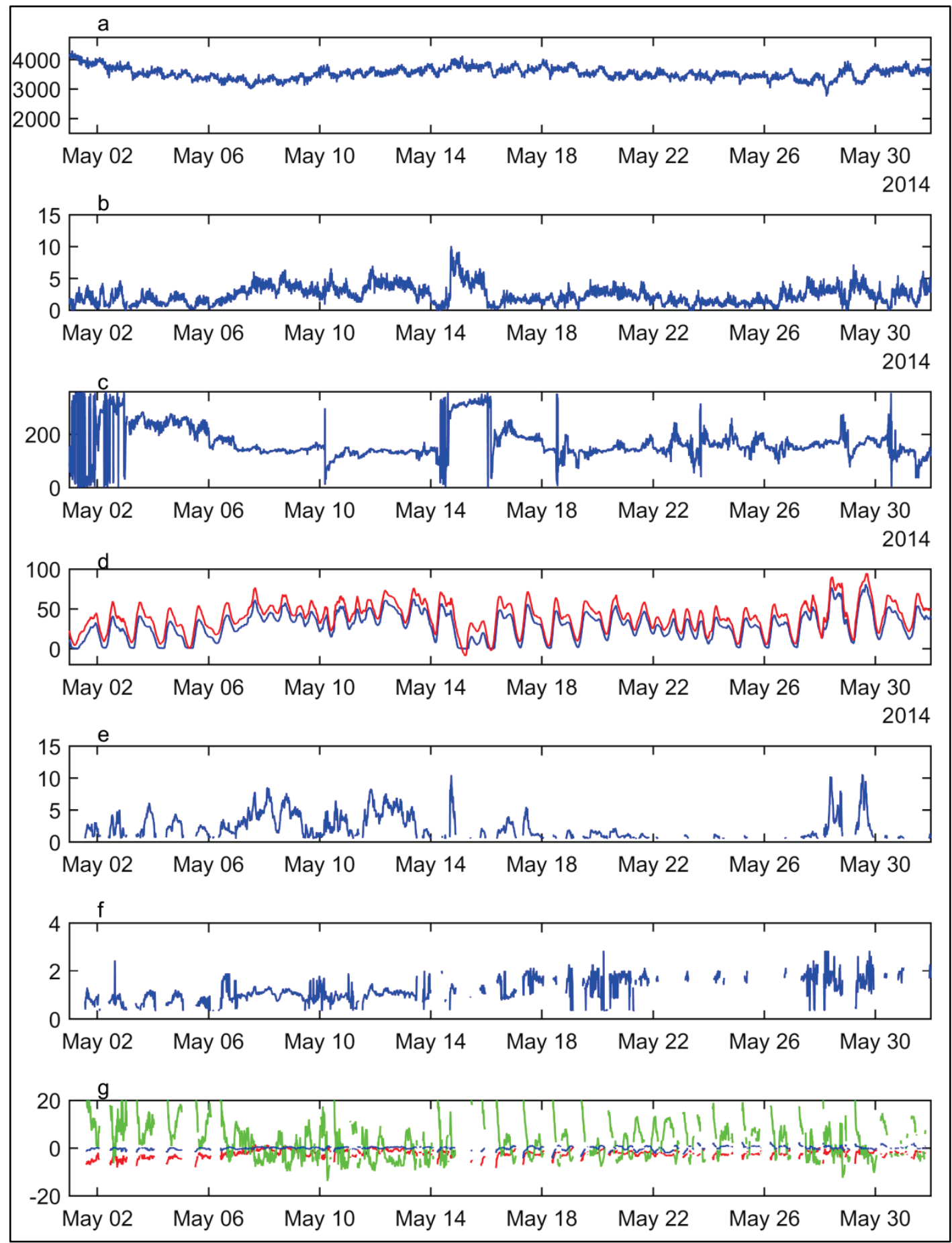


Figure 45. Data for 1 June to 1 July 2014 for Wax Lake Remote Station 2 where a) Wax Lake Discharge $\left(\mathrm{m}^{3} / \mathrm{s}\right)$, b) Wind Speed $(\mathrm{m} / \mathrm{s})$, c) Wind Direction (degrees), d) Water Level (blue local, red-Buoy AMRL1, cm), e) Wave Height (cm), f) Wave Period (s), and g) Velocity (rednorth, green-east, blue-vertical, $\mathrm{cm} / \mathrm{s}$ ).

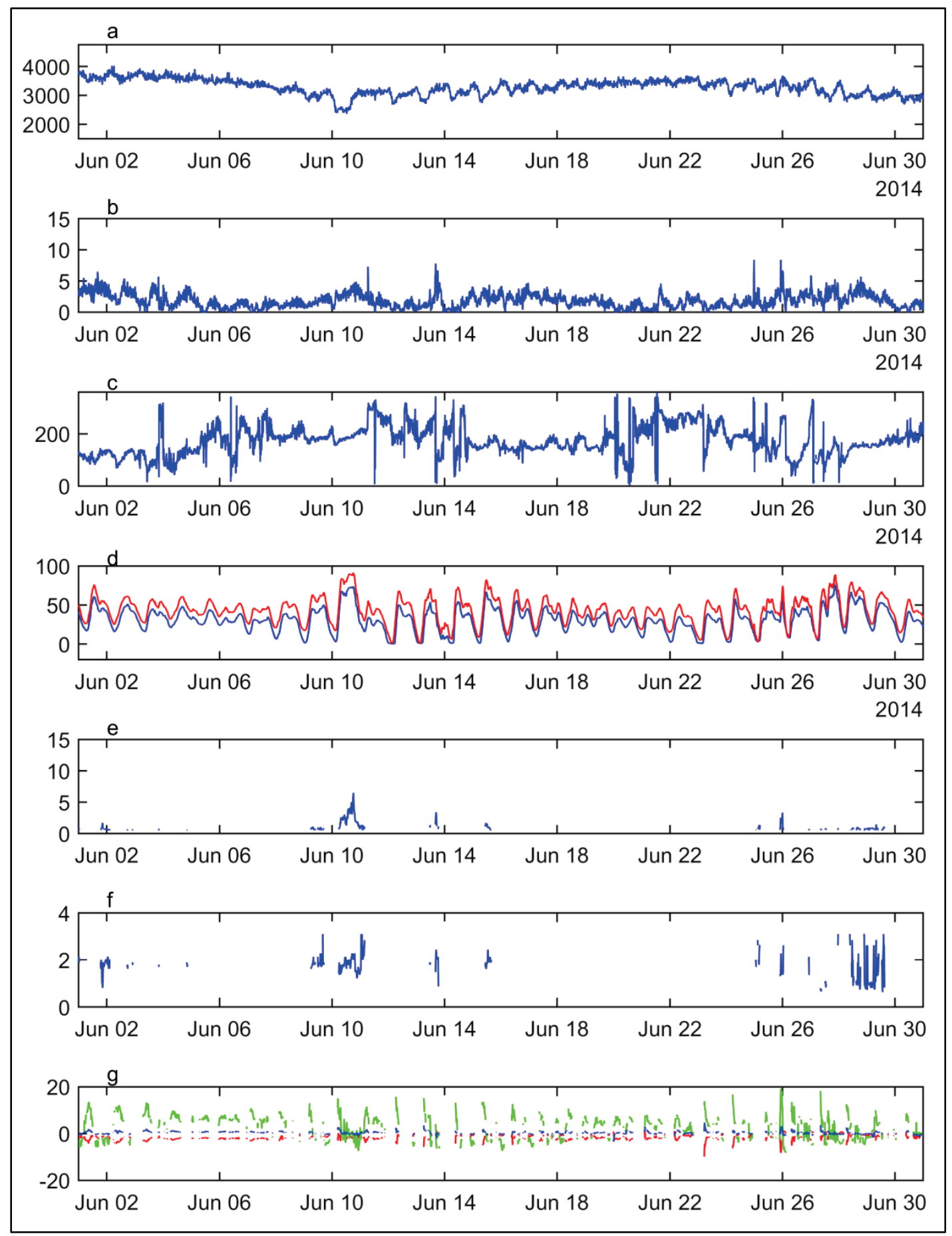


Figure 46. Data for 1 July to 1 August 2014 for Wax Lake Remote Station 2 where a) Wax Lake Discharge $\left.\left(\mathrm{m}^{3} / \mathrm{s}\right), \mathrm{b}\right)$ Wind Speed $(\mathrm{m} / \mathrm{s})$, c) Wind Direction (degrees), d) Water Level (blue -local, red-Buoy AMRL1, cm), e) Wave Height (cm), f) Wave Period (s), and g) Velocity (rednorth, green-east, blue-vertical, $\mathrm{cm} / \mathrm{s})$.

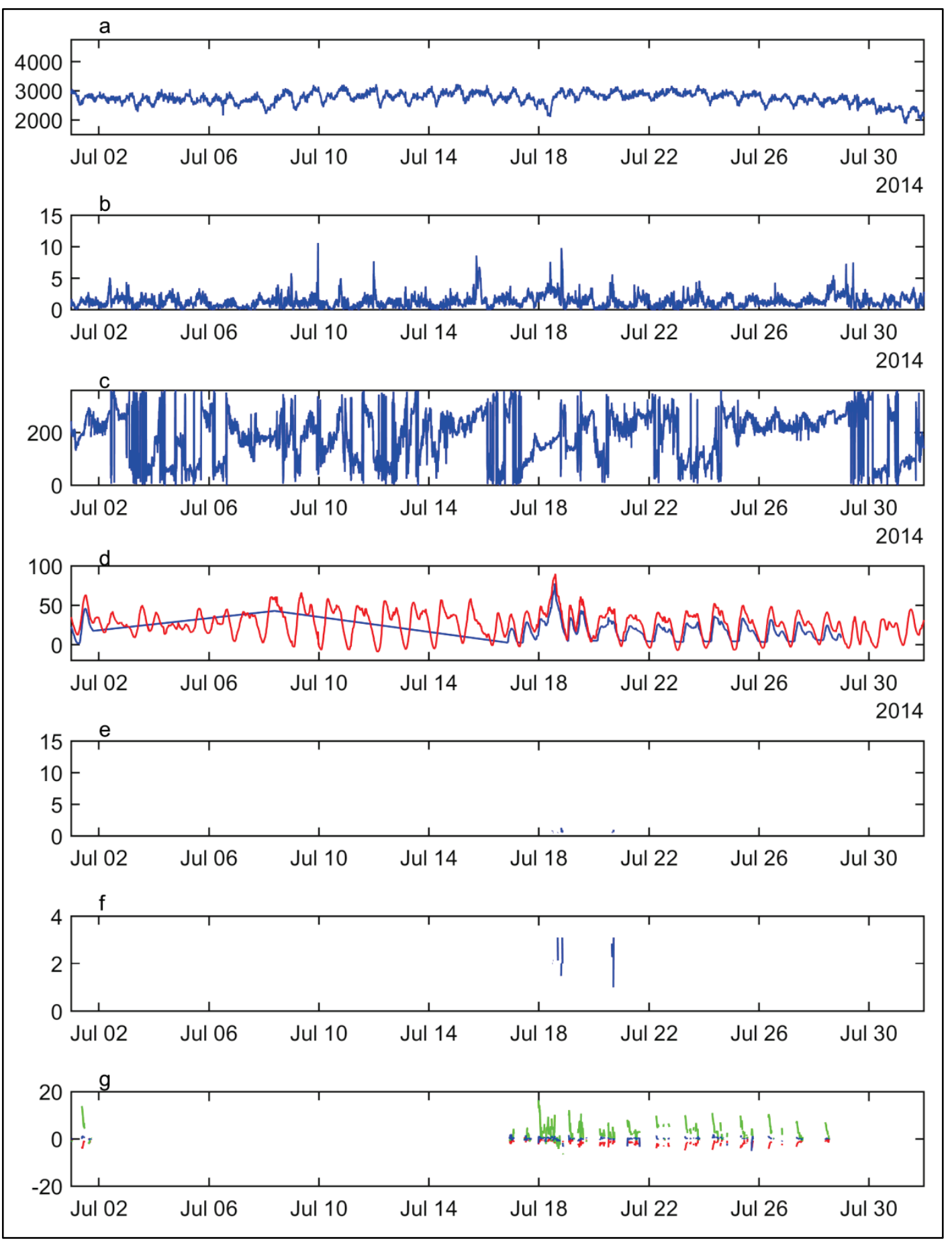


Figure 47. Data for 5 February to 1 March 2014 for Wax Lake Remote Station 3 where a) Wax Lake Discharge $\left(\mathrm{m}^{3} / \mathrm{s}\right)$, b) Wind speed $(\mathrm{m} / \mathrm{s}), \mathrm{c}$ ) Wind Direction (degrees), d) Water Level (blue -local, red-Buoy AMRL1, cm), e) Wave Height (cm), f) Wave Period (s), and g) Velocity (rednorth, green-east, blue-vertical, cm/s).

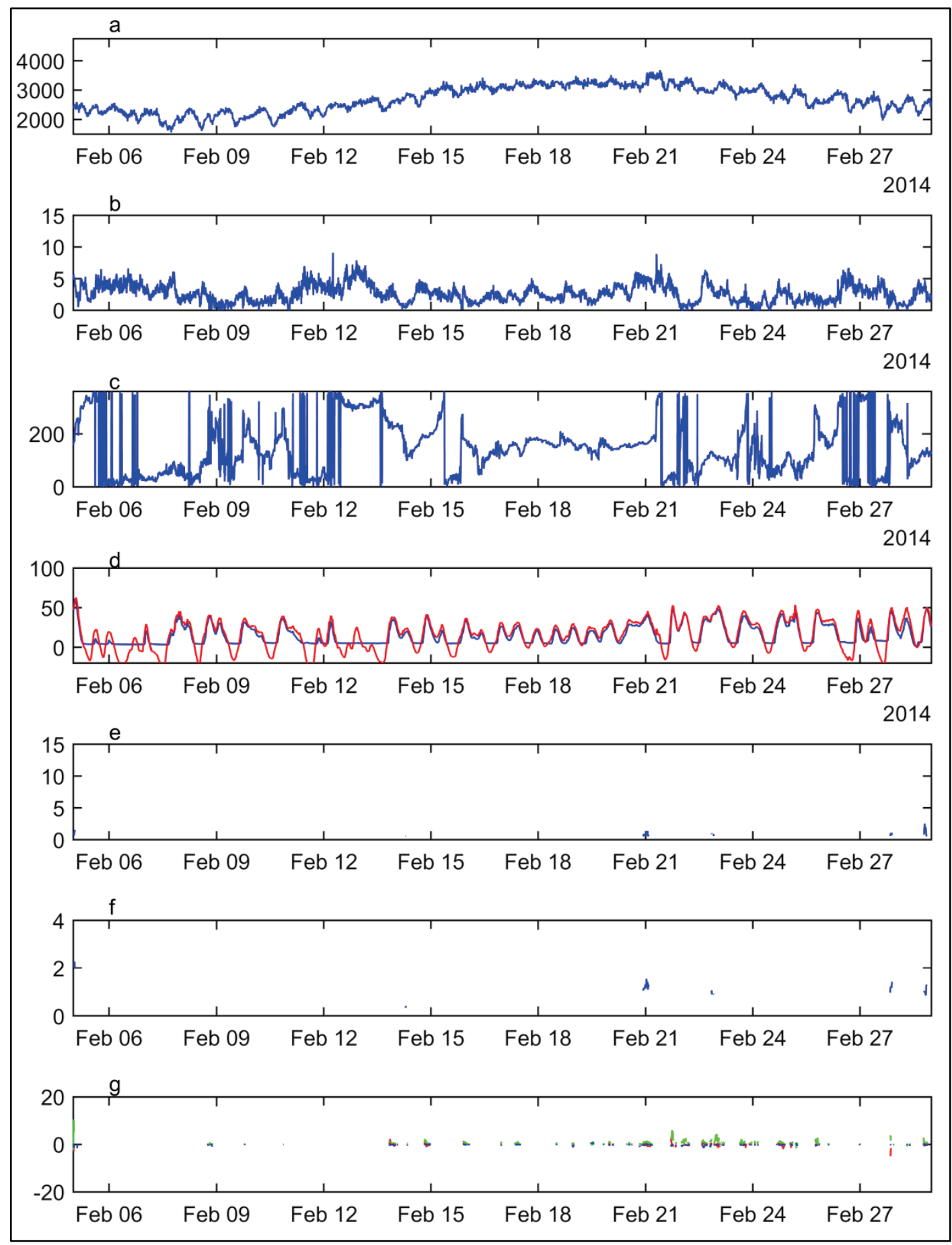


Figure 48. Data for 1 March to 1 April 2014 for Wax Lake Remote Station 3 where a) Wax Lake Discharge $\left.\left(\mathrm{m}^{3} / \mathrm{s}\right), \mathrm{b}\right)$ Wind Speed $(\mathrm{m} / \mathrm{s})$, c) Wind Direction (degrees), d) Water Level (blue -local, red-Buoy AMRL1, cm), e) Wave Height (cm), f) Wave Period (s), and g) Velocity (rednorth, green-east, blue-vertical, $\mathrm{cm} / \mathrm{s})$.

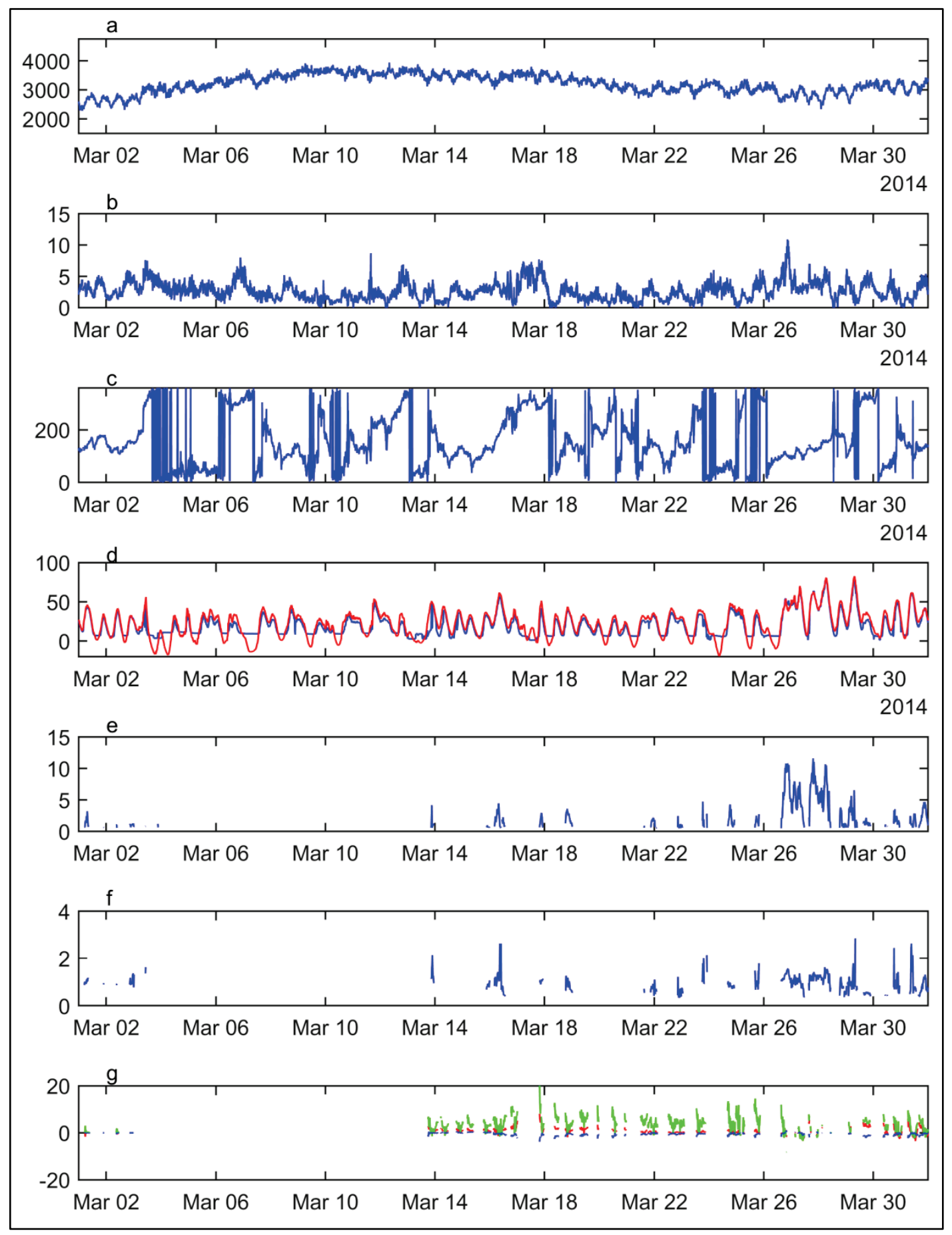


Figure 49. Data for 1 April to 1 May 2014 for Wax Lake Remote Station 3 where a) Wax Lake Discharge $\left(\mathrm{m}^{3} / \mathrm{s}\right)$, b) Wind Speed $(\mathrm{m} / \mathrm{s})$, c) Wind Direction (degrees), d) Water Level (blue local, red-Buoy AMRL1, cm), e) Wave Height (cm), f) Wave Period (s), and g) Velocity (rednorth, green-east, blue-vertical, $\mathrm{cm} / \mathrm{s}$ ).

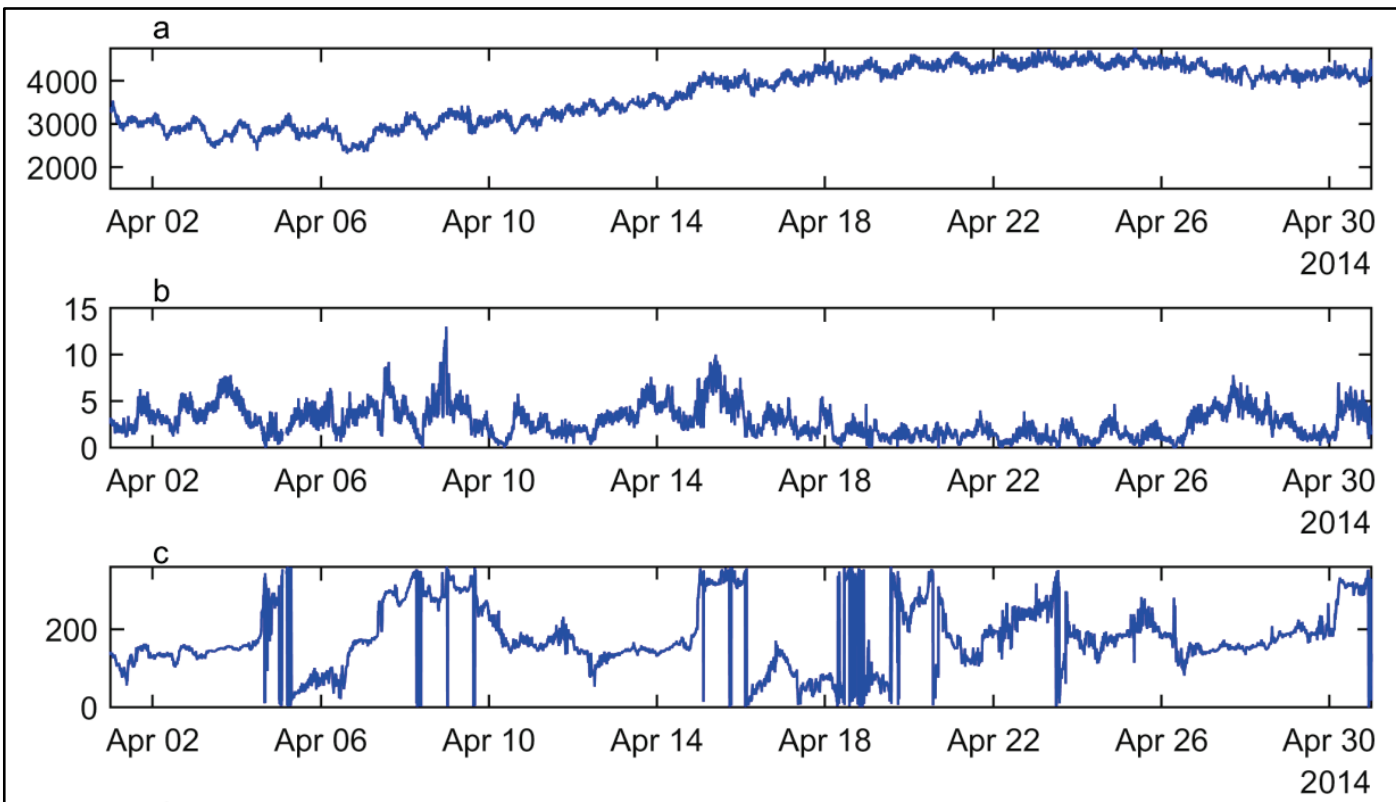

$\underset{\text { Apr } 02}{\text { Apr } 06} \underset{\text { Apr } 10}{\text { Apr } 14} \underset{\text { Apr } 18}{\text { Apr } 22} \underset{\text { Apr } 26}{\text { Apr } 30}$

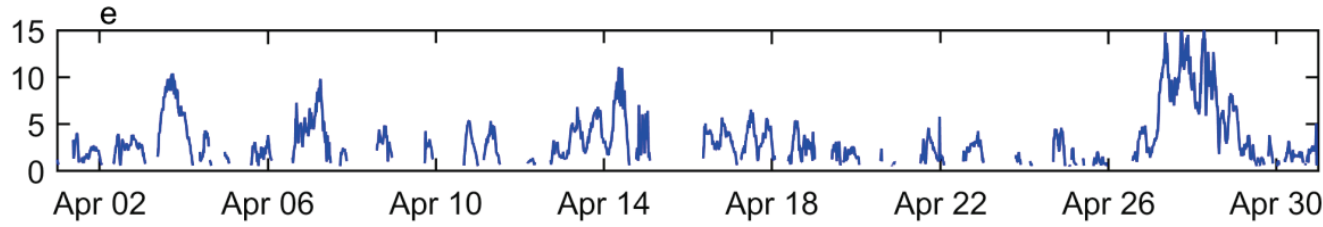

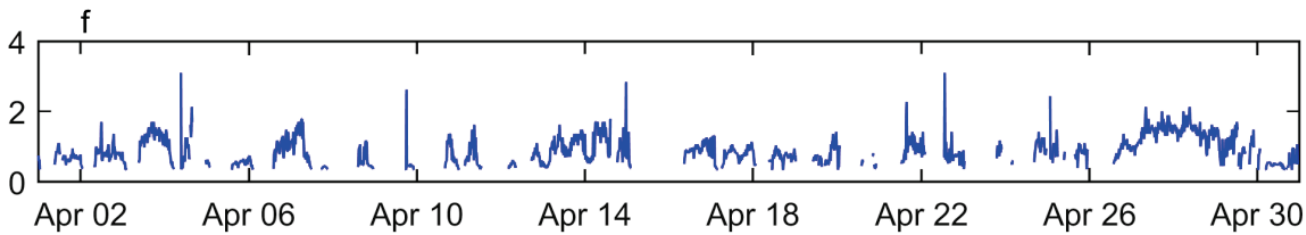

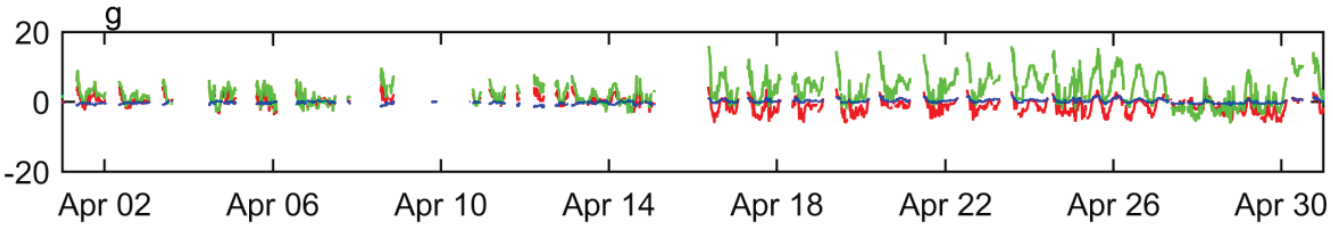


Figure 50. Data for 1 May to 1 June 2014 for Wax Lake Remote Station 3 where a) Wax Lake Discharge $\left(\mathrm{m}^{3} / \mathrm{s}\right)$, b) Wind Speed $(\mathrm{m} / \mathrm{s})$, c) Wind Direction (degrees), d) Water Level (blue local, red-Buoy AMRL1, cm), e) Wave Height (cm), f) Wave Period (s), and g) Velocity (rednorth, green-east, blue-vertical, $\mathrm{cm} / \mathrm{s}$ ).

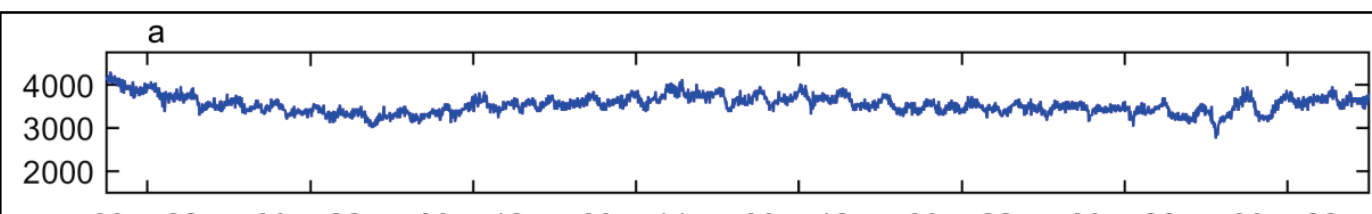

May 02 May 06 May 10 May 14 May 18 May 22 May 26 May 30
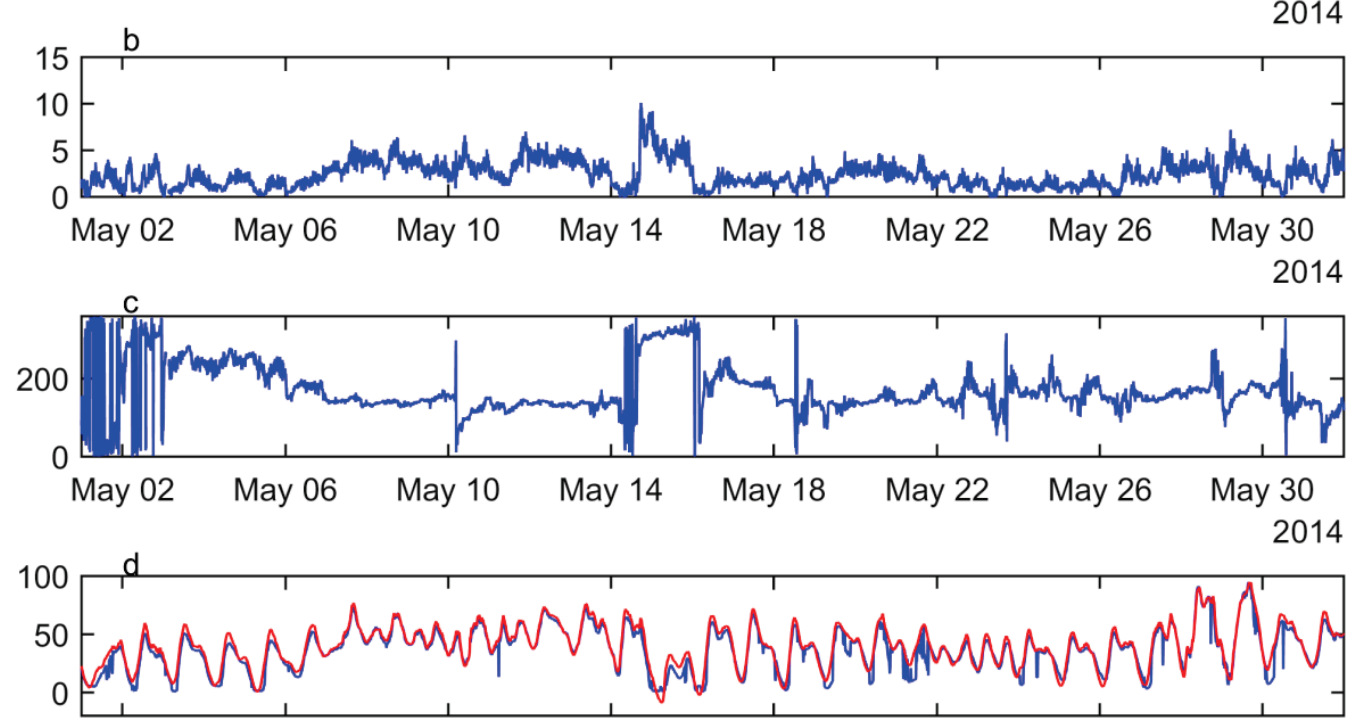

May 02 May 06 May $10 \quad$ May 14 May 18 May 22 May 26 May 30
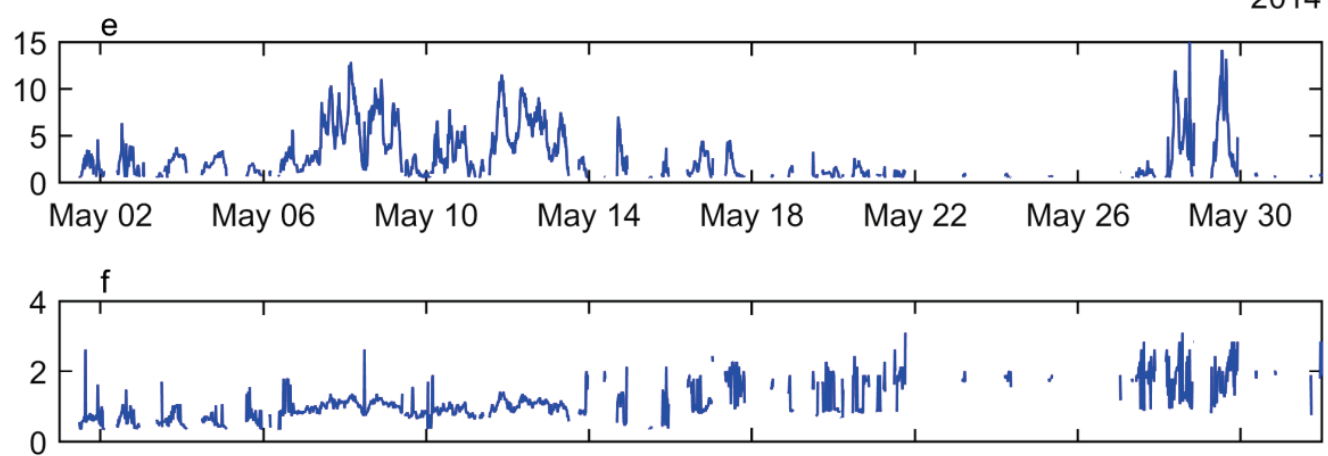

May 02 May 06 May 10 May 14 May 18 May 22 May 26 May 30

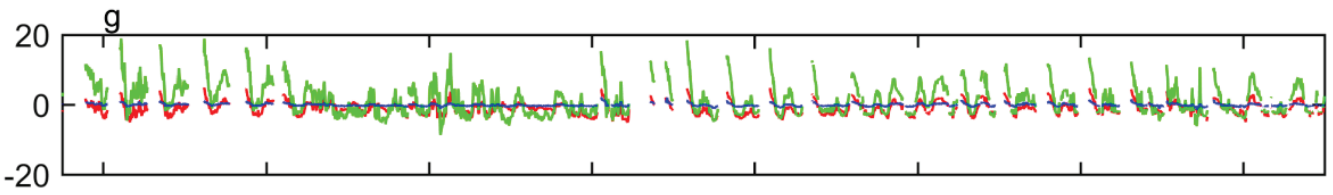

May 02 May 06 May 10 May 14 May 18 May 22 May 26 May 30 
Figure 51. Data for 1 June to 1 July 2014 for Wax Lake Remote Station 3 where a) Wax Lake Discharge $\left(\mathrm{m}^{3} / \mathrm{s}\right)$, b) Wind Speed $(\mathrm{m} / \mathrm{s})$, c) Wind Direction (degrees), d) Water Level (blue local, red-Buoy AMRL1, cm), e) Wave Height (cm), f) Wave Period (s), and g) Velocity (rednorth, green-east, blue-vertical, cm/s).
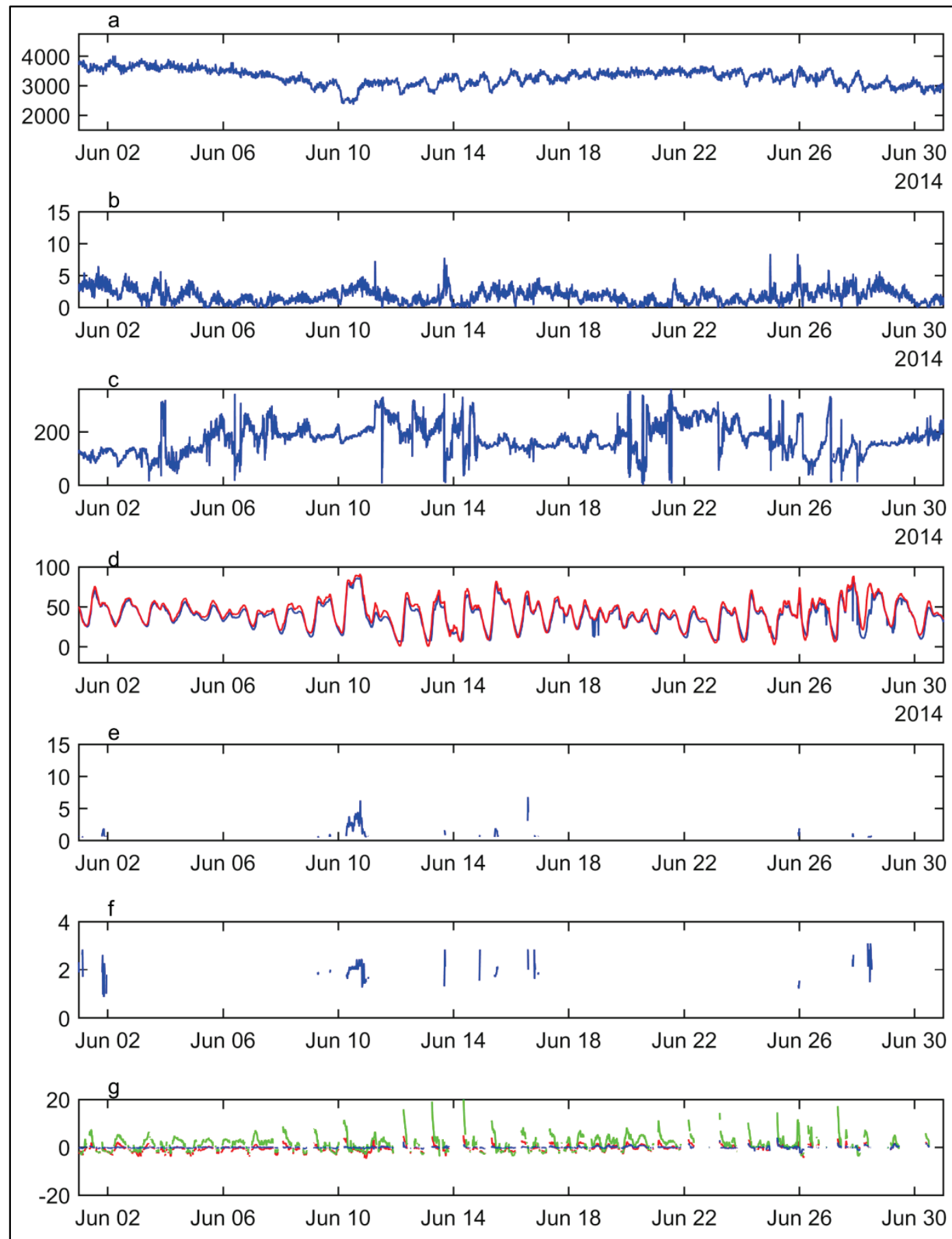
Figure 52. Data for 1 July to 1 August 2014 for Wax Lake Remote Station 3 where a) Wax Lake Discharge $\left.\left(\mathrm{m}^{3} / \mathrm{s}\right), \mathrm{b}\right)$ Wind Speed $(\mathrm{m} / \mathrm{s})$, c) Wind Direction (degrees), d) Water Level (blue -local, red-Buoy AMRL1, cm), e) Wave Height (cm), f) Wave Period (s), and g) Velocity (rednorth, green-east, blue-vertical, cm/s).

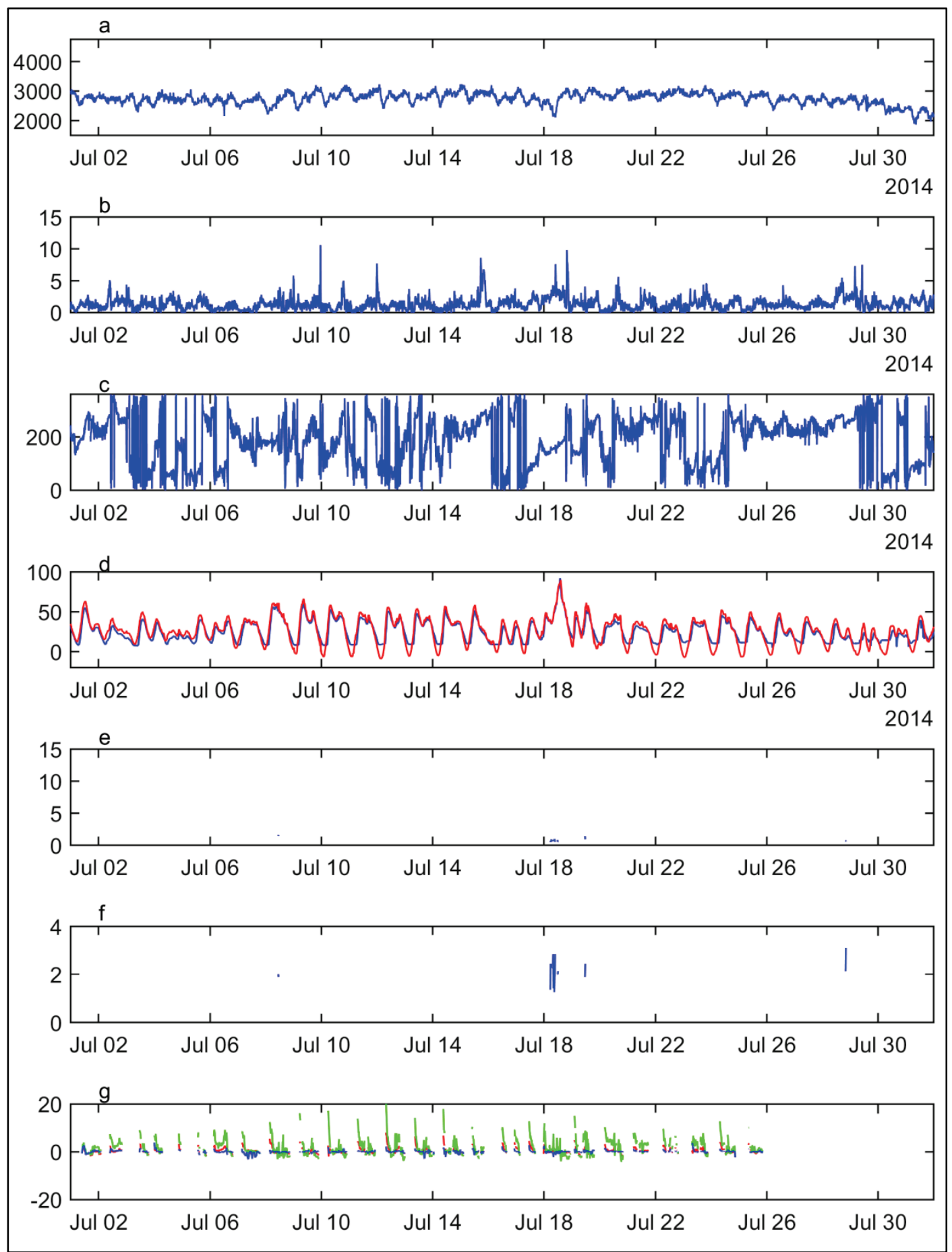


Figure 53. Data for 5 February to 1 March 2014 for Wax Lake Remote Station 4 where a) Wax Lake Discharge $\left.\left(\mathrm{m}^{3} / \mathrm{s}\right), \mathrm{b}\right)$ Wind Speed $(\mathrm{m} / \mathrm{s})$, c) Wind Direction (degrees), d) Water Level (blue -local, red-Buoy AMRL1, cm), e) Wave Height (cm), f) Wave Period (s), and g) Velocity (rednorth, green-east, blue-vertical, cm/s).

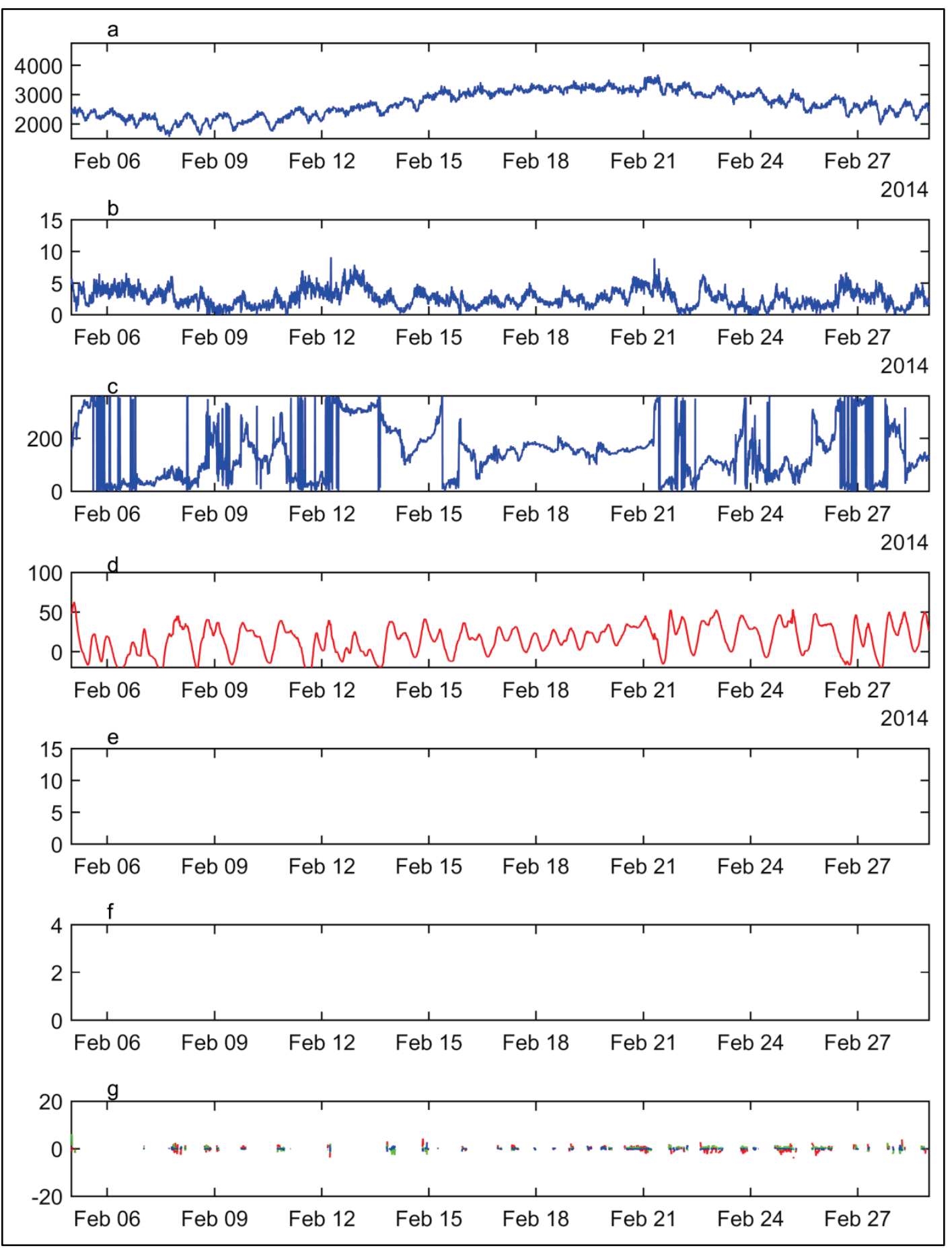


Figure 54. Data for 1 March to 1 April 2014 for Wax Lake Remote Station 4 where a) Wax Lake Discharge $\left.\left(\mathrm{m}^{3} / \mathrm{s}\right), \mathrm{b}\right)$ Wind Speed $(\mathrm{m} / \mathrm{s})$, c) Wind Direction (degrees), d) Water Level (blue -local, red-Buoy AMRL1, cm), e) Wave Height (cm), f) Wave Period (s), and g) Velocity (rednorth, green-east, blue-vertical, cm/s).

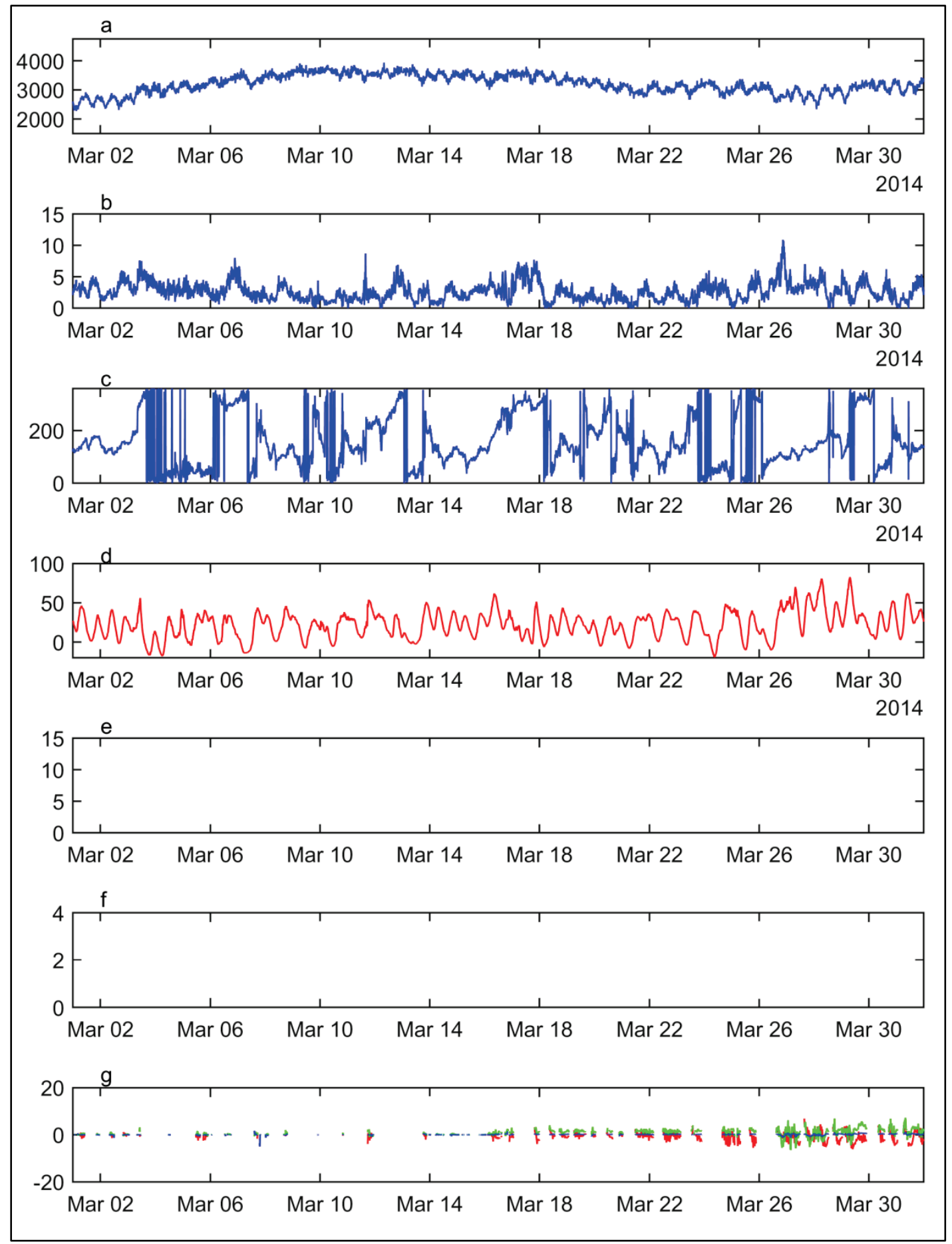


Figure 55. Data for 1 April to 1 May 2014 for Wax Lake Remote Station 4 where a) Wax Lake Discharge $\left(\mathrm{m}^{3} / \mathrm{s}\right)$, b) Wind Speed $(\mathrm{m} / \mathrm{s}), \mathrm{c}$ ) Wind Direction (Degrees), d) Water Level (blue local, red-Buoy AMRL1, cm), e) Wave Height (cm), f) Wave Period (s), and g) Velocity (rednorth, green-east, blue-vertical, $\mathrm{cm} / \mathrm{s}$ ).

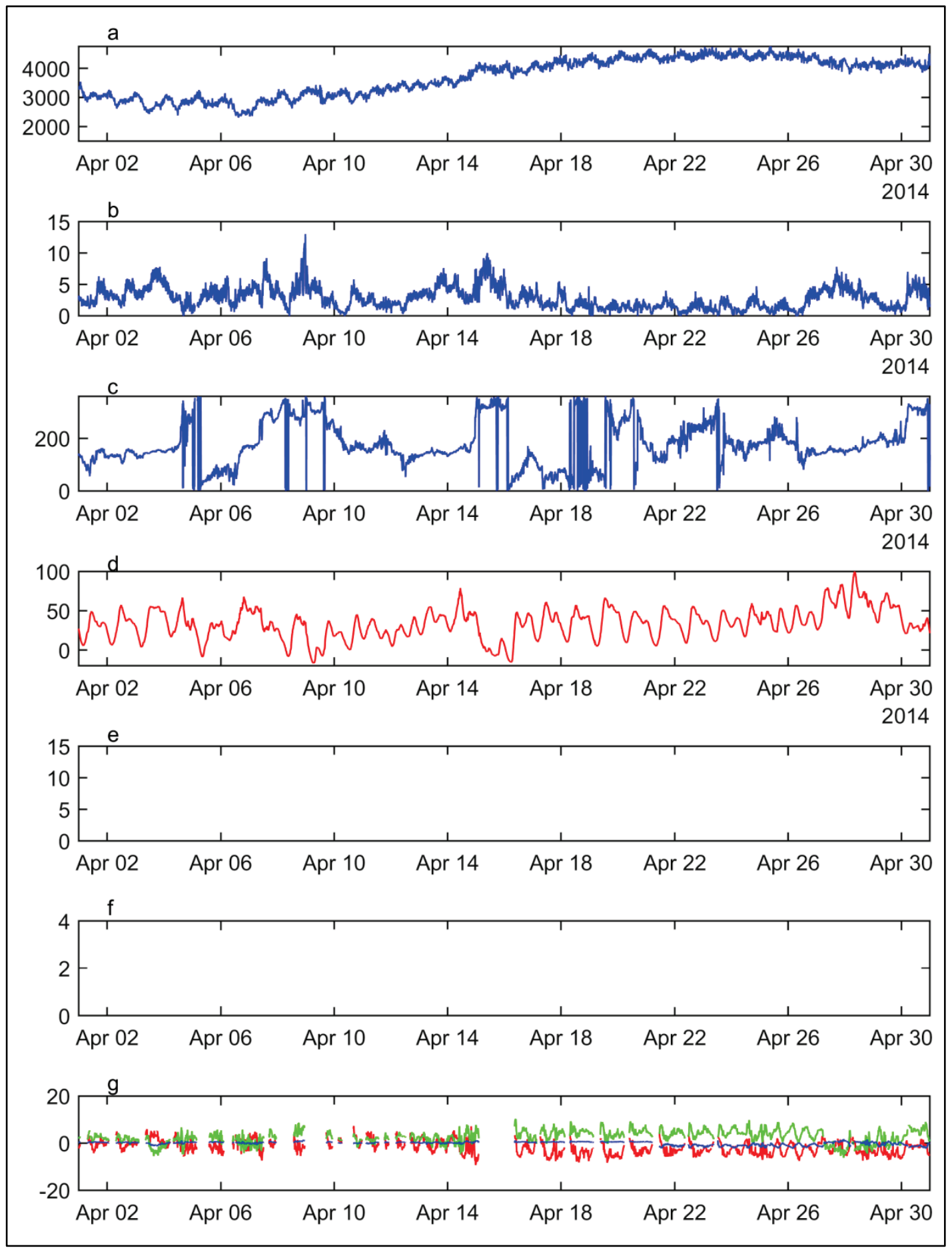


Figure 56. Data for 1 May to 1 June 2014 for Wax Lake Remote Station 4 where a) Wax Lake Discharge $\left(\mathrm{m}^{3} / \mathrm{s}\right)$, b) Wind Speed $\left.(\mathrm{m} / \mathrm{s}), \mathrm{c}\right)$ Wind Direction (Degrees), d) Water Level (blue local, red-Buoy AMRL1, cm), e) Wave Height (cm), f) Wave Period (s), and g) Velocity (rednorth, green-east, blue-vertical, $\mathrm{cm} / \mathrm{s}$ ).

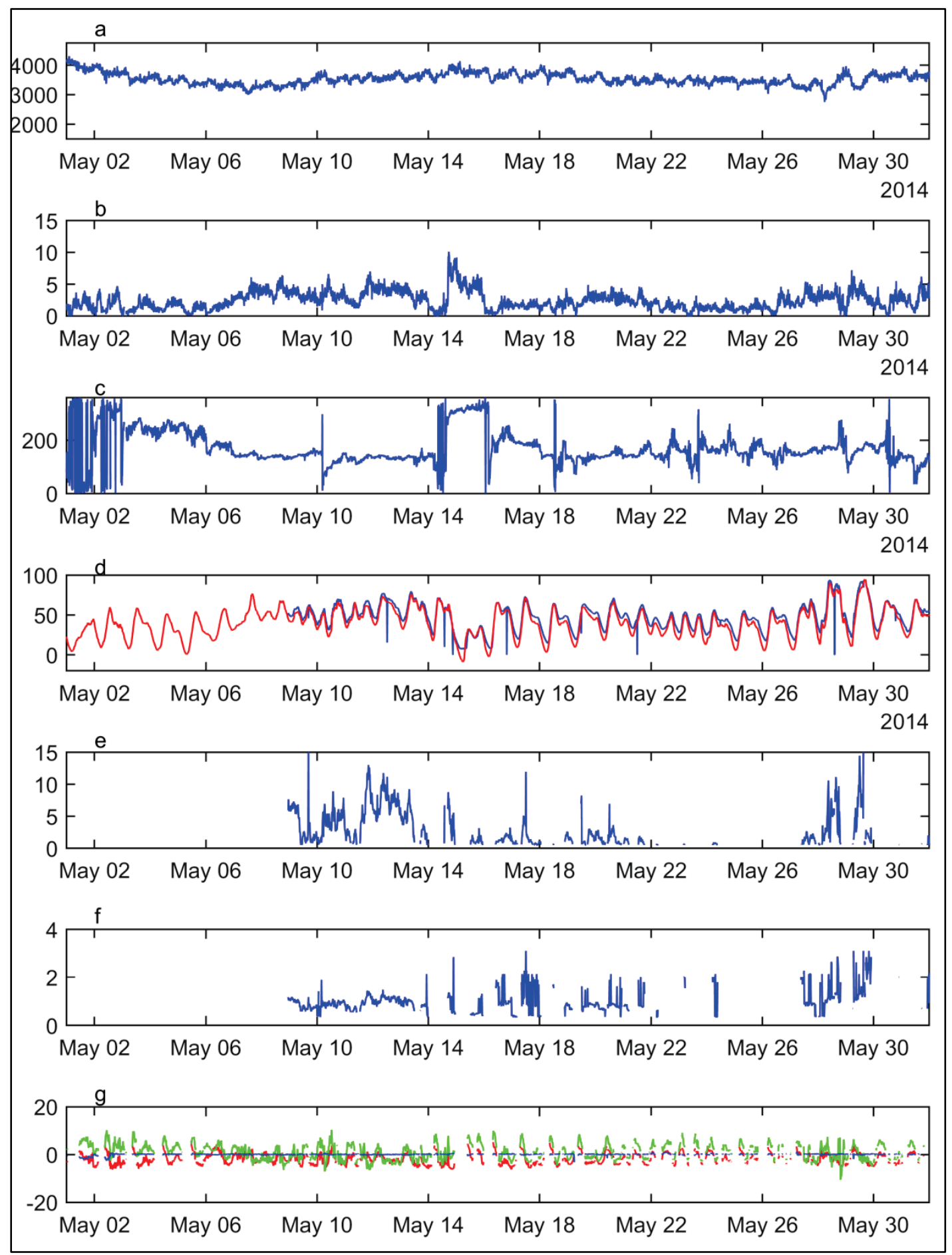


Figure 57. Data for 1 June to 1 July 2014 for Wax Lake Remote Station 4 where a) Wax Lake Discharge $\left(\mathrm{m}^{3} / \mathrm{s}\right)$, b) Wind Speed $(\mathrm{m} / \mathrm{s})$, c) Wind Direction (degrees), d) Water Level (blue local, red-Buoy AMRL1, cm), e) Wave Height (cm), f) Wave Period (s), and g) Velocity (rednorth, green-east, blue-vertical, $\mathrm{cm} / \mathrm{s}$ ).

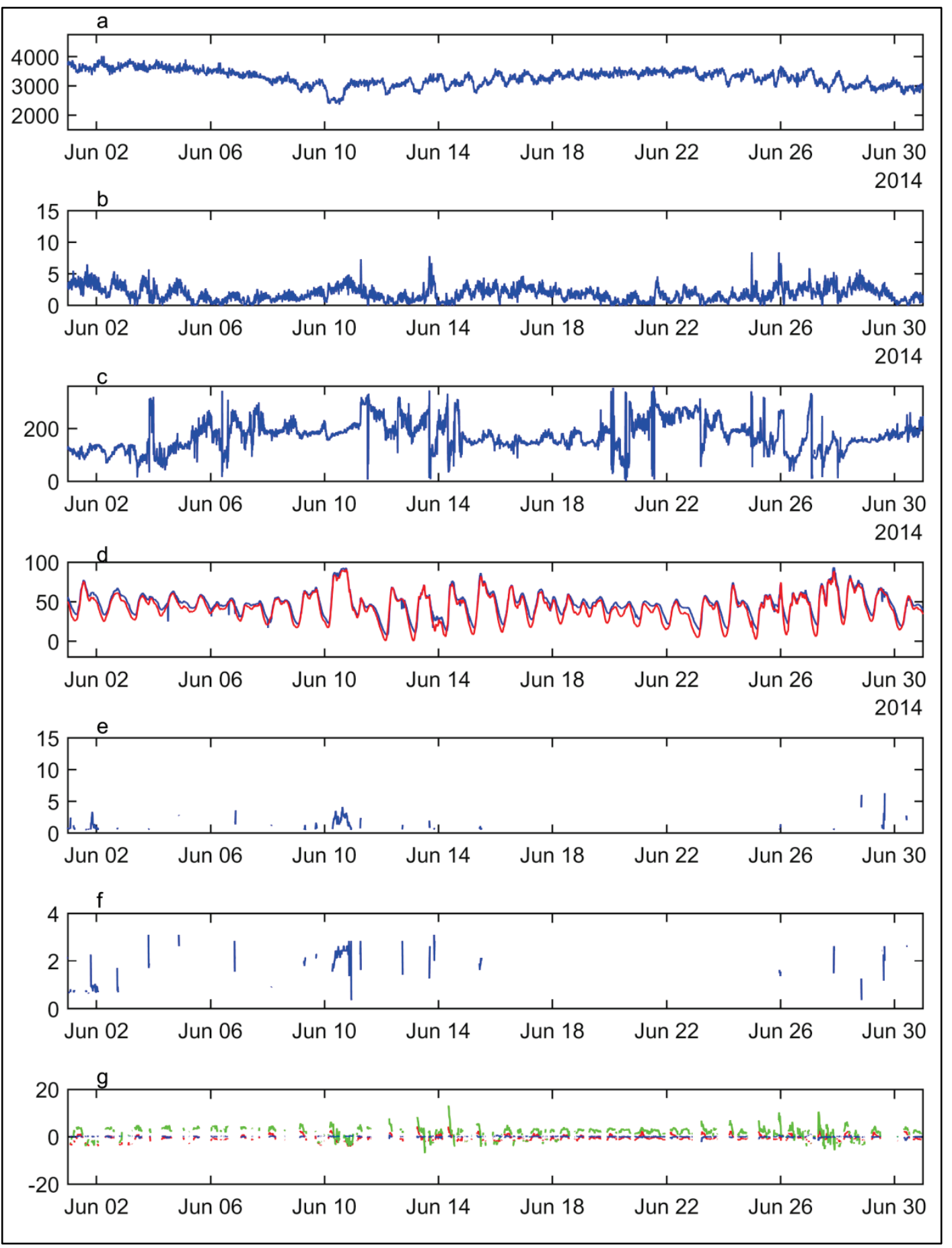


Figure 58. Data for 1 July to 1 August 2014 for Wax Lake Remote Station 4 where a) Wax Lake Discharge $\left.\left(\mathrm{m}^{3} / \mathrm{s}\right), \mathrm{b}\right)$ Wind Speed $(\mathrm{m} / \mathrm{s})$, c) Wind Direction (degrees), d) Water Level (blue -local, red-Buoy AMRL1, cm), e) Wave Height (cm), f) Wave Period (s), and g) Velocity (rednorth, green-east, blue-vertical, $\mathrm{cm} / \mathrm{s})$.

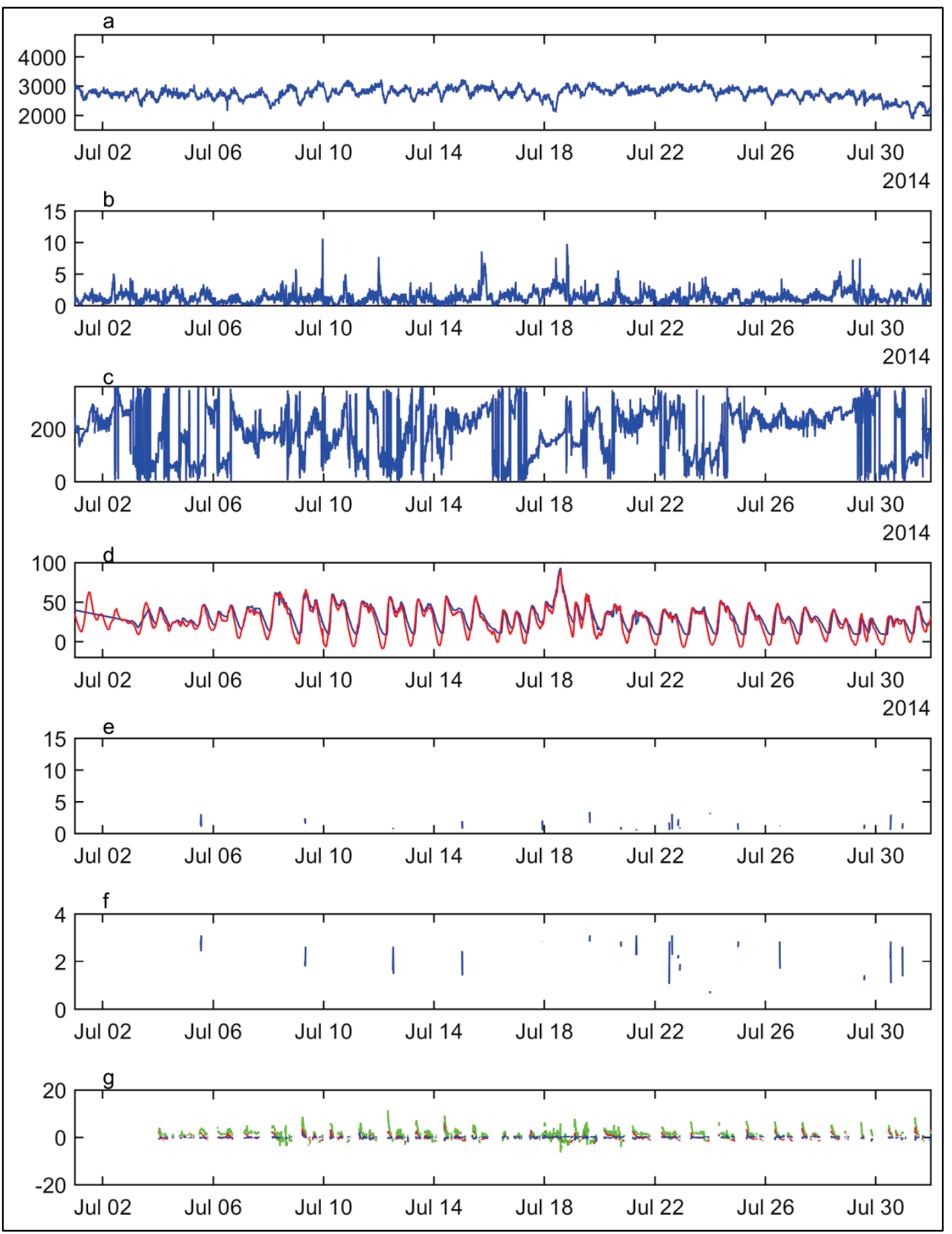




\section{Appendix B: Feldspar Samples to Measure Bed Accretion for Each Station}

Appendix B lists the individual feldspar samples. Several plots were extracted from each site, and up to four thickness measurements were acquired from each plot. In some instances, the plot was too degraded to extract multiple samples. Station averages are presented in the results section. Accumulation (Acc.) rate is order of magnitude estimate based on the 6-month data and is presented as a general reference.

Table 4. Raw feldspar data.

\begin{tabular}{|c|c|c|c|c|c|c|c|}
\hline Station & Plot & Sample 1 & Sample 2 & Sample 3 & Sample 4 & $\begin{array}{c}\text { Station } \\
\text { Mean }\end{array}$ & $\begin{array}{c}\text { Acc. } \\
\text { Rate }\end{array}$ \\
\hline 1 & 1 & 31.5 & 23.6 & 30.8 & & $\mathrm{~mm}$ & $\mathrm{~mm} / \mathrm{yr}$ \\
\hline 1 & 2 & 44.15 & & $\mathrm{~mm}$ & & & \\
\hline 1 & 3 & 64.5 & 37.85 & 69.08 & 66.13 & & \\
\hline 2 & 1 & 44.7 & 41.8 & 58.3 & & 46.18 & 89.7 \\
\hline 2 & 2 & 39.9 & & & & & \\
\hline 3 & 1 & $<2$ & & & & & \\
\hline 3 & 2 & $<2$ & & & & & \\
\hline 4 & 1 & 15.0 & 17.3 & 14.4 & & & \\
\hline
\end{tabular}




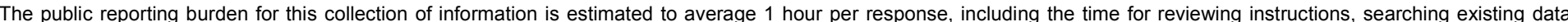

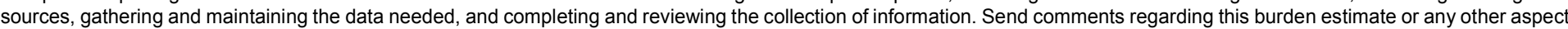

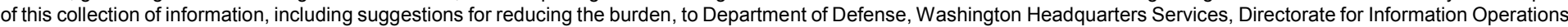

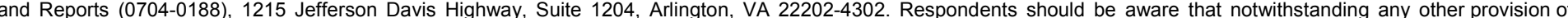
law, no person shall be subject to any penalty for failing to comply with a collection of information if it does not display a currently valid OMB control number.

PLEASE DO NOT RETURN YOUR FORM TO THE ABOVE ADDRESS.

\begin{tabular}{l|l|l}
\hline $\begin{array}{l}\text { 1. REPORT DATE } \\
\text { July } 2017\end{array}$ & $\begin{array}{l}\text { 2. REPORT TYPE } \\
\text { Final Report }\end{array}$ & 3. DATES COVERED (FrOm - To)
\end{tabular}

\section{TITLE AND SUBTITLE}

Sediment Dynamics in a Vegetated Tidally Influenced Interdistributary Island: Wax Lake, Louisiana

5a. CONTRACT NUMBER

5b. GRANT NUMBER

5c. PROGRAM ELEMENT NUMBER

6. AUTHOR(S)

Richard Styles, Duncan Bryant, Joe Gailani, Jarrell Smith, Brandon M. Boyd, and Greg

Snedden 5d. PROJECT NUMBER

5e. TASK NUMBER

5f. WORK UNIT NUMBER

ERDC-219CDR-14-TT-Sediment

Management

8. PERFORMING ORGANIZATION REPORT NUMBER

Coastal and Hydraulics Laboratory

U.S. Army Engineer Research and Development Center

3909 Halls Ferry Road, Vicksburg MS 39180

ERDC/CHL TR-17-12

Wetland and Aquatic Research Center

624 N. Fourth St.

U.S. Geological Survey

Baton Rouge, LA 70803

9. SPONSORING/MONITORING AGENCY NAME(S) AND ADDRESS(ES)

U.S. Army Engineer Research and Development Center

3909 Halls Ferry Road

Vicksburg, MS 39180-6199

10. SPO

11. SPONSOR/MONITOR'S REPORT NUMBER(S)

12. DISTRIBUTION/AVAILABILITY STATEMENT

Approved for public release; distribution is unlimited.

13. SUPPLEMENTARY NOTES

\section{ABSTRACT}

River deltas are maintained by a continuous supply of terrestrial sediments that provide critical land-building material to help sustain and protect coastal communities. In order to examine the mechanisms of sediment delivery, a field study was conducted at Wax Lake Delta (WLD) located in St. Mary Parish, LA. Instrumented platforms equipped with wave, current, tideand sediment sensors were installed on Mike Island, an interdistributary island located near the centerline axis of the delta complex. This report focuses on the hydrodynamic measurements, which imply multiple regimes of sediment delivery based on seasonal differences in climate and biological activity. In winter, vegetation is absent, and the primary flow is driven by tides. In the spring, increased river discharge inundates the island producing lateral flows and increase in suspended sediment concentrations that supply large quantities of terrestrial sediments to interior regions. In late spring, persistent southeasterly winds create setup along the coast and higher water levels over the island allowing waves to more easily penetrate the island interior. The emergence of American lotus (Nelumbo lutea) in summer forms a dense canopy over the island reducing wave and current energy, increasing the potential for sediment deposition.

\section{SUBJECT TERMS}

Deltas - Louisiana, Hydrodynamics, Nelumbo lutea, Sedimentation and deposition, Sediment transport, Suspended sediments, Tidal currents, Wetland management

16. SECURITY CLASSIFICATION OF:

\begin{tabular}{|l|c|l|}
\hline a. REPORT & b. ABSTRACT & c. THIS PAGE \\
Unclassified & Unclassified & Unclassified \\
\hline
\end{tabular}

17. LIMITATION OF ABSTRACT

SAR
18. NUMBER OF PAGES

100 19a. NAME OF RESPONSIBLE PERSON

Richard Styles

19b. TELEPHONE NUMBER (Include area code) 601.634 .4065 